\title{
Lyme arthritis in the Netherlands : a clinical and epidemiological study
}

Citation for published version (APA):

Blaauw, A. A. M. (1993). Lyme arthritis in the Netherlands : a clinical and epidemiological study. [Doctoral Thesis, Maastricht University]. Datawyse / Universitaire Pers Maastricht. https://doi.org/10.26481/dis.19930415ab

Document status and date:

Published: 01/01/1993

DOI:

10.26481/dis.19930415ab

Document Version:

Publisher's PDF, also known as Version of record

\section{Please check the document version of this publication:}

- A submitted manuscript is the version of the article upon submission and before peer-review. There can be important differences between the submitted version and the official published version of record.

People interested in the research are advised to contact the author for the final version of the publication, or visit the DOI to the publisher's website.

- The final author version and the galley proof are versions of the publication after peer review.

- The final published version features the final layout of the paper including the volume, issue and page numbers.

Link to publication

\footnotetext{
General rights rights.

- You may freely distribute the URL identifying the publication in the public portal. please follow below link for the End User Agreement:

www.umlib.nl/taverne-license

Take down policy

If you believe that this document breaches copyright please contact us at:

repository@maastrichtuniversity.nl

providing details and we will investigate your claim.
}

Copyright and moral rights for the publications made accessible in the public portal are retained by the authors and/or other copyright owners and it is a condition of accessing publications that users recognise and abide by the legal requirements associated with these

- Users may download and print one copy of any publication from the public portal for the purpose of private study or research.

- You may not further distribute the material or use it for any profit-making activity or commercial gain

If the publication is distributed under the terms of Article $25 \mathrm{fa}$ of the Dutch Copyright Act, indicated by the "Taverne" license above, 
Lyme Arthritis in the Netherlands 
CIP-DATA KONINKLIJKE BIBLIOTHEEK, DEN HAAG

Blaauw, Angelina Aleida Maria

Lyme arthritis in the Netherlands : a clinical and

epidemiological study / Angelina Aleida Maria Blaauw. -

Maastricht : Universitaire Pers Maastricht. - III.

Thesis Maastricht. - With ref. - With summary in Dutch.

ISBN 90-5278-065-X

NUGI $742 / 741$

Subject headings: Lyme arthritis / epidemiology.

Boekproduktie: Datawyse I Universitaire Pers Maastricht Omslagillustratie: Mevr. JC Blaauw-Goossens

This thesis was financially supported by grants from Kabi Pharmacia, SmithKline Beecham, Roche, Pfizer, Merck Sharp \& Dohme, Ciba-Geigy, Sarva-Syntex, Inpharzam, and "Het Nationaal Reumafonds". 


\section{Lyme Arthritis in the Netherlands}

\section{A Clinical and Epidemiological Study}

\section{PROEFSCHRIFT}

ter verkrijging van de graad van doctor

aan de Rijksuniversiteit Limburg te Maastricht, op gezag van de Rector Magnificus, Prof.mr. M.J. Cohen, volgens het besluit van het College van Dekanen, in het openbaar te verdedigen op donderdag, 15 april 1993 om 16.00 uur

door

Angelina Aleida Maria Blaauw

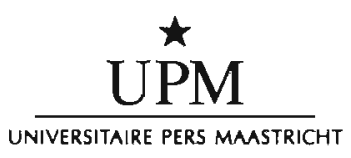




\section{Promotor:}

Prof.dr. JMJP van der Linden

Beoordelingscommissie:

Prof.dr. CPA van Boven (voorzitter)

Dr. J Diederiks

Prof.dr. JMA van Engelshoven

Prof.dr. R van Furth

Prof.dr. JA Knottnerus

Aan mijn ouders aan Dirk 


\section{Contents}

A guide to this thesis

Chapter 1:

Lyme borreliosis: an overview

Chapter 2:

Lyme arthritis in the Netherlands: a nationwide survey among rheumatologists.

Journal of Rheumatology 1991;18:1819-1822.

\section{Chapter 3:}

Lyme borreliosis: a very infrequent cause of arthritis of undetermined etiology in the southern part of the Netherlands.

British Journal of Rheumatology 1992;31:401-404.

\section{Chapter 4:}

Is there any evidence for an association between ankylosing spondylitis and Borrelia burgdorferi infection?

Journal of Rheumatology 1992;19:579-581.

\section{Chapter 5:}

Diagnostic tools in Lyme borreliosis: clinical history compared with serology.

Journal of Clinical Epidemiology 1992;11:1229-1236.

\section{Chapter 6:}

Rational diagnosis and treatment in unclassified arthritis: how clinical data may guide requests for Lyme serology and antibiotic treatment.

Annals of the Rheumatic Diseases, in press. 


\section{Chapter 7:}

Lyme disease.

RD Wigley, editor. The Primary Prevention of Rheumatic Diseases.

Parthenon Publishing, United Kingdom, in press.

\section{Chapter 8:}

How well do general practitioners, rheumatologists and dermatologists recognize Lyme borreliosis?

Chapter 9:

General discussion

Summary

Samenvatting

Acknowledgments

Curriculum vitae 


\section{A guide to this thesis}

The first publications of the clinical manifestations of Lyme borreliosis in Dutch literature date from 1984 (1-3). Wokke et al., described ten Dutch patients with lymphocytic meningoradiculitis (Bannwarth's syndrome). The authors already discussed similarities between this syndrome and Lyme disease in the USA (3).

The first cases of Lyme arthritis in the Netherlands were described by van den Hoogen et al (4). At about the same time we observed a patient with arthritis of his first metatarsal joint as part of a typical presentation of Lyme borreliosis (2). These observations led us to study the prevalence, incidence and clinical manifestations of Lyme arthritis in the Netherlands.

Chapter 1 provides an overview of Lyme borreliosis, and a survey among all Dutch rheumatologists regarding the prevalence of Lyme arthritis is reported in Chapter 2. This survey yielded 42 patients with Lyme arthritis. This assessment of the Burden of IIIness fits in with step one of the Technology Assessment Iterative Loop (figure 1) $(5,6)$. This chapter includes the clinical signs and symptoms, serological findings and the distribution of HLA DR alleles of these patients. Several of these patients had arthritis but no other clinical features of Lyme borreliosis, and positive antibodies to Borrelia burgdorferi (B. burgdorferi). Therefore, we hypothesized that unrecognized cases of Lyme arthritis might be present among patients with arthritis of undetermined etiology (Chapter 3). This paper describes the results of a study of 73 patients with arthritis of undetermined etiology for clinical manifestations suggestive of Lyme borreliosis. These patients were studied together with healthy controls and patients with classified arthritis (step number three of the Technology Assessment Iterative Loop).

In 1989, Weyand suggested that the spirochete B. burgdorferi might trigger reactive arthritis in a genetically susceptible HLA B27 positive host (7). This finding would have therapeutic implications and raised challenging new questions about pathogenetic mechanisms underlying the spondylarthropathies (8). Ankylosing spondylitis is the prototype of this group of disorders to which reactive arthritis belongs. Indeed, we also found positive antibodies to $B$. burgdorferi more often among Swiss ankylosing spondylitis patients than 


\section{1 - BURDEN OF ILLNESS}

potential for reducing

"modifiable" burden of illness

\section{7 - MONITORING AND}

\section{REASSESSMENT}

selection and application of

indicators of success and

reassessment of burden of illness

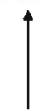

6 - SYNTHESIS AND

IMPLEMENTATION

integration of feasibility, effect, and efficiency

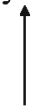

5 - EFFICIENCY

relationships between costs and effects

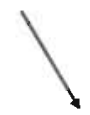

\section{2 - EFFICACY}

therapeutic potential in ideal circumstances

\section{3 - SCREENING AND DIAGNOSIS} accurate identification of those in need of treatment

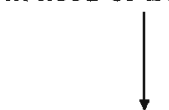

\section{4 - COMMUNITY} EFFECTIVENESS including clinical performance and compliance by patients and providers

Figure 1. The Technology Assessment Iterative Loop applied to the studies in the thesis: "Lyme Arthritis in the Netherlands, A Clinical and Epidemiological Study"

among their HLA B27 positive relatives (9). Chapter 4 is a study of the relationship between $B$. burgdorferi and seronegative spondylarthropathies in 125 Dutch patients with ankylosing spondylitis.

From a study by Fahrer $e$ t al. among Swiss orienteers, it became clear that positive serology is quite common, but that the clinical disease itself occurs infrequently (10). We were able to perform a similar study in a Dutch population at risk for Lyme borreliosis (Chapter 5). In the same study, we assessed the clinical usefulness of several diagnostic tools by calculating likelihood ratios for (1) the recognition of erythema migrans, (2) a history of tick bites, and (3) positive Lyme serology. 
In Chapter 6, we analyzed clinical data of 102 patients with arthritis of undetermined etiology to improve the appropriateness and efficiency of diagnostic serologic tests and subsequent antibiotic treatment. Likelihood ratios for different cut off levels in the clinical history of patients with arthritis of undetermined etiology were calculated and applied.

A brief overview how to prevent Lyme borreliosis and especially Lyme arthritis is given in Chapter 7. Regarding the latter, we conclude that recognition of erythema migrans in particular and the other early stages of Lyme borreliosis is of paramount importance in preventing Lyme arthritis.

Chapters 4 to 7 deal mainly with step number three of the Technology Assessment Iterative Loop. This step deals with accurate identification of those in need of treatment.

Evaluating knowledge of general practitioners about rheumatology, we were able to assess recognition and knowledge of Lyme borreliosis. We presented two cases of Lyme borreliosis and two photographs of erythema migrans to general practitioners, rheumatologists and dermatologists. The results of this educational study are presented in Chapter 8, which fits into step number four of the Technology Assessment Iterative Loop. Indeed, given an effective treatment, community effectiveness depends a great deal on clinical performance.

Chapter 9 gives a general discussion. The thesis ends with summaries in English and Dutch. 


\section{REFERENCES}

1 van Duin BJ. Erythema migrans als eerste teken van Lyme ziekte. Ned Tijdschr Geneeskd 1987;131:679-80.

2 Blaauw AAM, Braat S, van Santen-Hoefft HMS, van der Linden S. Cardiologische afwijkingen bij patiënten met Lyme borreliosis. Ned Tijdschr Geneeskd 1988;131:2111-14.

3 Wokke JHJ, Vanneste JAL, Vermeulen M, et al. Lymfocytaire meningoradiculitis na insektenbeet (syndroom van Bannwarth). Ned Tijdschr Geneeskd 1984;128:1796-99.

4 van den Hoogen FHJ, Boerbooms AMTh, Rasker JJ, van de Putte. Gewrichtsklachten na tekebeet; Lyme artritis in Nederland. Ned Tijdschr Geneeskd 1988;132:1300-03.

5 Tugwell P, Bennet KJ, Sackett DL, Haynes RB. The measurement iterative loop: a framework for the critical appraisal of need, benefits and costs of health interventions. J Chron Dis 1985;38:339-351.

6 Lawrence VA, Tugwell P, Gafni A, Kosuwon W, Spitzer WO. Acute Low Back Pain and Economics of Therapy: the Iterative Loop Approach. J Clin Epidemiol 1992;45:301-311.

7 Weyand CM, Goronzy JJ. Immune responses to Borrelia burgdorferi in patients with reactive arthritis. Arthritis Rheum 1989;9:1057-64.

8 Amett FC. The Lyme disease spirochete: another cause of Reiter's syndrome? Arthritis Rheum 1989;9:1182-4.

9 Blaauw I, van der Linden S, Nohlmans L. An increased prevalence of anti-Borrelia burgdorferi antibodies in ankylosing spondylitis: fact or artefact? Scand J Rheum 1990;87:148 (suppl).

10 Fahrer H, van der Linden SM, Sauvain MJ, Gern L, Zhioua E, Aeschlimann A. The prevalence and incidence of clinical and asymptomatic Lyme borreliosis in a population at risk. J Infect Dis 1991;163:305-10. 


\section{Lyme borreliosis: an overview.}




\section{Lyme borreliosis: an overview.}

In November 1975 a mother from Old Lyme, Connecticut, in the United States, informed the State Health Department that 12 children from that small community of 5,000 inhabitants, 4 of whom lived close together on the same road, had a disease diagnosed as juvenile rheumatoid arthritis. During the same month another mother from the same community reported to the Yale Rheumatology Clinic and to the Health Department that she, her husband, 2 of their children, and several neighbours all had arthritis. Again most of the children were thought to have juvenile rheumatoid arthritis. Allen Steere, who had received training in Epidemiology, performed subsequent studies of children and adults in that geographic region, and suggested that "Lyme arthritis" was a previously unrecognized clinical entity (1).

This epidemic form of arthritis occurred in eastern Connecticut from at least 1972, with a peak incidence of new cases in the summer and early fall. The illness was characterized by recurrent attacks of asymmetric swelling and pain in a few large joints, especially the knee. An erythematous papule that developed into an expanding red, annular lesion, up to 50 centimeter in diameter, was reported by $25 \%$ of the described patients. It was suggested that the disorder was transmitted by an arthropod, an ixodes tick (2).

The expanding skin lesion fitted the description of erythema chronicum migrans, already described by Afzelius and Lipschutz in Europe at the beginning of this century $(3,4)$. This skin lesion was thought to be caused by a tick, Ixodes ricinus. It was already known that a chronic skin lesion, acrodermatitis chronica atrophicans, could follow erythema migrans (5). Bannwarth from Germany had defined a syndrome that consisted of radicular pain, chronic lymphocytic meningitis and cranial or peripheral neuritis. In some cases this was preceded by erythema migrans, and caused by ticks (6). Spirochete-like structures in skin specimens of patients with erythema migrans were seen by Lennhoff in 1948 (7). Penicillin was used to treat the skin lesions (8). Arthritis had not been associated with erythema migrans before.

It soon became clear that Lyme disease was a multisystem illness that could affect the skin, nervous system, heart, and joints (9).

In November 1981, Willi Burgdorfer of the Rocky Mountain Laboratories of the National Institute of Allergy and Infectious Diseases, discovered that the etiological agent of Lyme disease was a spirochete (10). This spirochete was 
found mainly in the midgut of ticks, Ixodes dammini. Alan Barbour succeeded in growing the spirochetes in culture (11). The spirochete, now called Borrelia burgdorferi, was then recovered from patients with Lyme disease in the United States and Europe (12-16). The most common name for the disease is Lyme disease or Lyme borreliosis.

\section{Borrelia burgdorferi}

Borrelia burgdorferi ( $B$. burgdorferi) belongs to the phylum of spirochetes. Borrelia species have a protoplasmic cylinder that is surrounded by a cell membrane, flagella, and by an outer membrane (17). It is a loosely coiled, left handed helix. Genes encoding the outer membrane are located on plasmids, an arrangement that may be advantageous to the organism in making antigenic changes in these proteins (18).

B. burgdorferi is the longest $(20-30 \mu \mathrm{m})$ and narrowest $(0.2$ to $0.3 \mu \mathrm{m})$ of its species (19). It contains at least 30 different proteins, including the two major outer-surface proteins, called outer-surface protein A (30 to $32 \mathrm{kd}$ ), and outersurface protein B (34 to $36 \mathrm{kd})(18,20-23)$. The 41-kd antigen is located on the flagellum (24). The p-39 antigen is also a specific antigen, which stimulates antibody production especially in late Lyme borreliosis (25). B. burgdorferi grows, as fastidious, microaerophilic bacteria, at $33^{\circ}$ Celsius in a complex, liquid medium called Barbour-Stoenner-Kelly medium (11). B. burgdorferi grow slowly; they elongate for 12-24 hours and then divide into two cells (11). After 10 to 15 passages, $B$. burgdorferi loses pathogenicity in culture (26). After that time, organisms are no longer infectious.

It is difficult to isolate $B$. burgdorferi from patients, but, relatively easy to do so from ticks $(12,13)$. The spirochete is only present in very small numbers in mammalian tissue.

Certain differences have been noted between American and European isolates of $B$. burgdorferi in morphology, outer surface proteins, plasmids, and DNA homology (19,27-29).

\section{Vector}

$B$. burgdorferi is transmitted by ixodes ticks that are part of the Ixodes ricinus complex; in the north eastern United States, Ixodes dammini, in the western United States, ixodes pacificus, in Europe, Ixodes ricinus, and in Asia, Ixodes persulcatus (30-33). Only ticks from the Ixodes ricinus complex seem to be important in the transmission of the spirochete to humans. 


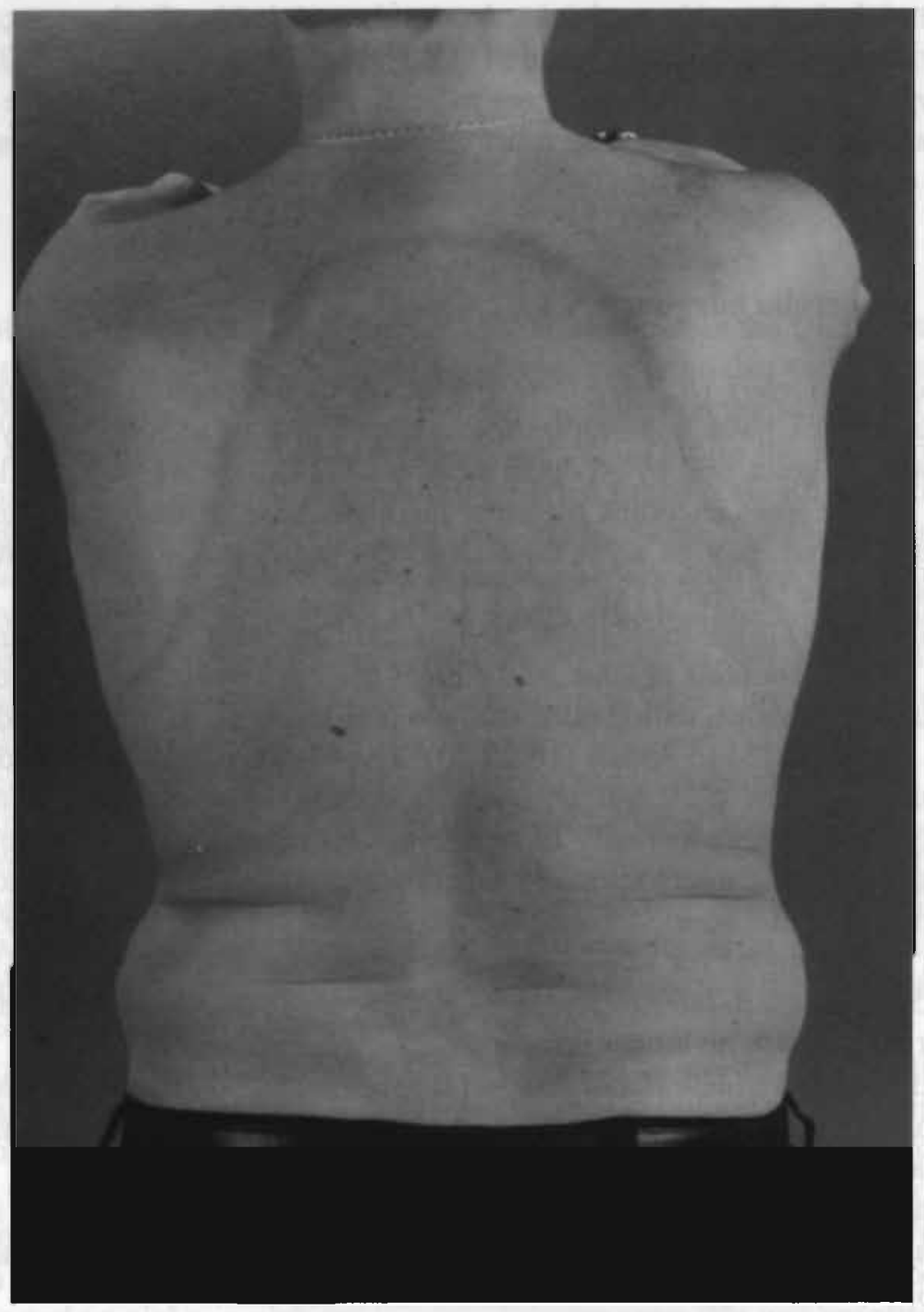

Figure 1. Erythema migrans

The life cycle of the ticks normally spans two years. Eggs are deposited in the spring and hatch into free-living larvae a month later. During the first summer the larva feeds once with the blood of a host and then enters a resting stage coincident with the onset of cold weather in the fall. The following spring the larva molts, enters a second immature stage, called the nymphal stage, and again attaches itself to an animal host, to feed for another three or four days. The 


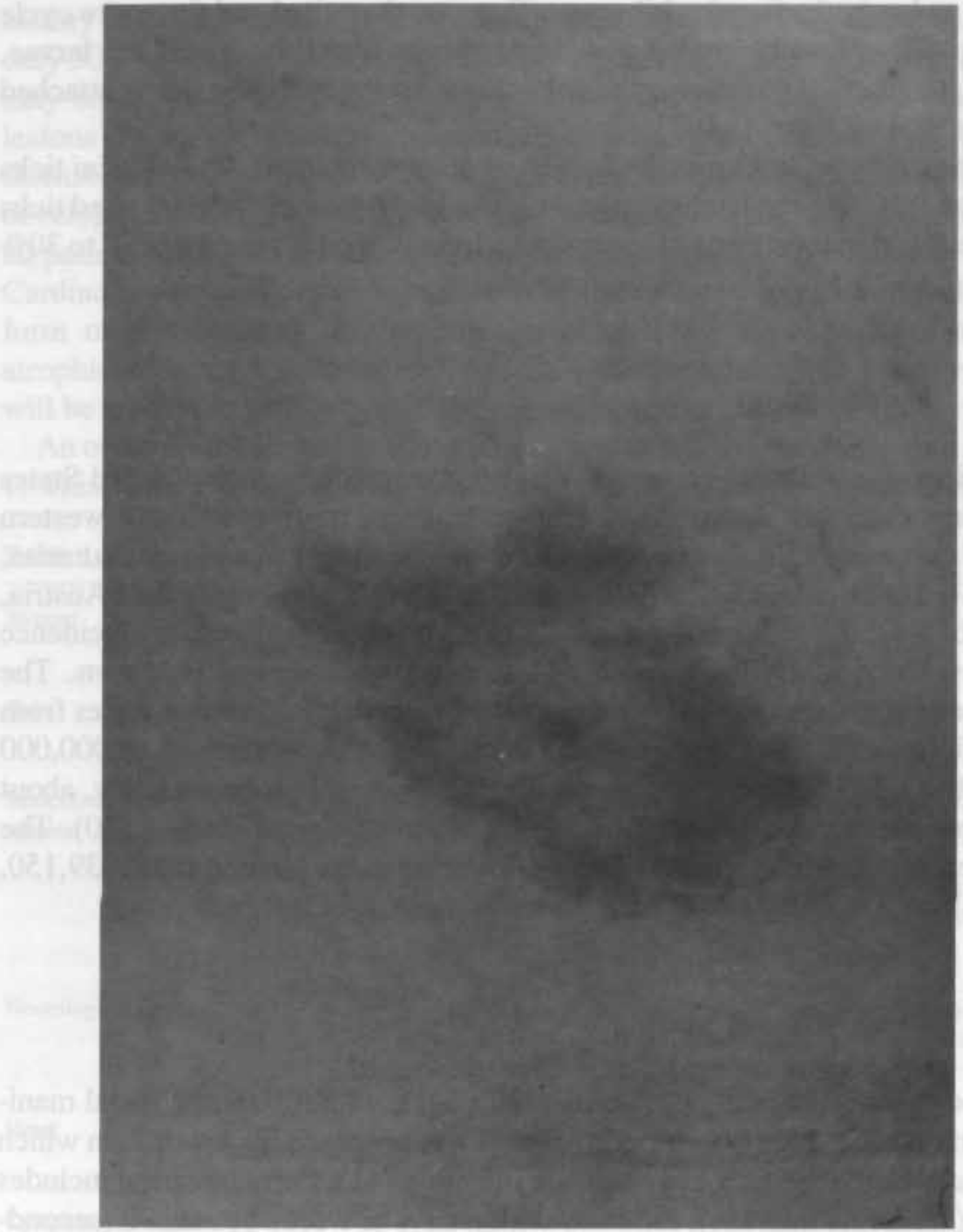

Figure 2. Erythema migrans

majority of the ticks are found on the white-footed mouse, Peromyscus leucopus. In this stage, they are likely to attack humans. At the end of the summer nymphs molt into adults. They can be found in brush about one meter above the ground, from where they can attach themselves to larger animals, predominantly the white-tailed deer, Odocoileus virginianus. The adult male ticks mate on the host soon after the female tick attaches herself to it. The males die soon after 
mating, and only the females hibernate. Eggs are deposited and the entire cycle repeats itself. Humans may be infected during bloodmeals of the larvae, nymphs, or adults. Transmission of spirochetes occurs when the tick is attached for more than 48 hours (34).

Infection rates of ticks may be as high as 50 percent in Ixodes dammini ticks on Shelter Island in the United States $(12,35)$. In the Netherlands, infected ticks could be found in most parts of the country. Infection rates varied from 2 to $30 \%$ (36).

\section{Epidemiology}

Lyme disease is the most common vector-borne infection in the United States (37). Most cases are described in the northeastern, midwestern, and western parts of the country. In Europe, cases have been reported from most countries, such as Great Britain, Germany, Sweden, Belgium, Italy, France and Austria, and probably thousands of new cases occur each year (38). The exact incidence and prevalence of Lyme borreliosis in the Netherlands are unknown. The presence of antibodies to $B$. burgdorferi among Dutch blood donors varies from 2 to $17 \%$ (mean $8.7 \%$ ) (39). Assuming a total Dutch population of $15,000,000$ means that $1,305,000$ people have positive antibodies. In a Swiss study, about $3 \%$ of people with positive antibodies have clinical Lyme disease (40). The estimated prevalence of clinical Lyme borreliosis in the Netherlands is 39,150 . The estimated incidence of clinical Lyme borreliosis is 560 each year.

\section{Clinical manifestations}

Lyme borreliosis generally occurs in three stages, with different clinical manifestations at each stage (9). A modified plan was proposed by Äsbrink, in which the disease is divided into early and late infection (41). Early infection includes stage 1 (erythema migrans), followed within days or weeks by stage 2 (secondary erythema migrans and disseminated infection), and within weeks or months by intermittent symptoms. Late infection, or stage 3 (persistent infection), usually begins a year or more after the onset of the disease. A patient may have one or all stages, and the infection may not become symptomatic until stage 2 or 3 (42). Lyme borreliosis typically begins with erythema migrans, often accompanied by constitutional symptoms, such as fever, lymphadenopathy, fatigue and headache. Erythema migrans may expand with partial central clearing or with central induration or vesicle formation. Erythema migrans is usually located at the site of the tick bite (figure 1 and 2). After 3 to 4 weeks (range, 1 day to 1 year), erythema migrans lesions fade, even in untreated patients. A 
history of a tick bite at the site of the skin lesion can be a helpful clue, however, only $50 \%$ of the patients remember being bitten by a tick. The initial skin lesion may be followed by similar, but generally smaller, lesions. These secondary lesions are probably due to a hematogenous or lymphatic spread (disseminated disease, stage 2 ). Within a few weeks or months, about $15-25 \%$ of patients develop clear neurological involvement, which may be accompanied by radicular pain, meningitis, cranial nerve involvement or peripheral neuropathy $(43,44)$. Cardiac abnormalities occur in $8-10 \%$ of the patients, most commonly in the form of a fluctuating atrio-ventricular block (45). Acrodermatitis chronica atrophicans is a late skin disorder caused by the spirochete (46). Joint symptoms will be extensively discussed in the following section.

An overview of all manifestations of Lyme borreliosis is summarized in Table 1. This table is derived from an article by Steere, which gives an extensive

Table 1. Clinical manifestations of Lyme disease

\begin{tabular}{|c|c|c|c|}
\hline System & Localized (stage 1) & $\begin{array}{l}\text { Early infection } \\
\text { Disseminated (stage 2) }\end{array}$ & $\begin{array}{l}\text { Late infection } \\
\text { Persistent (stage 3) }\end{array}$ \\
\hline Skin & Erythema migrans & $\begin{array}{l}\text { Secondary erythema migrans } \\
\text { Lymphadenosis benigna cutis }\end{array}$ & $\begin{array}{l}\text { Acrodermatitis chronica } \\
\text { atrophicans }\end{array}$ \\
\hline $\begin{array}{l}\text { Musculoskeletal } \\
\text { system }\end{array}$ & & $\begin{array}{l}\text { Migratory pain in joints, } \\
\text { tendons, muscle, bone; brief } \\
\text { arthritis attacks. }\end{array}$ & $\begin{array}{l}\text { Prologed arthritis attacks, } \\
\text { chronic arthritis, peripheral } \\
\text { enthesopathy, joint } \\
\text { subluxations below lesions of } \\
\text { acrodermatitis chronica } \\
\text { atrophicans. }\end{array}$ \\
\hline Neurological system & & $\begin{array}{l}\text { Meningitis, cranial neuritis, } \\
\text { Bell's palsy, motor or sensory } \\
\text { radiculoneuritis, encephalitis }\end{array}$ & $\begin{array}{l}\text { Chronic encephalomyelitis, } \\
\text { spastic parapareses, mental } \\
\text { disorders, dementia }\end{array}$ \\
\hline Heart & & $\begin{array}{l}\text { Atrio-ventricular block, } \\
\text { myopericarditis, pancarditis }\end{array}$ & \\
\hline Lymphatic system & $\begin{array}{l}\text { Regional } \\
\text { lymphadenopathy }\end{array}$ & $\begin{array}{l}\text { Regional or generalized } \\
\text { lymphadenopathy }\end{array}$ & \\
\hline Eyes & & Conjunctivitis, iritis & Keratitis \\
\hline Liver & & Hepatitis & \\
\hline Respiratory system & & Nonproductive cough & \\
\hline Kidney & & $\begin{array}{l}\text { Microscopic hematuria or } \\
\text { proteinuria }\end{array}$ & \\
\hline $\begin{array}{l}\text { Constitutional } \\
\text { symptoms }\end{array}$ & Minor & Fatigue, malaise & Fatigue \\
\hline
\end{tabular}


review of the clinical manifestations of Lyme borreliosis (42). This thesis will focus primarily on Lyme arthritis.

\section{Lyme arthritis}

A mean of six months after the onset of the disease (range, two weeks to two years), commonly after intermittent episodes of arthralgia or migratory musculoskeletal pain, about 60 percent of the patients in the United States begin to have brief attacks of asymmetric oligo articular arthritis, primarily in the large joints, and especially the knee (47). Episodes of arthritis often become longer during the second and third years of the illness, lasting months rather than weeks. Chronic arthritis - defined as a year or more of continuous joint inflammationcharacteristically begins during this period as well (47). Typically, only one or a few large joints are affected, most commonly the knee. The clinical evolution of Lyme arthritis has been described by Steere among 55 patients who had not received antibiotic therapy for erythema migrans. These patients were followed for a mean duration of 6 years (47). Of these 55 patients, 11 (20\%) had no subsequent manifestations of Lyme borreliosis at all. From one day to eight weeks after disease onset, 10 of the patients $(18 \%)$ began to have brief episodes of joint, periarticular, or musculoskeletal pain lasting as long as six years, but none developed objective joint abnormalities. From four days to two years after disease onset, $28(51 \%)$ had one episode or began to have intermittent attacks of arthritis, primarily in large joints. The duration of these episodes ranged from three days to 11.5 months, with a mean of three months. Episodes of arthritis were often separated by months or even years of complete remission. The total number of these patients who continued to have recurrences, decreased by $10-20 \%$ each year. Six patients (11\%) developed chronic synovitis.

\section{Radiology}

In 25 patients with severe arthritic manifestations the most frequent radiographic finding was knee joint effusion (48). Intra-articular edema was often accompanied by a continuum of soft-tissue changes involving the infra-patellar fat pad, periarticular soft tissues, and the entheses, which were sometimes thickened, calcified, or ossified. Late in the illness, the joints of some patients showed typical changes of an inflammatory arthritis, including juxta-articular osteoporosis, cartilage iss, and cortical or marginal bone erosions. Less rommonly, patients demonstrate 1 characteristics of degenerative arthritis, inc'uding cartilage loss, subarticular sclerosis, and osteophytes (48). 


\section{Synovium}

In 17 patients with Lyme arthritis, synovial specimens, showed non-specific villous hypertrophy, synovial cell hyperplasia, prominent microvasculature, lymhoplasmacellular infiltration, and sometimes lymphoid follicles (49). Surgically obtained specimens also showed striking deposition of fibrin in synovial stroma and a form of endarteritis obliterans. In 2 patients, spirochetes could be demonstrated in and around blood vessels by the Dieterle silver stain. Compared with 55 synovial specimens from cases with articular disease, obliterative microvascular lesions were seen only in Lyme synovia; stromal deposition of fibrin was a non-specific finding.

\section{Immunology}

A specific IgM response, often directed against the 4l-kd flagellar antigen of the spirochete, peaks between the third and sixth week but may persist $(12,50)$. This specific IgM response is frequently associated with evidence of the polyclonal activation of B cells, including elevated total serum IgM levels and the presence of cryoprecipitations, circulating immune complexes, and occasionally, rheumatoid factor, antinuclear antibodies, or anticardiolipin antibodies (51-54). Specific IgG antibodies develop after 6 to 8 weeks to different spirochetal polypeptides, particular to the 31-, 34-, and 66-kd outer surface proteins, the 41-kd flagellar antigen, and the 55/58-kd antigen (50). Immune antibodies are required for the serum-mediated killing of the spirochete by the classical complement pathway (55). Polymorphonuclear leukocytes and monocytes readily phagocytose and kill the spirochete. Histologically, all affected tissues show infiltration of lymphocytes with plasma cells (56). IgG antibodies may persist for years in patients with continuing infection.

$B$. burgdorferi is also capable of inducing a specific cellular immune response. Antigen-specific responses are concentrated at the sites of inflammation. The cellular immune responses are directed to multiple spirochetal polypeptides. These responses, however, ranged from marked to minimal (57-58).

As with a number of rheumatic diseases, chronic Lyme arthritis appears to have an immunogenetic basis involving D-locus alleles of the major histocompatibility complex. These class II histocompatibility molecules, which are Iocated primarily on B lymphocytes and macrophages, present peptide fragments of foreign antigens to $T$ helper cells that initiate the immune response against the antigens. In a study of 80 patients with Lyme arthritis, those with chronic joint involvement had a significantly increased frequency of HLA-DR4, often combined with HLA-DR3 or DR2, and these patients often did not respond to multiple courses of antibiotic therapy (59). It was concluded that in genetically 
susceptible people, $B$. burgdorferi may trigger an immune response with autoreactive features, that continues for some time after the organism has been killed.

The small number of spirochetes found in synovial tissue is probably the antigenic stimulus for chronic synovial inflammation (60). Interleukin-1 and Interleukin-1-producing cells are found in the synovial fluids of Lyme patients. This Interleukin-1 is probably a major endogenous mediator of Lyme- and other types of arthritis (61). Other cytokines like Interleukin-6 and tumor necrosing factor may also contribute to the pathogenesis of Lyme arthritis.

\section{Diagnosis}

Lyme borreliosis is primarily a clinical diagnosis. At the tissue level, infection with $B$. burgdorferi can rarely be proven, because of the scarcity of organisms seen on histologic staining of affected tissues and the technical difficulty associated with culturing from clinical specimens (12). Only culturing from erythema migrans is relatively easy (62). There are only 2 reports of a positive culture from synovial fluids from patients with Lyme arthritis $(63,64)$. Serologic tests can only serve as an adjunct to a clinical diagnosis. False positive results and asymptomatic infection are well known (40,65-67). Pitfalls of diagnostic testing will be discussed in the general discussion section of this thesis.

\section{Laboratory investigations}

A specific immune response to $B$. burgdorferi is detectable by indirect immunofluorescence assay or an enzyme-linked immunosorbent assay (ELISA) (68). ELISA's are preferred, because their sensitivity and reproducability are better than those of immunofluorescence assays (69). As these methods are not standardized, serologic results should be interpreted with caution. The tests offered by various laboratories differ in sensitivity and specificity (65-67). False positive results and considerable inter and intra laboratory variation have been reported. At present, interpreting laboratory results is difficult unless one is familiar with the reference laboratory used and its validation procedures (70).

In most ELISA's, extracts of sonicated whole $B$. burgdorferi are used as antigens. There are several modifications of this technique such as an IgM capture technique, adsorption of test serum with Escherichia Coli, and use of purified flagellin protein (71-73). However, these modifications also vary widely. True seronegativity is uncommon in patients with clinical manifestations of disseminated or chronic Lyme disease. 
Western blotting could be helpful in distinguishing true positive from false positive ELISA results (74). To date, it is only used as a. validation procedure. The test is not widely available.

Cell-mediated Immunity testing has been used as a means of identifying exposure to $B$. burgdorferi. The earliest immune response after the onset of infection is a T-cell response (58). Clinical usefulness has not been confirmed (88).

$B$. burgdorferi antigens may be excreted in the urine of experimentally infected animals and naturally infected humans (75). These urine antigen tests have not been clinically validated and should not be used in the diagnosis of patients with Lyme disease.

Polymerase chain reaction is under development for identification of spirochetal DNA in patient tissues and fluids (76). This test also is not currently available in the clinical situation.

\section{Therapy}

Lyme borreliosis is treated with antibiotics (77). Antibiotic sensitivities to $B$. burgdorferi have been determined in vitro and in experimental animals (78-80). $B$. burgdorferi is highly sensitive to tetracycline, but only moderately to penicillin. Ampicillin, ceftriaxon, and imepenem are also highly active against $B$. burgdorferi. Erythromycin is very active against the spirochete in vitro, but not as effective in vivo.

Oral tetracycline or doxycycline are currently recommended as treatment for early and mild Lyme disease $(42,81)$. This includes isolated facial palsy and first degree atrio-ventricular block (42). Too short a treatment period may result in failure of therapy (82). Duration of therapy for early symptoms should be guided by clinical manifestations and typically varies from 10-30 days (42). Intravenous ceftriaxon is currently the treatment of choice for neurological abnormalities and a high degree of atrio-ventricular block. Ceftriaxon is used, because it crosses the blood-brain barrier more readily and only once-a-day or twice-a-day administration is required $(42,83)$. For acrodermatitis chronica atrophicans, oral antibiotic therapy is usually adequate but prolonged courses with antibiotics can be necessary. An overview of treatment recommendations for the different clinical manifestations of Lyme borreliosis is given in Table 2. These recommendations are subject to change as more clinical antibiotic trials will become available.

A Jarisch-Herxheimer reaction after antibiotic therapy is found in about $15 \%$ of patients (9).

Prophylactic antibiotic treatment of tick bites is not recommended. The risk of Lyme disease among people with a tick bite is low, even in endemic areas (84-86). 


\begin{tabular}{|c|c|c|c|c|c|}
\hline & \multirow[t]{2}{*}{ Antibiotic } & \multirow[t]{2}{*}{ Route } & \multirow[t]{2}{*}{ Duration* } & \multicolumn{2}{|l|}{ Dosis } \\
\hline & & & & $<12$ years & $>12$ years \\
\hline \multirow[t]{4}{*}{ Erythema migrans } & Amoxicillin & oral & $14^{*}$ & $20-40 \mathrm{mg} / \mathrm{kg} 3 x$ daily & $500 \mathrm{mg} .3 x$ daily \\
\hline & Penicillin & oral & $14^{*}$ & $50 \mathrm{mg} / \mathrm{kg} 3 \times$ daily & $500 \mathrm{mg}, 3 x$ daily \\
\hline & Erythromycine & oral & $21^{*}$ & $20-40 \mathrm{mg} / \mathrm{kg} 4 \mathrm{x}$ daily & $250 \mathrm{mg}, 4 \mathrm{x}$ daily \\
\hline & Doxycycline & oral & $14^{*}$ & & $100 \mathrm{mg}, 2 \mathrm{x}$ daily \\
\hline \multirow{3}{*}{$\begin{array}{l}\text { Neuroiogic } \\
\text { abnormalities*** }\end{array}$} & Ceftriaxon & iv & 14 & $100 \mathrm{mg} / \mathrm{kg}$ daily & $2 \mathrm{~g}$ daily \\
\hline & & $\mathrm{im}$ & 14 & 2 divided dosis & 2 divided dosis \\
\hline & Penicillin & iv & 14 & $\begin{array}{l}\text { I00.000- } \\
250.000 \mathrm{U} / \mathrm{kg} / \text { daily } \\
4-6 \text { doses daily }\end{array}$ & $\begin{array}{l}20 \times 10^{6} \mathrm{U} / \text { daily } \\
4-6 \text { doses daily }\end{array}$ \\
\hline \multirow{3}{*}{$\begin{array}{l}\text { Cardiologic } \\
\text { abnomalities** }\end{array}$} & Ceftriaxon & iv & 14 & $100 \mathrm{mg} / \mathrm{kg}$ daily & $2 \mathrm{~g}$ daily \\
\hline & & $\mathrm{im}$ & 14 & 2 divided doses & 2 divided doses \\
\hline & Penicillin G & iv & 14 & $\begin{array}{l}100.000-250.000 \\
\mathrm{U} / \mathrm{kg} / \text { daily } \\
4-6 \text { doses daily }\end{array}$ & $\begin{array}{l}20 \times 10^{6} \\
4-6 \text { doses daily }\end{array}$ \\
\hline \multirow[t]{4}{*}{ Arthritis } & Doxycycline & oral & 30 & & $100 \mathrm{mg}, 2 x$ daily \\
\hline & Amoxicillin & oral & 30 & $50 \mathrm{mg} / \mathrm{kg} 3 \mathrm{x}$ daily & $500 \mathrm{mg} .3 \mathrm{x}$ daily \\
\hline & Ceftriaxon & iv & 14 & $100 \mathrm{mg} / \mathrm{kg} /$ daily & $2 \mathrm{~g}$ daily \\
\hline & & $\mathrm{im}$ & 14 & 2 divided doses & 2 divided doses \\
\hline \multirow{3}{*}{$\begin{array}{l}\text { Acrodermatitis } \\
\text { chronica atrophicans }\end{array}$} & Doxycycline & oral & 30 & & $100 \mathrm{mg}, 2 \mathrm{x}$ daily \\
\hline & Ceftriaxon & iv & 14 & & 2 g daily \\
\hline & & $\mathrm{im}$ & 14 & & 2 divided doses \\
\hline
\end{tabular}

* The duration of therapy is dependent on clinical response. Treatment failures have occurred, and retreatment may be necessary; ** For facial palsy alone, and first degree atrio-ventricular block, oral antibiotics may be adequate.

\section{Treatment of Lyme arthritis}

Lyme arthritis has been treated successfully with parenteral penicillin (87). Forty patients with Lyme arthritis were treated either with placebo or penicillin ( 2.4 million units of benzathine penicillin weekly for 3 weeks). Seven, out of 20 patients treated with penicillin responded fully, while none of placebo treated patients did. Eleven of 20 patients treated with penicillin intravenously (20 
million units daily for 10 days), responded slowly (87). Dattwyler treated 7 patients with recurrent oligoarthritis with penicillin ( 24 million units daily for 10 days) and compared the results with 9 ceftriaxon treated patients (4 grams intravenously for 14 days) (83). Patients treated with ceftriaxon all responded, whereas 5 patients treated with penicillin did not respond at all. He also treated 23 consecutive patients with Lyme arthritis with ceftriaxon, 4 or 2 gram intravenously daily for 14 days. Only 3 patients did not respond. Liu compared two oral treatment regimens (88). Thirty eight patients were randomly assigned to receive either doxycycline (100 mg orally twice daily) or amoxicillin and probenecid ( $500 \mathrm{mg}$ each orally four times daily) for 30 days. In the doxycycline group, 13 of 18 patients ( $72 \%$ ) responded compared to 11 of 18 patients (61\%) in the amoxicillin group. The latter group reported more side effects. In the same study, 29 patients with recurrent or persistent arthritis despite oral antibiotic therapy, were given either penicillin intravenously (20 million units daily for 14 days) or ceftriaxon intravenously ( 2 or 4 gram daily for 14 days). Results for both treatment groups were disappointing. Only 5 out of 14 penicillin treated patients (35\%) responded, and only 6 out of 15 ceftriaxon treated patients (40\%). In a randomized therapeutic study, 18 patients with recurrent arthritis were treated with penicillin (penicillin G 2 million units daily for 10 days) and 16 patients with cefotaxime ( 2 x 3 grams daily for 10 days) (89). Four of 18 penicillin treated patients $(22 \%)$ responded, compared to 7 of cefotaxime treated patients (44\%).

These studies indicate that the optimal therapy for Lyme arthritis has not yet been established (90). Initial treatment with an oral antibiotic is recommended, preferably oral doxycycline $200 \mathrm{mg}$ daily for 30 days. Since response to antibiotic therapy may take at least 3 months to occur, repetition with a second course of doxycycline should not be initiated before 3 months have passed since the first treatment. In patients with persistent arthritis, ceftriaxon intravenously can be prescribed, however the response is hardly predictable.

Twenty patients underwent arthroscopic synovectomy for refractory chronic Lyme arthritis of the knee (91). Sixteen (80\%) had resolution of joint inflammation during the first month after surgery or soon thereafter, and they have remained well during the 3-8 year follow-up period. The remaining 4 patients $(20 \%)$ had persistent or recurrent synovitis. 


\section{REFERENCES}

1 Steere AC, Malawista SE, Snydham DR, et al. Lyme arthritis: an epidemic of oligoarticular arthritis in children and adults in three Connecticut communities. Arthritis Rheum 1977;20:7-17.

2 Steere AC, Malawista SE, Hardin JA, et al. Erythema chronicum migrans and Lyme arthritis: epidemiologic evidence for a tick vector. Am J Epidemiol 1978;108:312-21.

3 Afzelius A. Erythema chronicum migrans. Acta Derm Venereol (Stockh) 1921;2:120-5.

4 Lipschütz B. Weiterer Beitrag zur Kenntnis des "Erythema chronicum migrans:. Arch Dermatol Syph 1923:143:365-74.

5 Herxheimer K, Hartmann K. Ueber Acrodermatitis chronica atrophicans. Arch Dermatol Syph 1902;61:57-76.

6 Bannwarth A. Zur Klinik und Pathogenese der "chronischen lymphocytaren Meningitis". Arch Psychiatr Nervenkr 1944;1 17:161-85.

7 Lennholf C. Spirochaetes in aetiologically obscure disease. Acta Derm Venereol (Stockh) 1948;28:295-329.

8 Hollström E. Successful treatment of erythema migrans Afzelius. Acta Derm Venereol (Stockh) 1951;31:235-43.

9 Steere AC, Bartenhagen $\mathrm{NH}, \mathrm{Craft} \mathrm{JE}$, et al. The early clinical manifestations of Lyme disease. Ann Intem Med 1983;99:76-82.

10 Burgdorfer W, Barbour AG, Hayes SF, Benach $几$, Grunwaldt E, Davis JP. Lyme disease-a tick-borne spirochetosis? Science 1982;216:1317-9.

11 Barbour AG. Isolation and cultivation of Lyme disease spirochetes. Yale J Biol Med 1984;57:521-5.

12 Steere AC, Grodzicki RL, Komblatt AN, et al. The spirochetal etiology of Lyme disease. N Engl J Med 1983;308:733-40.

13 Benach JL, Bosler EM, Hanrahan JP, et al. Spirochetes isolated from the blood of two patients with Lyme disease. N Engl J Med 1983;308:740-2.

14 Ackerman R, Kabatzki J, Boiste HP, et al. Spirochäten-Ätiologie der Erythema-chronicum-migrans-Krankheit. Dtsch Med Wochenschr 194;109:92-7.

I5 Preac-Mursic V, Wilske B, Schierz G, Pfister HW, Einhaupl K. Repeated isolation of spirochetes from the cerebrospinal fluid of a patient with meningoradiculitis Bannwarth. Eur J Clin Microbiol 1984;3:564-5.

16 Äsbrink E, Hovmark A. Successful cultivation of spirochetes from skin lesions of patients with erythema chronicum migrans afzelius and acrodermatitis chronica atrophicans. Acta Pathol Microbiol Immunol Scand 1985;93:161-3.

17 Barbour AG, Hayes SF. Biology of Borrelia species. Microbiol Rev 1986:50:381-400.

18 Barbour AG, Tessier SL, Todd WJ. Lyme disease spirochetes and ixodid tick spirochetes share a common surface antigenic determinant defined by a monoclonal antibody. Infect Immun 1983;41:795-804.

19 Hovind-Hougen K, Äsbrink E, Stiemstedt G, Steere AC, Hovmark A. Ultrastructural differences among spirochetes isolated from patients with Lyme disease and related disorders, and from Ixodes ricinus ticks. Zentralbl Bakteriol Mikrobiol Hyg [A] 1986;263:103-11.

20 Coleman JL, Benach $\pi$. Isolation of antigenic components from the Lyme disease spirochete: their role in early diagnosis. J Infect Dis 1987;155:756-65. 
21 Barbour AG, Burgdorfer W, Grunwaldt E, Steere AC. Antibodies of patients with Lyme disease to components of the Ixodes dammini spirochete. J Clin Invest 1983;72:504-15.

22 Benach JL, Coleman JL, Golightly MG. A murine IgM monoclonal antibody binds an antigenic determinant in outer surface protein $A$, an immunodominant basic protein of the Lyme disease spirochete. J Immunol 1988;140:265-72.

23 Barbour AG, Tessier SL, Hayes SF. Variation in a major surface protein of Lyme disease spirochetes. Infect Immun 1984;45:94-100.

24 Barbour AG, Hayes SF, Heiland RA, Schrumpf ME, Tessier SL. A Borrelia-specific monoclonal antibody binds to a flagellar epitope. Infect Immun 1986;52:549-54.

25 Klempner MS, Noring R, Steere AC, Schwan T. Antibodies to a $39 \mathrm{kDa}$ Antigen of Borrelia burgdorferi are a specific marker of late but not early human Lyme disease. Fifth Conference on Lyme borreliosis 1992, Arlington, Virginia, USA.

26 Schwan TG, Burgdorfer W, Garon CF. Changes in infectivity and plasmid profile of the Lyme disease spirochete, $B$. burgdorferi, as a result of in vitro cultivation. Infect Immun 1988;56:1831-6.

27 Barbour AG, Heiland RA, Howe TR. Heterogeneity of major proteins in Lyme disease borreliae: a molecular analysis of North American and European isolates. J Infect Dis 1985;152:478-84.

28 Barbour AG. Plasmid analysis of B. burgdorferi, the Lyme disease agent. J Clin Microbiol 1988;26:475-8.

29 LeFebvre RB, Perng GC, Johnson RC. Characterization of B. burgdorferi isolates by restriction endonuclease analysis and DNA hybridization. $J$ Clin Microbiol 1989;27:636-9.

30 Steere AC, Malawista SE. Cases of Lyme disease in the United States: locations correlated with distribution of Ixodes dammini. Ann Intern Med 1979;91:703-3.

31 Burgdorfer W, Lane RS, Barbour AG, Gresbrink RA, Anderson JR. The western black-legged tick, Ixodes pacificus: a vector of B. burgdorferi. Am J Trop Med Hyg 1985;34:925-30.

32 Krampitz HE. In vivo isolation and maintenance of some wild strains of European hard tick spirochetes in mammalian and arthropod hosts: a parasitologist's view. Zentralb] Bakteriol Mikrobiol Hyg [A] 1986;263:21-8.

33 Dekonenko EJ, Steere AC, Berardi VP, Kravchuk LN. Lyme borreliosis in the Soviet Union: a cooperative US-USSR report. J Infect Dis 1988;158:748-53.

34 Piesman J. Abortion of $B$. burgdorferi Transmission via prompt removal of nymphal Ixodes dammini. Fifth Conference on Lyme borreliosis 1992 Arlington, Virginia, USA.

35 Bosler EM, Ormiston BG, Coleman JL, Hanrahan JP, Benach JL. Prevalence of Lyme disease spirochete in populations of white-tailed deer and white footed-mice. Yale $\mathrm{J}$ Biol Med 1984;57:651-9.

36 Nohlmans MKE, de Boer R, van den Bogaard AEJM, Blaauw AAM, van Boven CPA Voorkomen van B. burgdorferi in Nederland. Ned Tijdschr Geneeskd 1990;134:1300-3.

37 Lyme disease-Connecticut. MMWR 1988;37:1-3.

38 Stanek G, Pletschette M, Flamm H, et al. European Lyme borreliosis. Ann NY Acad Sci 1988;539:274-82.

39 Nohlmans MKE, van den Bogaard AEJM, Blaauw AAM, van Boven CPA. Prevalentie van Lyme borreliose in Nederland. Ned Tijdschr Geneeskd 1991; 135:2288-92.

40 Fahrer H, van der Linden SM, Sauvain MJ, Gem L, Zhioua E, Aeschlimann A. The prevalence and incidence of clinical and asymptomatic Lyme borreliosis in a population at risk. J Infect Dis 1991;163:305-10. 

borreliosis (erythema migrans borreliosis, Lyme borreliosis). Ann NY Acad Sci 1988;539:4-15.

42 Steere AC. Lyme disease. N Engl J Med 1989;321:586-595.

43 Pachner AR, Steere AC, Bartenhagen NH, Shope RE, Malawista SE. The triad of neurologic manifestations of Lyme disease: meningitis, cranial neuritis, and radiculoneuritis. Neurology 1985;35:47-53.

44 Ackermann R, Rehse E, Gollmer E, Schmidt R. Chronic neurologic manifestations of erythema migrans borreliosis. Ann NY Acad Sci;539:16-23.

45 Steere AC, Batsford WP, Weinberg M, et al. Lyme carditis: Cardiac abnormalities of Lyme disease. Ann Intern Med 1980;93:8-16.

46 Äsbrink E, Hovmark A, Hedersted B. The spirochetal etiology of acrodermatitis atrophicans Herxheimer. Acta Derm Venereol 1984;64:506-512.

47 Steere AC, Schoen RT, Taylor E. The clinical evolution of Lyme arthritis. Ann Intern Med 1987;107:725-731.

48 Lawson J, Steere AC. Lyme arthritis: Radiologic Findings. Radiology 1985; 154:37-43.

49 Johnston YE, Duray PH, Steere AC, et al. Lyme arthritis. Spirochetes found in synovial microangiopathic lesions. Am J Pathol 1985;1 18:26-34.

50 Craft JE, Fischer DK, Shimamoto GT, Steere AC. Antigens of B. burgdorferi recognized during Lyme disease: appearance of a new immunoglobulin $M$ response and expansion of the immunoglobulin $G$ response late in the illness. J Clin Invest 1986;78:934-9.

51 Steere AC, Hardin JA, Ruddy S, Mummaw JG, Malawista SE. Lyme arthritis: correlation of serum and cryoglobulin IgM with activity, and serum $\operatorname{IgG}$ with remission. Arthritis Rheum 1979;22:471-83.

52 Hardin JA, Steere AC, Malawista SE. Immune complexes and the evolution of Lyme arthritis: dissemination and localization of abnormal C1q binding activity. N Engl J Med 1979;301:1358-63.

53 Kujala GA, Steere AC, Davis JS IV. IgM rheumatoid factor in Lyme disease: correlation with disease activity, total serum IgM, and IgM antibody to $B$. burgdorferi. J Rheumatol 1987;14:772-6.

54 Mackworth-Young CG, Harris EN, Steere AC, et al. Anticardiolipin antibodies in Lyme disease. Arthritis Rheum 1988;31:1052-6.

55 Kochi SK, Johnson RC. Role of immunoglobulin G in killing of $B$. burgdorferi by the classical complement pathway. Infect Immun 1988;56:314-21.

56 Duray PH, Steere AC. Clinical pathologic correlations of Lyme disease by stage. Ann NY Acad Sci 1988;539:65-79.

57 Yoshinari NH, Reinhardt BN, Steere AC. T-cell responses to polypeptide fractions of $B$. burgdorferi in patients with Lyme arthritis. Arthritis Rheum 1991;34:707-13.

58 Dattwyler RJ, Volkman DJ, Luft BJ, Halperin JJ, Thomas J, Golightly MG. Dissociation of specific T- and B-lymphocytes responses to B. burgdorferi. $\mathbf{N}$ Engl $\mathbf{J}$ Med 1988;319:1441-6.

59 Steere AC, Dwyer E, Winchester R. Association of chronic Lyme arthritis with HLADR4 and HLA-DR2 alleles. N Engl J Med 1990;323:219-223.

60 Steere AC, Duray PH, Butcher EC. Spirochetal antigens and lymphoid cell surface markers in Lyme synovitis. Arthritis Rheum 1988;31:487-495.

61 Beck G, Benach JL, Habicht GS. Isolation of Interleukin 1 from Joint fluids of patients with Lyme disease. J Rheumatol 1989;16:800-6. 
62 van Dam AP, Kuiper H, Vos K, et al. Cutaneous disseminated Borreliosis: differences in protein patterns between $B$. burgdorferi isolates. Fifth Conference on Lyme borreliosis 1992 Arlington, Virginia, USA.

63 Snydham DR, Schenkein DP, Berardi VP, Lastavica CC, Pariser KM. B. burgdorferi in joint fluid in chronic Lyme arthritis. Ann Intern Med 1986; 104:798-800.

64 Schmidli J, Hunziker Th, Moesli P, Schaad U. Cultivation of B. burgdorferi from joint fluid three months after treatment of facial palsy due to Lyme borreliosis. J Infect Dis 1988; 158:905-06.

65 Schwartz BS, Goldstein MD, Ribeiro JM, Schultz TL, Shahied SI. Antibody testing in Lyme disease. JAMA 1989;262:3431-4.

66 Luger SW, Krauss E. Serologic tests for Lyme disease: interlaboratory variability. Arch Intern Med 1990;150:761-3.

67 Hedberg CW, Osterholm MT. Serologic tests for antibody to B. burgdorferi. Another Pandora's box for medicine? Arch Intern Med 1990;150:732-733.

68 Shrestha M, Grodzicki RL, Steere AC. Diagnosing early Lyme disease. Am J Med 1985; 78:235-240.

69 Craft JE, Grodzicki RL, Steere AC. Antibody response in Lyme disease: evaluation of diagnostic tests. J Infect Dis 1984;149:789-95.

70 Magnarelli LA. Quality of Lyme disease tests [Editorial]. JAMA 1989;262:3464-5.

71 Berardi VP, Weeks KE, Steere AC. Serodiagnosis of early Lyme disease: analysis of $\mathrm{IgM}$ and $\mathrm{IgG}$ antibody responses by using an antibody-capture enzyme immunoassay. J Infect Dis 1988; 158:754-60.

72 Fawcett PT, O'Brien AE, Dought RA. An adsorption procedure to increase the specificity of enzyme-linked immunosorbent assays for Lyme disease without decreasing sensitivity. Arthritis Rheum 1989;32:1041-4.

73 Hansen K, Äsbrink E. Serodiagnosis of erythema migrans and acrodermatitis chronica atrophicans by the $B$. burgdorferi flagellum enzyme-linked immunosorbent assay. J Clin Microbiol 1989;27:545-51.

74 Dressler F, Steere AC. Westem blotting in the serodiagnosis of Lyme borreliosis. Fifth Conference on Lyme borreliosis 1992, Arlington, Virginia, USA.

75 Hyde FW, Johnson RC, White TJ, Shelburne CE. Detection of antigens in urine of mice and humans infected with $B$. burgdorferi, etiologic agent of Lyme disease. J Clin Microbiol 1990;28:566-72.

76 Persing DH, Telford SR 111, Spielman A, Barthold SW. Detection of B. burgdorferi infection in Ixodes dammini ticks with the polymerase chain reaction. J Clin Microbiol 1990;28:566-72.

77 Steere AC, Malawista SE, Newman JH, Spieler PN, Bartenhagen NH. Antibiotic therapy in Lyme disease. Ann Intern Med 1980;93:1-8.

78 Johnson SE, Klein GC, Schmid GP, Feeley JC. Susceptibility of the Lyme disease spirochete to seven antimicrobial agents. Yale J Biol Med 1984;57:549-53.

79 Preac-Mursic V, Wilske B, Schierz G. European B. Burgdorferi isolated from humans and ticks: culture conditions and antibiotic sensitivities. Zentralbl Bakteriol Mikrobiol Hyg [A] 1986;263:112-8.

80 Johnson RC, Kodner C, Russell M. In vitro and in vivo susceptibility of the Lyme disease spirochete, $B$. burgdorferi, to four antimicrobial agents. Antimicrob Agents Chemother 1987;31:164-7.

81 Steere AC, Hutchinson GJ, Rahn DW, et al. Treatment of the early manifestations of Lyme disease. Ann Intem Med 1983;99:22-6. 
82 Dattwyler RJ, Halperin JJ. Failure of tetracycline therapy in early Lyme disease. Arthritis Rheurn 1987;30:448-50.

83 Dattwyler RJ, Halperin JJ, Volkman DJ, Luft BJ. Treatment of late Lyme borreliosis-a randomized comparison of ceftriaxone and penicillin. Lancet 1988;1:1191-4.

84 Shapiro ED, Gerber MA, Persing D, Berg AT, Feder H.Prevention of Lyme disease: a randomized clinical trial of antimicrobial prophylaxis for people bitten by a deer tick. Fifth Conference on Lyme borreliosis 1992, Arlington, Virginia, USA.

85 Magid D, Schwartz B, Craft J, Scwartz J.S. Prevention of Lyme disease after Tick Bites-A Cost-effectiveness Analysis. N Engl J Med 1992;327:534-541.

86 Kassirer J.P. Is a Tíck's Bark Worse than its Bite? Formulating an Answer with Decision Analysis. N Engl J Med 1992;327:562-563 (Editorial).

87 Steere AC, Green J, Schoen RT, et al. Successful parenteral penicillin therapy of Lyme arthritis. N Engl J Med 1985;312:869-74.

88 Liu NY, Dinermann H, Levin RE, et al. Randomized trial of doxycycline vs. amoxicillin/probenecid for the treatment of Lyme arthritis: treatment of non-responders with IV penicillin or ceftriaxone. Arthritis Rheum 1989;32:S46 (abstract).

89 Hassler D, Zöller L, Haude M, Hufnagel HD, Heinrich F, Sonntag. Cefotaxime versus Penicillin in the late stage of Lyme disease-prospective, randomized therapeutic study. Infection 1990; 18:24-28.

90 Rahn DW, Malawista SE. Lyme disease recommendations for diagnosis and treatment. Ann Intem Med 1991; 1 14:472-481.

91 Schoen RT, Aversa JM, Rahn DW, Steere AC. Treatment of refractory chronic Lyme arthritis with arthroscopic synovectomy. Arthritis Rheum 1991;34:1056-60. 


\title{
Lyme arthritis in the Netherlands: a nationwide survey among rheumatologists.
}

\author{
AAM Blaauw, MKE Nohlmans*, E van den Berg-Loonen**, \\ JJ Rasker***, Sj van der Linden
}

Department of Internal Medicine, Division of Rheumatology, Department of Medical Microbiology*, and the Tissue typing Laboratory** of the University Hospital Maastricht; Department of Rheumatology*** of Medisch Spectrum Twente, The Netherlands.

Reprinted by permission of the Journal of Rheumatology $1991 ; 18: 1819-1822$ 


\section{Lyme arthritis in the Netherlands: a nationwide survey among rheumatologists.}

\section{ABSTRACT}

A nation wide survey among all 118 Dutch rheumatologists (response rate $85 \%$ ) yielded 42 patients with Lyme arthritis. The arthritis was nonpersistent in all these patients. A tick bite was reported by 23 of these 42 patients $(55 \%)$. Erythema migrans was recalled by 19 patients (45\%). Cardiac manifestations occurred in 4 patients (9\%) and neurologic symptoms in 14 patients (33\%). By immunoabsorbent assay or immunofluorescence technique 37 patients (88\%) had positive IgG antibodies to Borrelia burgdorferi. The distribution of HLADR alleles of 28 of these patients was not different from the healthy population. The response to antibiotic treatment was considered good in 34 patients $(81 \%)$. The clinical features of the Dutch patients with Lyme arthritis closely resemble the description of the disease reported from the United States.

\section{INTRODUCTION}

Lyme borreliosis is a zoonosis caused by the spirochete Borrella burgdorferi ( $B$. burgdorfer $l$ ), and transmitted primarily by Ixodes ticks. In Europe the tick species is Ixodes ricinus (1). The disease runs in 3 stages. Rheumatic manifestations occur in stage 2 as migratory pain in joints, tendons, bursae and brief arthritis attacks. Late infection or stage 3 usually begins a year or more after the onset of the disease with manifestations such as acrodermatitis chronica atrophicans, prolonged arthritis attacks, peripheral enthesopathy, chronic arthritis, chronic encephalomyelitis and chronic axonal polyradiculopathy (2). A patient may show all 3 stages, and the infection may not become symptomatic until stage 2 or 3 .

In the United States, about $60 \%$ of the patients with Lyme borreliosis experience brief attacks of asymmetric, oligoarticular arthritis, primarily in the large joints, especially the knee (3). This occurs on the average 6 months (range 2 weeks to 2 years) after the onset of stage 1 of the disease and is commonly preceded by intermittent episodes of arthralgia or migratory musculoskeletal 
pain. Involvement of the joints, however, is thought to be a less frequent manifestation of the illness in Europe, although this is controversial (4-15).

The reported differences in the prevalence of Lyme arthritis between North America and Europe might merely reflect differences in the awareness of Lyme arthritis or may reflect real differences in the occurrence of this disease (16).

Our purpose was (1) to investigate how frequently Lyme arthritis was diagnosed by Dutch rheumatologists; (2) to determine whether there are striking differences in the clinical pattern of Lyme arthritis between the United States and Europe, and (3) to assess the prevalence of HLA-DR antigens among Dutch patients with Lyme arthritis.

\section{METHODS}

\section{Survey}

In May 1988 a survey was sent to all $(n=118)$ Dutch rheumatologists. They serve a population of 15 million people. The questionnaire included items about the diagnosis of Lyme arthritis, for example, how often a diagnosis of Lyme arthritis was made, whether the diagnosis was confirmed by serology and in which part of the country the disease was contracted.

The reported cases of Lyme arthritis were restudied by indepth chart review. Whenever possible, patients were examined by one of the investigators (AB).

Patients were included if erythema migrans, Bannwarth syndrome or facial palsy had been present preceding or simultaneously with rheumatic symptoms such as arthralgia or arthritis. Patients with arthritis who had positive antibodies to $B$. burgdorferi without another definable cause for arthritis were also included. These patients were felt not to have infectious arthritis, psoriatic arthritis, ankylosing spondylitis, rheumatoid arthritis, systemic lupus erythematodes, crystal induced arthritis and reactive arthritis. In addition, patients known to have sacroiliitis or Reiter's syndrome were also excluded. Antibodies to $B$. burgdorferi had been determined at the rheumatologist's local laboratory.

\section{Serology}

We restudied these patients and new serum specimens were obtained. These sera were tested in our laboratory for the presence of IgG antibodies to B. burgdorferi by an immunofluorescence assay (IFA) as well as an enzyme linked immunosorbent assay (ELISA) (17). 


\section{ELISA}

The ELISA was performed essentially as described by Craft, et al (18). For interpretation of the test results a cutoff value of 0.35 was calculated. This optical density value was 2 standard deviations above the mean value of 128 sera from Dutch healthy laboratory staff members.

\section{IFA}

The IFA was performed as described by Wilske et al (19). Based on the results for 128 Dutch healthy laboratory staff members the cutoff level after adsorption with Treponema phagedenis was at a titer of 1:64 (specificity 98\%).

\section{HLA-antigens}

Twenty-eight patients could be tissue typed for their HLA-DR antigens by means of the 2-color fluorescence test and a set of 120 platelet-absorbed sera (20). Sixteen DR specificities (DR1-DR16) were tested for. A panel of 500 random Dutch Caucasian blood donors was used as healthy controls.

\section{RESULTS}

One hundred of the 118 questionnaires were returned (85\%). Forty nine cases of Lyme arthritis were reported by 20 Dutch rheumatologists. Seven cases did not meet our inclusion criteria and were excluded from the study. Thirteen rheumatologists reported 1 patient each. Three rheumatologists reported 2 patients, one 3 patients and one 4 patients. Two rheumatologists reported 8 patients each. The 42 patients were restudied by clinical chart review and 24 of them (57\%) were examined personally by one of us (AB). The male to female ratio was $1: 1$. The mean age of the patients was 40 years (range 14-72 years) at time of diagnosis. Seven patients had jobs like foresters or farmers that might expose them to $B$. burgdorferi at a higher rate.

The infections were reported from all parts of the country. However, 15 patients (36\%) came from the middle-east part and 13 patients (31\%) from the south east part of the country.

Thirty of the 42 patients presented to their rheumatologists with arthritis, 12 complained about severe arthralgia (figure 1). Of the 30 patients with arthritis, 16 showed other manifestations that could be ascribed to Lyme borreliosis. Of these 16 patients, 13 patients showed positive antibodies to $B$. burgdorferi 
13 antibody +

2 antibody -

1 not done

14 no extra-articular manifestations

14 antibody +

12 arthralgia

\section{2 extra-articular manifestations}

30 arthritis

16 extra-articular manifestations

42 patients
11) antibody +

2 antibody -

Figure 1. Distribution of symptoms and signs in 42 Dutch patients with L.yme arthritis

(range ELISA 0.65-1.64, range IFA 1:256-1:2048). In one of the 3 remaining patients no serologic test was performed. She had atrial fibrillation and oligoarthritis after a tick bite in 1979. One patient did not have positive antibodies to $B$. burgdorferi. He presented with arthritis of the knee and classical Bannwarth syndrome (neuroborreliosis). Another patient, also seronegative, developed arthritis of her ankle joints 3 weeks after a tick bite and in spite of antibiotic treatment for erythema migrans. Fourteen patients with arthritis had no other Lyme symptoms, they all had positive antibodies to B. burgdorferi (range ELISA 0.74-1.95, range IFA 1:256-1:2048).

Arthritis was localized in the knee joint in 20 patients (48\%), 10 of them with no other symptoms of Lyme borreliosis.

In 14 cases arthritis was monarticular. Other affected joints were ankles ( 7 cases), hands ( 7 cases), wrists ( 6 cases), elbow ( 4 cases), feet ( 4 cases), shoulder (1 case) and hip (1 case).

The 12 patients with severe arthralgia showed other symptoms that could be ascribed to Lyme borreliosis (figure 1). Ten of these 12 patients had positive antibodies to $B$. burgdorferi (range ELISA 0.67-1.30, range IFA 1:128-1:1024). Two of these 12 patients complained about arthralgia following erythema migrans, but showed no positive antibodies to $B$. burgdorferi.

A history of a tick bite was reported by 23 patients $(55 \%)$. Nineteen of the 42 patients recalled erythema migrans (45\%). The tick bite definitely preceded erythema migrans in 14 patients.

Cardiac manifestations, second degree or total atrioventricular block, atrial fibrillation and sinus bradycardia, were documented in 4 patients $(9 \%)$.

Fourteen (33\%) patients had neurologic symptoms, 6 of them after erythema migrans. Neurological syndromes included severe radicular pain (5 cases), 
paresthesia (4 cases), polyneuropathy (one), Bannwarth syndrome (one), Bannwarth syndrome and facial palsy (one), acusticus neuritis (one) and facial palsy (one).

No late skin manifestations such as acrodermatitis chronica atrophicans had occurred among the 42 patients.

\section{HLA antigens}

HLA-DR determination could be done for 28 of the $42(66 \%)$ patients. No significant differences in HLA-DR frequencies of 28 patients with Lyme arthritis compared to the controls were found (table 1). The HLA-DR4 specificity was found in 6 Lyme patients (21\%), the HLA-DR2 specificity in 8 Lyme patients $(28 \%)$.

HLA-DR4 in association with DR2 was found in one patient. However, none of the 28 studied patients showed chronic arthritis.

Table 1. Prevalence of HLA-DR antigens in patients with Lyme arthritis and in Caucasian blood donors.

\begin{tabular}{ccc}
\hline & $\begin{array}{c}\text { Lyme arthritis } \\
\mathrm{n}=28\end{array}$ & $\begin{array}{c}\text { controls } \\
\mathrm{n}=500\end{array}$ \\
\hline DR 1 & $28 \%$ & $19.4 \% *$ \\
DR2 & $28 \%$ & $25 \%$ \\
DR 15 & $28 \%$ & $21.5 \%$ \\
DR 16 & - & $3.5 \%$ \\
DR3 & $18 \%$ & $21.2 \%$ \\
DR4 & $21 \%$ & $24.6 \%$ \\
DR5 & $18 \%$ & $24.8 \%$ \\
DR 11 & $11 \%$ & $20.4 \%$ \\
DR 12 & $7 \%$ & $4.4 \%$ \\
DR6 & $39 \%$ & $33.6 \%$ \\
DR 13 & $36 \%$ & $25.3 \%$ \\
DR 14 & $3 \%$ & $8 \%$ \\
DR7 & $18 \%$ & $23.4 \%$ \\
DR8 & $8 \%$ & $6.8 \%$ \\
DR9 & $7 \%$ & $2.8 \%$ \\
DR10 & - & $2.6 \%$ \\
\hline
\end{tabular}

*RR 1.8 
All but 2 of the 42 patients were treated with antibiotics. The 2 untreated patients had recovered spontaneously after several weeks. Ten patients had received 20-24 million units penicillin/day intravenousiy for 10-14 days. Eight of them recovered. After this therapy one patient complained about persistent arthralgia and fatigue and received a second course of penicillin therapy without improvement. However, after ceftriaxone intravenously she recovered within 2 weeks. The other patient showed persistent arthritis of his knee joint after penicillin therapy. His arthritis resolved after oral doxycycline for 30 days. Two patients recovered after oral penicillin therapy. Only 2 of 25 patients treated with oral tetracycline or doxycycline did not respond to this therapy. One of these two patients still complained about arthralgia even after a second course of 30 days doxycycline. The other patient recovered from his knee arthritis after ceftriaxone intravenously. Three patients were treated with ceftriaxone intravenously. One responded immediately, another responded very slowly. One patient could not tolerate ceftriaxone and was treated with doxycycline orally.

Overall response to therapy was adequate in 34 of 39 patients. Five patients still complained about arthralgia and fatigue. The response to antibiotic treatment was unknown for 3 patients.

\section{DISCUSSION}

There are striking differences in the reported prevalence of rheumatic manifestations of Lyme borreliosis, between various countries, especially between the United States and Europe. Arthritis is said to be a common manifestation of the disease in Germany, Switzerland and Belgium $(12,13,16)$. Other studies also from Europe, have reported considerably lower prevalence of rheumatic manifestations of Lyme borreliosis (4-15).

Several reasons have been proposed for these differences. First of all, a diversity between American and European isolates of $B$. burgdorferi has been pointed out (4). Secondly, early (versus late or no) treatment of erythema migrans could have prevented the development of arthritis (21). Thirdly, a lack of diagnostic awareness of Lyme borreliosis or its rheumatic manifestations could be responsible for the reported differences (16).

The present study was performed to determine how frequently a diagnosis of Lyme arthritis was made by Dutch rheumatologists and to determine the clinical spectrum of the disease. Our study supports the view that the incidence of nonrheumatic manifestations in our Dutch patients is quite comparable to reported findings. Of the 42 patients with Lyme arthritis, $9 \%$ showed cardiac abnormalities and $33 \%$ neurological symptoms, whereas in the US comparable 
figures have been reported: $4-8 \%$ had cardiac involvement and 15-20\% developed neurologic manifestations $(22,23)$. All patients studied presented themselves primarily to rheumatologists. At this time it is impossible to say whether there are real differences in the incidence of rheumatic manifestations of Lyme borreliosis. In the US about $60 \%$ of patients with untreated erythema migrans develop brief attacks of asymmetric oligoarthritis, commonly after intermittent episodes of arthralgia or migratory musculoskeletal pain (3). It is unlikely that such data from Europe will ever become available. However, it is still possible to compare the incidence of Lyme arthritis after antibiotic treatment of erythema migrans. Until such data exist no reliable conclusions about real differences in the incidence of rheumatic manifestations of Lyme borreliosis can be drawn.

Nonetheless our study also supports the view that major clinical or serological differences regarding rheumatic Lyme manifestations between the US and the Netherlands do not exist (16). Most patients with Lyme arthritis in the US have raised IgG antibody titer to $B$. burgdorferi (3). In our study 37 of 42 patients (88\%) showed positive IgG antibodies to $B$. burgdorferi either in IFA or ELISA. The 5 patients who did not have positive antibodies either at time of diagnosis or at time of survey were nonetheless clinically thought to have Lyme borreliosis. Prompt antimicrobial therapy, as was done in 4 of these 5 patients could have aborted the development of a mature humoral response or have arrested the evolution of the antibody response (24).

As in other reports the knee was the most frequently affected joint (3). Indeed, the clinical signs and symptoms of the 42 patients in this study fit the description of Lyme borreliosis in the US. Since our survey was completed new cases of Lyme arthritis are more frequently reported. Therefore Lyme arthritis was probably underdiagnosed in the Netherlands.

Our study has not been designed to specifically assess the effects of antibiotic treatment of Lyme arthritis. Treatment results of these patients should therefore be interpreted with caution since recurrence of Lyme arthritis after antibiotic treatment has been described (25).

However, the recovery of patients with Lyme arthritis after antibiotic treatment reinforces the importance of early diagnosis of the disease and the potential to reduce the burden of illness due to Lyme borreliosis successfully. Especially if arthritis of unknown etiology is localized in the knee joint, Lyme arthritis should be considered a possible diagnosis.

As with a number of rheumatic diseases, chronic Lyme arthritis appears to have an immunogenetic basis involving D-locus alleles of the major histocompatibility complex (26). Chronic Lyme arthritis is associated with HLA-DR4 or DR2 alleles. None of the 28 patients typed for HLA-DR antigens had chronic persistent arthritis. The distribution of HLA-DR frequencies in our patients were about the same as in the healthy population. 
In conclusion, Lyme arthritis has been diagnosed regularly by Dutch rheumatologists although the disease may have been underrecognized in the past. The clinical pattern of Lyme arthritis in 42 Dutch patients closely resemble the pattern described in the literature. Rheumatologists should be aware of Lyme arthritis as a highly treatable condition.

Acknowledgement

The authors wish to acknowledge the Dutch Rheumatologists and Drs. van Hulsteijn, Alleman and Venenkamp for their cooperation in this study. We thank MA Khan for critically reading the manuscript and providing helpful comments. 


\section{REFERENCES}

1. Burgdorfer W, Barbour AG, Hayes SF, Benach JL, Grunwaldt E, Davis JP. Lyme disease - a tick-borne spirochetosis? Science 1982;216:1317-19.

2. Steere AC. Lyme Disease. N Engl J Med 1989;321:586-95.

3. Steere AC, Schoen RT, Taylor E. The clinical evolution of Lyme Arthritis. Ann Intem Med 1987; 107:725-31.

4. Stanek J, Wewalka G, Groh V, Neumann R, Kristoferitsch W. Differences between Lyme disease and European arthropod-borne borrelia infections. Lancet 1985;i:401 .

5. Muhlemann MF, Wright DJM. Emerging pattem of Lyme disease in the United Kingdom and Irish Republic. Lancet 1987;i:260-62.

6. Hovmark A, Äsbrink E, Olsson I. Joint and bone involvement in Swedish patients with Ixodes ricinus-borne Borrelia Infection. Zbl Bakt Hyg A 1986;263:275-84.

7. Dekonenko EJ, Steere AC, Berardi VP, Kravchuk LN. Lyme borreliosis in the Soviet Union: A cooperative US-USSR Report. J Infect Dis 1988;158:748-53.

8. Hoogen van den FHJ, Boerbooms AMTH, Rasker JJ, Putte van de LBA. Gewrichtsklachten na tekebeet; Lyme-artritis in Nederland. Ned Tijdschr Geneeskd $1988 ; 132: 1300-03$

9. Korff KJ, Kreek de EJ. Gewrichtsklachten na tekebeet; Lyme artritis in Nederland (letter). Ned Tijdschr Geneeskd 1989;132:1595-96.

10. Giraudet JS, Awada H, Amor B, Menkes CJ. Manifestations rhumatologiques de la maladie de Lyme. Ann Med Interne 1988;139:460-63.

11. Benhamou CL, Gauvain JB, Calamy G, et al. Lyme disease. Clinical, biological and developmental aspects. 29 cases in the Orleans region. Rev Rhum Mal Osteoartic 1988;55:647-53.

12. Aeschlimann A, Chamot E, Gigon F, Jeanneret JP, Kesseler D, Walther C. B. burgdorferi in Switzerland. Zbl Bakı Hyg A 1986;263:450-58.

13. Bigaignon J, Tomasi J-P, Goubau, et al. A clinical and sero-epidemiological study of 190 Belgian patients suffering from Lyme borreliosis. Acta Clin Belgica 1989;44: 17481 .

14. Huaux JP, Bigaignon G, Stadisbaeder S, Zangerle PF, Nagant de Deuxchaisnes C. Pattern of Lyme Arthritis in Europe: report of 14 cases. Ann Rheum Dis 1988;47:16465.

15. Bianchi G, Rovetta G, Montefore P, et al. Articular involvement in European patients with Lyme disease. A report of 32 Italian patients. Br J Rheumat 1990;29:178-80.

16. Herzer P. Lyme arthritis in Europe: comparisons with reports from North America. Ann Rheum Dis 1988;47:789-9।.

17. Barbour AG. Isolation and cultivation of Lyme disease spirochetes. Yale J Biol Med 1984;57:52I-25.

18. Craft JE, Grodzicki RL, Steere AC. The antibody response in Lyme disease: evolution of diagnostic tests. J Infect Dis 1984;149:789-95.

19. Wilske B. Schierz G, Preac-Mursic V, Weber K, Pfister H-W, Einhäupl K. Serological Diagnusis of Erythema Migrans Disease and related disorders. Infection 1984;12:33237.

20. Rood van JJ, Leeuwen van A, Ploem JS. Simultaneous detection of two cell populations by two-colour fluorescence and application to the recognition of $\mathrm{B}$ cell detemninants. Nature 1976:262:795-97. 
21. Hollström E. Successful treatment of erythema chronicum migrans Afzeliï. Acta Derm Venereol (Stockh) 1951;31:235-43.

22. Steere AC, Batsford WP, Weinberg M, et al. Lyme carditis: cardiac abnormalities of Lyme disease. Ann Intern Med 1980;93:8-16.

23. Pachner AR, Steere AC. The triad of neurologic manifestations of Lyme disease: meningitis, cranial neuritis and radiculoneuritis. Neurology 1985;35:47-52.

24. Stiernstedt G, Eriksson G, Enfors W, et al. Erythema Chronicum Migrans in Sweden: Clinical manifestations and antibodies to Ixodes ricinus spirochete measured by indirect immunofluorescence and enzyme linked immuno sorbent assay. Scand J Infect Dis 1986; 18:217-224.

25. Liu NY, Dinerman H, Levin, et al. Randomized trial of doxycycline versus amoxicillin/probenecid for the treatment of Lyme arthritis: treatment of the non responders with iv penicillin or ceftriaxone. Arthritis Rheum 1989;32:s32.

26. Steere AC, Dwyer E, Winchester R. Association of chronic Lyme arthritis with HLADR4 and HLA-DR2 alleles. N Engl J Med 1990;323:219-23. 



\title{
Lyme borreliosis: a very infrequent cause of arthritis of undetermined etiology in the southern part of the Netherlands.
}

\author{
AAM Blaauw, MKE Nohlmans*, P Leffers**, H Goei Thè***, \\ $\mathrm{Sj}$ van der Linden.
}

Department of Intemal Medicine, Division of Rheumatology and Department of Medical Microbiology*, University Hospital Maastricht. Department of Epidemiology**, University of Limburg. Department of Rheumatology*** of de Wever Hospital Heerlen and Maasland Hospital Sittard, The Netherlands.

Reprinted by permission of the British Journal of Rheumatology 1992;31:401-404 


\title{
Lyme borreliosis:
}

\section{a very infrequent cause of arthritis of undetermined etiology in the southern part of the Netherlands.}

\begin{abstract}
Seventy-three patients with undiagnosed arthritis of undetermined etiology, 94 patients with classified arthritis (rheumatoid arthritis, ankylosing spondylitis etc.) and 70 controls were studied for clinical and serological manifestations of Lyme borreliosis. The patients were recruited from the three rheumatology units in the most southem part of the Netherlands. A clinical diagnosis of possible Lyme borreliosis was made in seven of 73 patients with arthritis of undetermined etiology, in four of 94 patients with classified arthritis and in one of the controls. A definite diagnosis of Lyme borreliosis could be made in only one patient who belonged to the arthritis of undetermined etiology group. This patient had erythema migrans, arthritis of the knee joint and showed positive antibodies to $B$. burgdorfiri. In the southern part of the Netherlands, Lyme arthritis does not seem to be a frequent cause of arthritis of undetermined etiology.
\end{abstract}

\section{INTRODUCTION}

Lyme borreliosis is a zoonosis caused by the spirochete Borrelia burgdorferi ( $B$. burgdorferi). In Europe the disease is transmitted primarily by Ixodes ricinus ticks (1). Migratory pain in joints and brief, or in later stages prolonged or chronic, arthritis attacks, are reported as frequent rheumatic symptoms of Lyme borreliosis $(2,3)$. The musculoskeletal symptoms may occur without preceding erythema migrans, cardiac or neurological symptoms (4).

In The Netherlands determination of antibodies to B. burgdorferi is not routinely performed in patients with arthritis of undetermined etiology. Therefore, there is a possibility that unrecognized cases of Lyme borreliosis may be present among such patients. Indeed, to date a few cases of Lyme arthritis have been reported $(5,6)$. But in a nationwide survey in the Netherlands 18 patients have been described who had positive antibodies to $B$. burgdorferi together with 
arthritis or severe arthralgia but who had no other clinical features of Lyme borreliosis (7). Early diagnosis of Lyme arthritis may reduce the burden of illness and will prevent later stages of the disease. Lyme arthritis is a curable disorder in the majority of cases (8-10).

In the present study patients with arthritis of undetermined etiology, were studied by questionnaire and interviewed for clinical manifestations suggestive of Lyme borreliosis. These patients were studied together with healthy controls and patients who had classified arthritis. In addition, the prevalence of positive antibodies to $B$. burgdorferi was determined.

\section{PATIENTS AND METHODS}

\section{Patients with arthritis of undetermined etiology}

In 1989 consecutive patients with arthritis of undetermined etiology were recruited from three rheumatology units: the Maasland Hospital Sittard, de Wever Hospital Heerlen, and the University Hospital Maastricht, The Netherlands. These three hospitals are situated in the most southern part of the Netherlands and they provide rheumatic care to the entire population living in this part of the country.

All adult patients with mono-, oligo- as well as polyarticular acute or chronic arthritis of undetermined etiology were included in the study. The diagnosis of arthritis of undetermined etiology was based upon the judgement of the rheumatologist of the participating center. In particular, these patients were felt not to have infectious arthritis, psoriatic arthritis, ankylosing spondylitis, rheumatoid arthritis, systemic lupus erythematodes, crystal induced arthritis and reactive arthritis according to existing criteria (11-15). For the purpose of this article such diagnoses are collectively labelled as classified arthritis. Patients considered by their physician as having seronegative rheumatoid arthritis and who fulfilled the 1987 ACR criteria were included in the classified arthritis group.

\section{Controls}

Consecutive adult patients with classified arthritis served as a first control group. The second control group consisted of healthy family members of patients with arthritis of undetermined etiology and of healthy laboratory staff members. 


\section{Questionnaire}

Four different pictures of erythema migrans but not of other skin diseases were shown to all patients and controls. They were asked whether they had ever had a skin disorder as shown on these pictures. Explanation about the clinical evolution of erythema migrans was provided by the rheumatologist if felt necessary. All patients filled out a questionnaire regarding the number of recalled tick bites, and about outdoor activities. In addition neurological, cardiac and musculoskeletal manifestations suggestive of Lyme borreliosis were assessed.

A presumptive clinical diagnosis of Lyme borreliosis was based upon this questionnaire. For all patients and controls a clinical diagnosis of possible Lyme borreliosis was made if arthritis had been preceded by erythema migrans, heart block or neurological symptoms. None of the healthy controls had had rheumatic problems in the past. A clinical diagnosis of possible Lyme borreliosis was made in all cases without prior knowledge of antibody titers to B. burgdorferi.

A definite diagnosis of Lyme borreliosis was made if the possible clinical diagnosis of Lyme borreliosis was confirmed by a positive antibody titer to $B$. burgdorferi.

\section{Serology}

Blood samples from all patients and controls were tested for B. burgdorferi specific IgG antibodies by an enzyme linked immunosorbent assay (ELISA) as described elsewhere $(16,17)$.

A cut-off value of 0.35 was calculated. This optical density value was 2 standard deviations above the mean value of 128 sera from Dutch healthy laboratory staff members.

\section{Statistics}

For categorical data a $\mathrm{X}^{2}$ test was used to test for significant differences between groups at an alpha level of 0.05 .

\section{Ethics}

The protocol was approved by the Ethics Committee of the University Hospital Maastricht. All patients had given written informed consent. 


\section{RESULTS}

A total of 237 patients were studied; 73 patients suffered from arthritis of undetermined etiology. The mean age of this group was 45 years (range 18 to 73). The male to female ratio was 1:1. Ninety-four patients with classified arthritis had a mean age of 51.8 years (range 11 to 79 ). The male to female ratio in this group was 1:1. Also 70 healthy persons were tested. The mean age in this group was 39.2 years (range 18 to 77 ). The male to female ratio was 2.8:1.

Of the 73 patients with arthritis of undetermined etiology, 29 showed monarthritis. In 17 of these the knee joint was affected and in five the ankle. The other affected joints were hip (one patient), wrist (one patient), metacarpophalangeal joints (three patients), manubriosternal joint (one patient) and proximal interphalangeal joints (one patient).

Thirty-three patients suffered from oligoarthritis which was localized in the upper extremities in 11 patients, in the lower extremities in eight patients and in both in 14 patients. In eight of these 33 patients (or $24 \%$ ) the knee was among the affected joints.

Eleven patients showed polyarthritis of both upper and lower extremities.

Seven of the 73 patients reported they recognized erythema migrans from the pictures shown to them. Five of these seven patients suffered from monarthritis (knee, 3 cases; ankle, one case; metacarpophalangeal joint, one case), two had oligoarthritis. Based upon this recognition a clinical diagnosis of possible Lyme arthritis was made.

Only one patient who had arthritis of his knee joint and who reported to have had erythema migrans, showed a high titer of antibodies to $B$. burgdorferi. A definite diagnosis of Lyme arthritis was made in this case. The patient was treated with doxycycline $200 \mathrm{mg} /$ day during 30 days. At examination 4 months later all signs of arthritis had subsided. The other six patients had no elevated IgG antibodies to $B$. burgdorferi.

Three of the 73 patients with arthritis of undetermined etiology showed borderline positive IgG antibodies (ELISA titer $0.39,0.43$ and 0.43 ) to $B$. burgdorferi. These patients did not report any other (non-articular) manifestations of Lyme borreliosis. The arthritis of these three patients was localized in ankle, knee and metacarpophalangeal joints. The patient with ankle arthritis subsequently developed rheumatoid factor negative polyarthritis with symmetric involvement of metacarpophalangeal and proximal interphalangeal joints. The other two patients had been successfully treated with non-steroidal anti-inflammatory drugs. Until now, none of these patients developed any other features of Lyme borreliosis.

Also, 94 patients with classified arthritis were studied: 44 patients had seropositive rheumatoid arthritis, 17 seronegative rheumatoid arthritis, nine 
Table 1. Results of the clinical diagnosis and serology in patients with arthritis of undetermined etiology, classified arthritis and controls.

\begin{tabular}{|c|c|c|c|c|}
\hline Diagnosis & Number & $\begin{array}{l}\text { Possible clinical } \\
\text { Lyme } \\
\text { Borreliosis }\end{array}$ & $\begin{array}{l}\text { Positive antibodies } \\
(\text { ELISA }>0.35)\end{array}$ & $\begin{array}{l}\text { Definite } \\
\text { Lyme } \\
\text { Borreliosis }\end{array}$ \\
\hline \multirow{2}{*}{$\begin{array}{l}\text { Arthritis of } \\
\text { undetermined etiology }\end{array}$} & 73 & possible: 7 & 1 & 1 \\
\hline & & no: $\quad 66$ & 3 & 0 \\
\hline \multirow[t]{2}{*}{ Arthritis classified } & 94 & possible: 4 & I & 0 \\
\hline & & no: & 1 & 0 \\
\hline \multirow[t]{2}{*}{ Controls } & 70 & possible: 1 & 0 & 0 \\
\hline & & no: $\quad 69$ & 4 & 0 \\
\hline
\end{tabular}

psoriatic arthritis, eight gout, six HLA-B27 related peripheral arthritis, five systemic lupus erythematodes and five reactive arthritis.

Four of the 94 patients with classified arthritis recognized erythema migrans from the pictures. They had definite seronegative rheumatoid arthritis (2 patients), psoriatic arthritis or HLA-B27 associated arthritis. One of these patients (who was considered to have seronegative rheumatoid arthritis) showed a marginally elevated IgG antibody titer (ELISA 0.38). Because he had symmetrical erosive polyarthritis localized in hand and feet, he was not considered to suffer from Lyme arthritis. Another patient with seronegative rheumatoid arthritis showed a IgG antibody titer of 0.41 without any other sign or symptom which could be ascribed to Lyme borreliosis. Therefore, in this case a diagnosis of definite Lyme arthritis was also rejected.

From the group of 70 healthy controls one person recognized erythema migrans, but did not show positive IgG antibodies. Two asymptomatic cases showed slightly elevated IgG antibody titer (ELISA 0.37 and 0.38 ). One case showed a titer of 0.50 without Lyme symptoms. Another person showed a high titer of positive IgG antibodies (ELISA 1.06). He did not recall any symptoms of Lyme borreliosis. Therefore, four of 70 controls (5.7\%) had positive ELISA serology. They were felt not to have clinical Lyme borreliosis and were therefore not treated.

The results among the three groups are summarized in Table 1.

The occurrence of positive antibodies in the arthritis of undetermined etiology group $(5.4 \%)$ was not statistically significant different from the prevalence of positive antibodies in the combined control group (classified arthritis patients and healthy controls $(3.7 \%)(\mathrm{p}>0.5)$. 


\section{DISCUSSION}

Musculoskeletal symptoms as arthritis may occur in Lyme borreliosis without preceding erythema migrans, cardiac or neurological symptoms $(2,7,18)$. Although differences in the clinical characteristics of Lyme borreliosis in Europe and North America have been suggested, this might reflect a lack of awareness of Lyme arthritis in Europe (3). Indeed, in a Danish study six cases of Lyme arthritis were detected among 126 patients with oligoarthritis or seronegative polyarthritis (18). These authors warn against underestimation of the occurrence of Lyme arthritis since in three of these six cases arthritis was the first presentation of the disease.

The present study was performed to investigate whether Lyme arthritis might have been undetected among patients with unclassified arthritis.

In our country serologic testing for antibodies to $B$. burgdorferi is not usually performed in patients with arthritis of undetermined etiology. Therefore, Lyme arthritis may pass unnoticed.

Ten of 237 patients and controls in this study showed positive antibodies to $B$. burgdorferi (4.2\%). This is fully comparable to the percentage positive antibodies in a population of blood donors from the same area (3\%) (unpublished findings). Also, no significant difference was found in the percentage positive antibodies in the arthritis of undetermined etiology group compared to patients with classified arthritis or healthy controls.

In the arthritis of undetermined etiology group a definite diagnosis of Lyme borreliosis could be made in only one patient according to our criteria set for this study. Three patients in this group showed marginally positive antibodies to $B$. burgdorferi. However, clinically they were not felt to have Lyme arthritis.

In the classified arthritis group also two patients with seronegative rheumatoid arthritis showed slightly elevated antibodies. We do not consider these two patients to have Lyme arthritis. In addition, four patients from the healthy controls showed positive antibodies without any symptoms of Lyme borreliosis. They were also not felt to have Lyme borreliosis.

A few points should be stressed. Pictures of erythema migrans in four different stages were shown to all patients. The validity of this diagnostic instrument is not clear. Twelve of the 237 subjects (5\%) thought they recognized erythema migrans from these pictures, seven patients of the arthritis of undetermined etiology group, four of the classified arthritis group and one of the healthy controls. In none of these cases a diagnosis of erythema migrans had been previously confirmed by a physician. Only pictures of erythema migrans were shown and pictures of other red annular cutaneous lesions were not included among the photographs. Recognition of erythema migrans could therefore have been biased. Indeed, overestimation of the true prevalence of erythema migrans should be taken into account in studies such as this one. Strikingly, only one of 
the patients who recognized erythema migrans from the pictures showed positive antibodies to $B$. burgdorferi.

One might argue whether the low prevalence of Lyme arthritis among cases of arthritis of undetermined etiology might be due to a selection bias. Patients with Lyme arthritis might have been diagnosed before the study started and could therefore not have been included in the group "arthritis of undetermined etiology". We feel this is unlikely because our study was performed in 3 hospitals. Lyme arthritis has not been diagnosed in these centres in the last 5 years before the study.

In summary, a diagnosis of definite Lyme borreliosis could be established in only one of 73 patients with arthritis of undetermined etiology based upon previous erythema migrans, arthritis of the knee joint and strongly positive IgG antibodies to $B$. burgdorferi.

Although we had postulated that at least in the southern part of The Netherlands the occurrence of Lyme arthritis might be underestimated, based on this study, Lyme arthritis does not seem to be a frequent cause of arthritis of undetermined etiology. Nonetheless, appropriate questions concerning past nonarticular signs and symptoms of Lyme borreliosis should be asked to any patient with arthritis of undetermined etiology. We feel that routinely performing serological tests for Lyme borreliosis in patients without Lyme signs or symptoms, can not be recommended in a setting with a low prevalence of Lyme arthritis as in this study. However, Lyme borreliosis should be considered in the differential diagnosis of arthritis because antibiotic treatment usually is highly effective. Progression of joint damage or other manifestations which occur in the later stages of the disease may be prevented if appropriate treatment is provided immediately after the diagnosis Lyme borreliosis is established.

\section{Acknowledgement}

The authors wish to thank Drs. HM van Santen-Hoeufft, $\mathrm{H}$ Houben and $\mathrm{H}$ van der Tempel for their support and cooperation in this study and MA Khan for helpful comments and critically reading the manuscript. 


\section{REFERENCES}

1. Burgdorfer W, Barbour AG, Hayes SF, Benach J, Grunwaldt E, Davis JP. Lyme disease - a tickborne spirochetosis? Science 1982;216:1317-19.

2. Steere AC, Schoen RT, Taylor E. The clinical evolution of Lyme Arthritis. Ann Intem Med 1987;107:725-31.

3. Herzer P. Lyme arthritis in Europe: comparisons with reports from North America. Ann Rheum Dis 1988;47:789-91.

4. Steere AC, Bartenhagen NH, Craft JE, et al. The early clinical manifestations of Lyme disease. Ann Intern Med 1983;99:76-82.

5. van den Hoogen FHJ, Boerbooms AMTH, Rasker JJ, van de Putte L.BA. Gewrichtsklachten na tekebeet; Lyme-arthritis in Nederland. Ned Tijdschr Geneesk 1988;132:1300-03.

6. Blaauw AAM, Braat S, van Santen-Hoeufft MS, van der Linden Sj. Cardiologische afwijkingen bij patiënten met Lyme borreliosis. Ned Tijdschr Geneesk 1988;131:211114.

7. Blaauw AAM, Nohlmans MKE, van den Berg Loonen E, Rasker JJ, van der Linden Sj. Lyme arthritis in the Netherlands, a nationwide survey among rheumatologists. J Rheum 1991;18:1819-22.

8. Steere AC, Hutchinson GJ, Rahn DW, et al. Treatment of the early manifestations of Lyme disease. Ann Intern Med 1983;99:22-6.

9. Steere AC, Green J, Schoen RT, et al. Successful parenteral penicillin therapy of established Lyme arthritis. N Engl J Med 1985;312:869-74.

10. Lui NY, Dinerman H, Levin RE, et al. Randomized trial of doxycycline vs. amoxicillin/probenecid for the treatment of Lyme arthritis: treatment of non responders with iv penicillin or ceftriaxone. Arthritis Rheum 1989;32:546. Abstract.

11. Arnett FC, Edworthy S, Block DA, et al. The American Rheumatism Association 1987 revised criteria for the classification of Rheumatoid Arthritis. Arthritis Rheum 1988;31:315-24.

12. Tan EM, Cohen AS, Fries JF, et al. The 1982 revised criteria for the classification of systemic lupus erythematosus (SLE). Arthritis Rheum 1982;25:1271-77.

13. Wallace SL, Robinson H, Mâsi AT, et al. Preliminary criteria for the classification of the acute arthritis of primary gout. Arthritis Rheum 1977;20:895-900.

14. Willkens RF, Amett FC, Bitter T, et al. Reiter's syndrome: Evaluation of preliminary criteria for definite disease. Arthritis Rheum 1981;24:844-49.

15. van der Linden Sj, Valkenburg HA, Cats A. Evaluation of diagnostic criteria for ankylosing spondylitis. A proposal for modification of the New York criteria. Arthritis Rheum 1984;27:361-68.

16. Barbour AG. Isolation and cultivation of Lyme disease spirochetes. Yale J Biol Med 1984;57:521-25.

17. Craft JE, Grodzicki RL, Steere AC. The antibody response in Lyme disease: evolution of diagnostic tests. J Infect Dis 1984;149:789-95.

18. Kryger P, Hansen K, Vinterberg H, Pedersen FK. Lyme borreliosis among Danish patients with arthritis. Scand J Rheum 1990;19:77-81. 



\section{Is there any evidence for an association between ankylosing spondylitis and Borrelia burgdorferi infection?}

AAM Blaauw, MKE Nohlmans*, AJ Peeters**, BAC Dijkmans**, $S$ van der Linden

Department of Intemal Medicine, Division of Rheumatology. Department of Medical Microbiology*, University Hospital Maastricht. Department of Rheumatolugy**, University Hospital Leiden, The Netherlands.

Reprinted by permission of the Journal of Rheumatology 1992;19:579-581 


\title{
Is there any evidence for an association between ankylosing spondylitis and Borrelia burgdorferi infection?
}

\begin{abstract}
The suggested relationship between Borrelia burgdorferi and seronegative spondylarthropathies has been studied in 125 patients with ankylosing spondylitis (AS). IgG antibodies to Borrelia burgdorferi were present in 11 of 125 patients (8.8\%) and in 25 of 125 controls (20\%). No patient had clinical Lyme borreliosis. HLA-B27 status was known for 82 patients with AS. There was no difference between B27+ and B27- patients. This study provides no evidence that Borrelia burgdorferi is associated with AS.
\end{abstract}

\section{INTRODUCTION}

In Lyme borreliosis, which is caused by the tick-borne spirochete Borrelia burgdorferi (B. burgdorferi), the musculoskeletal system is often involved (1). Migratory pain in joints, tendons and bursae, brief arthritis attacks and in later stages prolonged arthritis attacks, chronic arthritis and peripheral enthesopathy are frequent symptoms of this disease (2).

Recently, it has been suggested that the spirochete B. burgdorferi might trigger reactive arthritis in a genetically susceptible HLA-B27 positive host (3). This finding may have therapeutic implications and raises challenging new questions about pathogenetic mechanisms underlying the spondylarthropathies (4). Ankylosing spondylitis (AS) is the prototype of this group of disorders. Indeed, spinal involvement and sacroiliitis have been ascribed to patients with chronic $B$. burgdorferi infection $(5,6)$. Also, positive antibodies to $B$. burgdorferi were found more often among Swiss patients with AS than among their HLA-B27 positive relatives (7). However, these patients with AS were on average older than the relatives, i.e. they might have been exposed longer to infected ticks. Therefore, no definite conclusions could be drawn about the clinical significance of antibodies to B. burgdorferi for the etiology of AS. 
In patients with AS we assessed (1) the presence of clinical manifestations of Lyme borreliosis and (2) the prevalence of $\operatorname{IgG}$ antibodies to B. burgdorferi. Our findings were compared with age matched controls.

\section{MATERIALS AND METHODS}

\section{Patients and controls}

Patients with AS (modified New York criteria) from the outpatient departments of rheumatology of the University Hospital of Leiden, the Medisch Spectrum, Alkmaar, and the Gemini-Hospital of Den Helder, were interviewed for clinical manifestations of Lyme borreliosis (8).

Several pictures of erythema migrans were shown to all participants. A standardized questionnaire assessing tick bites, cardiac, neurologic, musculoskeletal manifestations, and outdoor activities was completed (9). Whenever felt necessary, additional explanation about the clinical evolution of erythema migrans and about signs and symptoms of Lyme borreliosis was provided by the interviewers. If the patients' responses suggested signs or symptoms of Lyme borreliosis in the past, clinical records and correspondence were studied, and patients' physicians were consulted.

A clinical diagnosis of Lyme borreliosis was made only if the patients had erythema migrans confirmed by a physician, or if they had Bannwarth's syndrome or atrioventricular block of otherwise unknown origin. Patients with AS with peripheral arthritis were not considered to have Lyme borreliosis unless they had at least one nonrheumatic manifestation of Lyme borreliosis.

The controls consisted of male, age matched healthy laboratory and hospital workers; patients from the outpatient department of rheumatology of the University Hospital of Leiden with non-inflammatory joint or muscle complaints; patients with coronary heart disease from the outpatient department of cardiology of the University Hospital Leiden; and blood donors from the same geographic region. For practical reasons the control group consisted of only men. In a previous study we have shown that gender does not influence seropositivity for Lyme borreliosis (10). A subgroup consisting of patients of the department of rheumatology and healthy laboratory and hospital workers $(n=34)$ was also interviewed and completed the questionnaire for clinical features of Lyme borreliosis. 


\section{Serology}

Serum $(10 \mathrm{ml})$ was obtained by venipuncture from all patients and controls. Serum samples were tested for B. burgdorferi specific IgG antibodies by an enzyme linked immunosorbent assay (ELISA) as described elsewhere $(11,12)$. As cutoff value an optical density (OD) of 0.35 was calculated. This value was 2 standard deviations (SD) above the mean value for 128 sera of Dutch healthy laboratory staff members and corresponded to the $95 \%$ specific cutoff value based on the results of these sera (10).

\section{Western blotting}

Western blots were performed for all ELISA IgG positive antibodies from patients with AS and controls (13). Western blot was considered positive when a $4 \mathrm{I} \mathrm{kDa}$ band was present in combination with either a $94 \mathrm{kDa}$ and a $31 \mathrm{kDa}$ band or with a $31 \mathrm{kDa}$ band and another band in the range of $18-40 \mathrm{kDa}$.

\section{Statistics}

For categorical data a $\mathrm{X}^{2}$ test was used to test for significant differences between groups. A probability value $<-0.05$ was considered statistically significant.

The study was approved by the Ethics Committee of the University Hospital of Leiden.

\section{RESULTS}

During the summer of 1990 , a total of 125 patients with AS were interviewed for clinical features of Lyme borreliosis. 95 were men (76\%) and 30 women. The mean age of these patients was 43.8 years with a SD of 10.0 years. The mean duration of the disease was 7.5 years (SD 7.4 years).

The controls consisted of 125 individuals: 13 patients of the outpatient department of rheumatology, 21 hospital workers, 47 patients of the outpatient clinic of cardiology and 44 blood donors. The mean age of this group was 44.4 years (SD 9.5 years).

The results of the reported clinical symptoms were compared to the presence of IgG antibodies to $B$. burgdorferi (Table 1 ).

Erythema migrans was recognized from the pictures by 8 patients with AS. However, erythema migrans was not confirmed by a physician. No patient had been treated with antibiotics for the skin lesion. No antibodies to $B$. burgdorfer $i$ 
Table 1. Results of the reported clinical symptoms compared to IgG antibodies to $B$. burgdorferi in 125 patients with AS.

Antibodies to $B$. burgdorferi

\begin{tabular}{lccc}
\cline { 3 - 4 } & Positive & Negative & Total \\
\hline Lyme symptoms reported & 0 & 12 & $12^{*}$ \\
No Lyme symptoms reported & 11 & 102 & 113 \\
Total & 11 & 114 & 125 \\
\hline
\end{tabular}

* None of these 12 patients had Lyme disease.

could be detected. Therefore, these 8 patients were not considered to have Lyme borreliosis.

No patient with AS reported past cardiac symptoms such as heart block or other rhythm disturbances. Four patients who reported to have had Bell's palsy, had no antibodies to B. burgdorferi.

Eleven patients with AS who did not report clinical manifestations of Lyme borreliosis had positive antibodies to $B$. burgdorferi. OD values of the seropositive patients ranged from $0.35-0.68$. Westem blots of these 11 patients were negative.

HLA-B27 status was known for $82(65.6 \%)$ of the 125 patients with AS. Eight $(10.8 \%)$ of $74 \mathrm{~B} 27+$ patients had antibodies to $B$. burgdorferi compared with 1 (12.5\%) of $8 \mathrm{~B} 27$ - patients (NS).

Twenty-five controls ( $20 \%$ ) had antibodies to $B$. burgdorferi. The OD values of the seropositive controls ranged from $0.35-1.06$. Western blots were performed for all 25 seropositive controls: 2 healthy controls had positive blots (ELISA 0.50 and 1.06). They denied any symptoms of Lyme borreliosis. The percentage positive antibodies in the control group was significantly higher than in the patients with AS $(\mathrm{P}<0.02)$.

Two individuals of the interviewed controls $(n=34)$ recognized erythema migrans from the pictures. They did not have antibodies to $B$. burgdorferi. No other signs or symptoms suggesting Lyme borreliosis were reported in this group.

Overall, none of the 125 patients with AS were thought to have clinical Lyme borreliosis, although $11(8.8 \%)$ patients did have positive antibodies to $B$. burgdorferi. 


\section{DISCUSSION}

The role of bacterial infections in the pathogenesis of reactive arthritis is widely accepted and suggested in other seronegative spondylarthropathies (14-16). It is as yet unclear whether the arthritis-inducing potential of microorganisms represents the sequelae of a persisting infection or the induction of a pathologic immune response (17). The strong association of the various types of spondylarthropathies with HLA-B27 supports the idea that the immune reactivity of the host plays a crucial role.

Recently $B$. burgdorferi has been added to the list of microorganisms that have been identified as disease inducing infectious agents preceding the sudden onset of reactive arthritis or Reiter's syndrome (3). Nine patients who presented with reactive arthritis were found to have antibodies to $B$. burgdorferi. Altogether 6 of them had sacroiliitis. The clinical descriptions of these patients, as well as the high prevalence of HLA-B27 in this group, support the clinical diagnoses of Reiter's syndrome rather than Lyme borreliosis (4). The diagnosis of chronic $B$. burgdorferi infection was strengthened by the demonstration of specific T-cell reactivity. All patients were treated with doxycycline. Although antibody titers decreased significantly, only 1 patient had a complete remission after antibiotic treatment.

Based upon these findings, we asked whether $B$. burgdorferi may play a role in the etiology of ankylosing spondylitis, as has been suggested in the literature (3-7). In this study we found antibodies to B. burgdorferi in $8.8 \%$ of patients with AS. Clinically, these patients were thought to have definite AS and no Lyme borreliosis. All these patients had negative Western blot patterns. Lymphoproliferative responses to B.burgdorferi were not performed in these patients, because elevated responses also occur frequently in healthy controls (18). No clear difference in the prevalence of positive Lyme serology among B27+ and B27-patients with AS was found. Positive Lyme serology in patients with AS is insufficient evidence to hold B. burgdorferi responsible for AS.

An unexpected (and unexplained) finding was the higher prevalence of antibodies to $B$. burgdorferi among controls than among patients. The percentage seropositivity among the controls, however, is quite comparable to the findings in a group of blood donors from the same geographic area (17\%) (10). The reason for the lower sero-prevalence among the patients remains unclear. The area from which the patients, controls and blood donors were recruited is situated near the Dutch North sea coast which has an extensive range of dunes. Ticks from this region are known to be infected with $B$. burgdorferi (19). Due to the limitations caused by their disease, patients with AS may have had lower exposure to infected ticks, although they reported to spend on average $3,5 \mathrm{~h}$ outdoors every day during the summer period. We have not assessed, however, 
how many of these hours have been spent in tick infected areas such as the coastal dunes.

In conclusion, we have found positive Lyme serology in $8.8 \%$ of Dutch patients with AS. Clinical manifestations of Lyme borreliosis did not occur in these patients. We do not feel these patients with AS have chronic Lyme borreliosis infection. Positive test results of Lyme serology should be carefully interpreted in populations with a low prevalence of Lyme disease $(20,21)$. Reactive arthritis and AS both belong to the spondylarthropathies. However, based on our study, the suggestion that $B$. burgdorferi triggers a reactive arthritis in genetically susceptible hosts can not be extended to patients with AS.

Acknowledgements

The assistance of C Bakker, C Braakman, A Hidding, C Jonker and A MackaayKluck is greatly acknowledged. 


\section{REFERENCES}

1 Steere AC. Lyme disease. N Engl J Med 1989;321:586-595.

2 Steere AC, Schoen RT, Taylor E. The clinical evolution of Lyme arthritis. Ann Intern Med. 1987; 107:725-31.

3 Weyand CM, Goronzy JJ. Immune responses to Borrelia burgdorferi in patients with reactive arthritis. Arthritis Rheum 1989;9:1057-64.

4 Arriett FC. The Lyme spirochete: another cause of Reiter's syndrome? Arthritis Rheum 1989;9:1182-84.

5 Kinigadner U, Mur E, Möst J, Frank R, Stanek G. Borrelia infection as a possible cause of HLA-B27 negative sacroiliitis. J Rheum 1991;3:484-85.

6 Prohaska E, Kristoferitsch W, Stanek G. Spinal involvement in Lyme borreliosis. Zbl Bakt 1989;(suppl 18)261-2.

7 Blaauw I, Linden van der S, Nohlmans L. An increased prevalence of anti-Borrelia burgdorferi antibodies in ankylosing spondylitis: fact or artefact? Scand J Rheum 1990; (Suppl 87):148.

8 Linden van der SM, Valkenburg HA, Cats A. Evaluation of diagnostic criteria for ankylosing spondylitis. A proposal for modification of the New York criteria. Arthritis Rheum 1984;27:361-69.

9 Blaauw AAM, Nohlmans MKE, Leffers P, Linden van der Sj. Lyme borreliosis: a very infrequent cause of arthritis of undetermined aetiology in the southem part of the Netherlands. Br J Rheumatol 1992;31:401-404.

10 NohImans MKE, Bogaard van den AEJM, Blaauw AAM, Boven van CPA. Prevalentie van Lyme borreliosis in Nederland. Ned Tijdschr Geneeskd 1991;135:2288-92.

11 Craft JE, Grodzicki RL, Steere AC. The antibody response in Lyme disease spirochetes. J Infect Dis 1984;149:789-95.

12 Barbour AG. Isolation and cultivation of Lyme disease spirochetes. Yale J Biol Med 1984;57:521-25.

13 Grodzicki RL, Steere AC. Comparison of immunoblotting and indirect enzyme-linked immunosorbent assay using different antigen preparations for diagnosing early Lyme disease. J Infect Dis 1988;4:790-797.

14 McGuigan LE, Prendergast JK, Geczy AF, Edmonds JP, Bashir HV. Significance of non-pathogenic cross reactive bowel flora in patients with ankylosing spondylitis. Ann Rheum Dis 1986;45:566-571.

15 Keat A. Reiter's syndrome and reactive arthritis in perspective. N Engl J Med 198.3;309:1606-1615.

16 Granfors K, Jalkanen S, von Essen R, et al. Yersinia antigens in synovial-fluid cells from patients with reactive arthritis. $N$ Engl J Med 1989;320:216-221.

17 Sheldon P. Specific cell-mediated responses to bacterial antigens and clinical correlations in reactive arthritis, Reiter's syndrome and ankylosing spondylitis. Immunological Reviews 1985;6:5-25.

18 Zoschke DC, Skemp AA, Defosse DL. Lymphoproliferative responses to Borrelia burgdorferi in Lyme disease. Ann Intern Med 1991;114:285-289.

19 Nohlmans L, Boer de R, Bogaard van den AEJM, Blaauw AAM, Boven van CPA. Prevalentie van Borrelia burgdorferi in Ixodes ricinus in Nederland. Ned Tijdschr Geneeskd 1990;34:1300-03. 
20 Fahrer H, Linden van der SJ, Sauvain M-J, Gern L, Zhioua E, Aeschlimann A. The prevalence and incidence of clinical and asymptomatic Lyme borreliosis in a population at risk. J Infect Dis 1991;163:305-310.

21 Blaauw AAM, Nohlmans MKE, Bogaard van den AEJM, Linden van der SJ. Diagnostic tools in Lyme borreliosis: clinical history compared with serology. J Clin Epidemiol 1992; $11: 1229-36$. 



\section{Diagnostic tools in Lyme borreliosis: clinical history compared with serology.}

AAM Blaauw, MKE Nohlmans*, AEJM van den Bogaard*, $S$ van der Linden.

Department of Internal Medicine, Division of Rheumatology, and Department of Medical Microbiology*, University Hospital Maastricht and University of Limburg, Maastricht, the Netherlands.

Reprinted by permission of the Journal of Clinical Epidemiology 1992;11:1229-12.36 


\title{
Diagnostic tools in Lyme borreliosis: clinical history compared with serology.
}

\begin{abstract}
The occurrence of a history of clinical Lyme borreliosis and the prevalence of positive antibodies to Borrelia burgdorferi were studied in 431 Dutch hunters. The majority of the hunters ( 336 or $78 \%$ ) did not report any complaints and had no positive IgG antibodies to Borrelia burgdorferi. Sixty-five hunters (15.1\%) had no clinical manifestations but did have positive antibodies to Borrelia burgdorferi. Only $1.9 \%$ of the population studied had had past symptoms of definite or probable Lyme borreliosis.

Likelihood ratios were high (21.3) for the recognition of erythema migrans, but much lower for tick bites (3.6) or positive IgG Lyme serology (3.5). Clinical history turned out to be a more powerful diagnostic tool than Lyme serology.
\end{abstract}

\section{INTRODUCTION}

Lyme borreliosis is a multi-system disease that can affect the skin, heart, nervous system and joints (1). Since the culture or direct visualization of Borrelia burgdorferi ( $B$. burgdorferi) from patient specimens is difficult, serology is currently considered to be the only practical laboratory aid in establishing a diagnosis (1). However, serologic results have to be interpreted with caution; the physician has to be aware of both false negative and false positive results and of interlaboratory variation $(2,3,4)$. In addition, a large number of people have asymptomatic $B$. burgdorferi infections. For instance, positive Lyme serology is quite common in Swiss orienteers, but the clinical disease itself occurs infrequently (5).

It is therefore necessary to gain knowledge about the ratio of apparent-to-inapparent infections and prevalence of the clinical disease in populations, where the serologic test is applied.

We were able to study the prevalence of positive Lyme serology and the past occurrence of clinical Lyme borreliosis in a population at risk (hunters). A clinical and serological follow-up was done among hunters, who either reported 
signs or symptoms suggestive of Lyme borreliosis, or had positive IgG Lyme serology.

We also assessed the clinical usefulness of several diagnostic tools by calculating likelihood ratios for (1) the recognition of erythema migrans (photographs of this skin condition were shown), (2) a history of tick bites, and (3) positive IgG Lyme serology.

\section{PATIENTS AND METHODS}

Dutch hunters, members of the Koninklijke Nederlandse Jagers Vereniging (Royal Dutch Hunting Society) living all over the country, were invited to participate in the study. Prior to the hunting season, they meet at different locations in the Netherlands to hold dog trials. The hunters were asked to participate in the study at one of these places. The board of the Hunting Society encouraged their participation.

In the Netherlands the infection rate of Ixodes ricinus with $B$. burgdorferi ranges from 2.4 to $14.3 \%$ (6).

\section{Study population}

Four pictures of erythema migrans in different stages of development were shown to all participating hunters. They were asked to complete a questionnaire on site, which dealt with exposure to ticks and possible manifestations of Lyme borreliosis. Specific questions were asked about tick bites, meningitis, facial palsy, rhythm disturbances and arthritis. Participants were encouraged to discuss problems associated with the questionnaire, or any questions they might have regarding the erythema migrans pictures with the investigators. After the questionnaire was completed, $10 \mathrm{ml}$ of blood was obtained by venipuncture to determine the presence of IgG antibodies to $B$. burgdorferi.

If the answers given in the questionnaire suggested Lyme borreliosis, e.g. redness of the skin, cardiac, neurologic or joint symptoms, further information from the participants was obtained by telephone.

If, after completion of the questionnaire and the telephone interview, the history of the participants still suggested Lyme borreliosis, a probable diagnosis of clinical Lyme borreliosis was made in cases where the hunter had not consulted a physician. A definite diagnosis of Lyme borreliosis was only made if it was confirmed by a physician. After this part of the study had been completed, all participants received a letter about the findings of the study. The letter included the participant's individual results. A copy for the general practitioner (GP) was enclosed. 
Hunters, who had a probable or definite diagnosis of Lyme borreliosis, positive serology, or who had ambiguous symptoms, were invited to participate in a 6-month follow-up study. The purpose of this follow-up study was (1) to detect a delayed increase in the optical density value of serum in hunters with ambiguous symptoms, and (2) to evaluate development of possible clinical Lyme manifestations in hunters with positive serology who did not have any symptoms in the first study. In this, the second part of the study, pictures of erythema migrans were sent to the selection of hunters mentioned above together with a second questionnaire, which again contained questions about clinical manifestations of Lyme borreliosis. These included tick bites, meningitis, facial palsy, rhythm disturbances and arthritis. In addition, names and addresses of their physicians were asked for. A second blood sample was obtained through their GPs. This specimen was sent to our laboratory. The same rules for the definition of definite or probable disease were applied in both parts of the study. When interpretation of reported symptoms remained unclear, a letter was sent to the patient's GP or any other physician consulted. This was done after obtaining informed consent. We asked specifically for findings that might help in establishing a definite diagnosis of clinical Lyme borreliosis.

\section{Serology}

Blood samples from all participants were tested for $B$. burgdorferi specific IgG antibodies, by an enzyme linked immunosorbent assay as described elsewhere $(7,8)$. An optical density value of 0.35 was taken as the cutoff point. This value was $2 \mathrm{SD}$ above the mean value of 128 sera based on Dutch healthy laboratory staff members (9). The intra and intertest precision were $94 \%$ and $91 \%$ at this cutoff point. Setting the cutoff point at 0.35 , meant that the sensitivity of the serologic test varied from $40 \%$ to $96 \%$ depending on the clinical manifestations in cases of definite Lyme borreliosis: early Lyme borreliosis, $40 \%(n=25)$; and late Lyme borreliosis, 96\% $(\mathrm{n}=27)$.

\section{Likelihood ratios}

Likelihood ratios (percentage true positive : percentage false positive) were calculated for (1) the recognition of erythema migrans, (2) a history of tick bites, and (3) the presence of IgG antibodies to B. burgdorferi (likelihood ratio of the positive test) (10). Data from two other recent studies were included in the calculation of these likelihood ratios $(11,12)$. Using larger numbers narrows the confidence interval for the likelihood ratio estimate (10). We feel that it was justified to pool the data of the three studies, because the same pictures of 
erythema migrans were shown. The same questions about clinical manifestations of Lyme borreliosis were asked and antibodies to $B$. burgdorferi were determined in the same laboratory. However, the participants in these three studies were probably not homogeneous concerning their rate of exposure.

Approximate $95 \%$ confidence intervals for the likelihood ratios were calculated. Confidence intervals for sensitivity, based on the binomial distribution, were divided by $100 \%$-specificity.

\section{RESULTS}

\section{Prevalence of clinical and serological Lyme borreliosis}

August through October 1989, serum samples were obtained from 431 hunters (35\% of the eligible study sample) who were all interviewed. Altogether, 289 $(67 \%)$ were male and $142(33 \%)$ were female. The mean age of the 431 hunters was 40.5 years (ranging from 10 to 76 ).

The majority of the hunters ( 336 or $78 \%$ ) did not report any complaints, had not suffered from erythema migrans as shown on the pictures provided them, and had no positive antibodies to B. burgdorferi (Table 1).

Five seropositive hunters reported clinical symptoms. One hunter had suffered from arthritis (confirmed by his GP). This case was definitely diagnosed as Lyme borreliosis. Four hunters recognized erythema migrans from the pictures shown. However, in these hunters erythema migrans was not confirmed

Table 1. Definite and probable Lyme borreliosis in Dutch hunters related to the results of ELISA antibody tests.

\begin{tabular}{|c|c|c|c|c|c|}
\hline & & & \multicolumn{3}{|c|}{ Antibodies to Borrelia burgdorferi } \\
\hline & & & Positive & Negative & Total \\
\hline \multirow{5}{*}{$\begin{array}{l}\text { Reported Clinical } \\
\text { Symptoms }\end{array}$} & Yes & Definite & 1 & 3 & 4 \\
\hline & & Probable & 4 & - & 4 \\
\hline & & No Lyme & - & 22 & 22 \\
\hline & No & & 65 & 336 & 401 \\
\hline & Total & & 70 & 361 & 431 \\
\hline
\end{tabular}


by their physicians. Therefore, a probable diagnosis of Lyme borreliosis was made in these 4 cases.

Twenty-five hunters reported clinical symptoms, but did not have positive antibodies to $B$. burgdorferi. Three of the 25 hunters had erythema migrans confirmed by their physicians. In these 3 cases a definite diagnosis of Lyme borreliosis was made (Table 1). They had been treated with antibiotics early in their disease course. Thirteen of the remaining 22 hunters reported recognizing erythema migrans from the pictures. However, the diagnosis of erythema migrans could not be confirmed by their physicians, who either never saw a rash, or saw a rash and did not feel it was erythema migrans. Four hunters had experienced musculoskeletal symptoms, two had had unclear cardiac symptoms in the past, and three had had neurological symptoms. This group of 22 hunters was not felt to have had clinical Lyme borreliosis on the basis of the answers given in the interview by telephone.

Sixty-five of the 431 hunters did not have any complaints, but had positive antibodies to $B$. burgdorferi. This meant that $15.1 \%$ of the hunters were asymptomatic seropositive.

Four seropositive hunters had probable clinical Lyme borreliosis (erythema migrans in all 4), whereas 4 others (1 seropositive and 3 seronegative) had definite clinical Lyme borreliosis (erythema migrans in 3, arthritis in 1). The total prevalence for probable and definite clinical Lyme borreliosis was $8 / 431$ or $1.9 \%$.

Altogether, $358(336+22)$ hunters (or $83 \%$ ) were seronegative and did not have clinical manifestations, which supported a diagnosis of Lyme borreliosis (Table 1).

Among those who must have been exposed to B. burgdorferi (i.e. those who had clinical Lyme disease or are still seropositive), there was a significant relationship between the recall of tick bites and the presence of clinical features of Lyme borreliosis. The 8 hunters with probable or definite Lyme borreliosis all recalled tick bites. $33.8 \%$ of the 65 asymptomatic seropositive hunters remembered at least one tick bite (Fisher Exact $\mathrm{p}<0.001$ ). However, there were no significant differences between the last group and the 358 seronegative hunters without Lyme borreliosis, of whom $31.8 \%$ remembered a tick bite $\left(\mathrm{X}^{2}\right.$ 0.10 - NS).

\section{Follow-up study}

The 95 hunters (or $22 \%$ of the whole group), who had reported clinical manifestations of Lyme borreliosis or showed positive Lyme serology, were invited to take part in the follow up study. Surveys and serum samples were received from 66 hunters $(69.5 \%$ ) (Table 2 ). 
Table 2. ELISA IgG antibodies to Borrelia burgdorferi in Dutch hunters in the autumn of 1989 compared with the presence of antibodies in the spring of 1990.

\begin{tabular}{lllll} 
& & \multicolumn{2}{l}{ IgG antibodies Autumn } & \\
\cline { 3 - 5 } & & Positive & Negative & Total \\
\hline IgG antibodies & Positive & 30 & 1 & 31 \\
Spring & Negative & 20 & 15 & 35 \\
& Total & 50 & 16 & 66 \\
\hline
\end{tabular}

The only hunter with definite Lyme borreliosis and positive antibodies also remained seropositive. He had been successfully treated for his arthritis with a course of oral doxycycline.

The optical density values of 3 out of the 4 hunters with probable Lyme borreliosis and positive antibodies to $B$. burgdorferi remained positive. One hunter did not respond at follow-up.

The 3 hunters with physician confirmed erythema migrans without antibodies remained seronegative. One of them developed secondary red annular lesions and was retreated with doxycycline.

Seven seronegative hunters, who reported recognizing erythema migrans during the first study, also took part in the follow-up study. They all remained seronegative. Three of the hunters with musculoskeletal complaints responded as well. They remained seronegative as did one of the hunters with unclear cardiac symptoms. By contrast, one of the hunters with neurologic complaints had become seropositive by the time the follow up was carried out. His optical density value had increased moderately from 0.27 to 0.39 . Unfortunately, he did not give permission to obtain information from his physicians. One other hunter with neurological complaints remained seronegative, while a third one did not respond.

Altogether, 26 hunters remained asymptomatic seropositive without any change in their IgG anti-Borrelia antibodies. Twenty hunters, who were asymptomatic seropositive, became seronegative during the follow-up period.

Therefore, we may conclude the follow-up study among the 66 hunters did not reveal any new cases of Lyme borreliosis. 


\section{Use of diagnostic tools}

In the present study, 20 hunters (4.6\%) said they recognized erythema migrans from the pictures shown them. In 3 out of the 20 cases a definite diagnosis of Lyme borreliosis was made. Twenty-one out of 362 patients and controls in the two earlier studies said they recognized erythema migrans from the pictures $(11,12)$. In 1 patient a definite diagnosis of Lyme borreliosis could be made. Combining the results of these three studies, 41 of $793(5.2 \%)$ individuals believed they had had erythema migrans at some time. In 4 cases a definite diagnosis of clinical Lyme borreliosis was made. This implies that for definite clinical Lyme borreliosis the positive predictive value equals $4 / 41$ (or 9.8\%). The positive predictive value covers all individuals with a positive test result (recognition of erythema migrans) who definitely have the disease. Although

Table 3. Likelihood ratio for erythema migrans confirmed by physician (pooled data).

\begin{tabular}{|c|c|c|c|c|}
\hline & & \multicolumn{3}{|c|}{ Erythema migrans, physician confirmed } \\
\hline & & yes & no & total \\
\hline \multirow{3}{*}{$\begin{array}{l}\text { Erythema migrans } \\
\text { recognized from } \\
\text { pictures }\end{array}$} & yes & 4 & 37 & 41 \\
\hline & no & 0 & 752 & 752 \\
\hline & & 4 & 789 & 793 \\
\hline
\end{tabular}

Likelihood ratio: Positive test $(\mathrm{LR}+)=(4: 4):(37: 789)=21.3(95 \%$ Confidence Interval 8.5, 21.3)

Table 4. Likelihood ratio for recalled tick bites (pooled data).

Lyme borreliosis

\begin{tabular}{llllr} 
& & present & absent & total \\
\hline \multirow{2nyyy}{*}{ Tick bite } & yes & 4 & 174 & 78 \\
& no & 1 & 614 & 615 \\
& & 5 & 788 & 793 \\
\hline
\end{tabular}

Likelihood ratio: Positive test $(\mathrm{LR}+)=(4: 5):(174: 788)=3.6(95 \%$ Confidence Interval 1.3, 4.5) 
Table 5. Likelihood ratio for positive Lyme serology (pooled data).

\section{Lyme borreliosis}

\begin{tabular}{llrrr} 
& & present & absent & total \\
\cline { 4 - 5 } & yes & 2 & 90 & 92 \\
Borrelia burgdorferi & no & 3 & 698 & 701 \\
& & 5 & 788 & 793 \\
\hline
\end{tabular}

Likelihood ratio: Positive test $(\mathrm{LR}+)=(2: 5):(90: 788)=3.5(95 \%$ Confidence Interval 0.5, 7.5)

this may seem rather low, it is still higher than the positive predictive value for the presence of IgG antibodies to B. burgdorferi. Only 1 of the 70 seropositive hunters in the present study had definite clinical Lyme disease (Table 1), which accounts for a positive predictive value of only $1.4 \%$.

Based upon the pooled data from the three studies, we calculated a likelihood ratio of 21.3 for the recognition of erythema migrans (Table 3 ) (10). By contrast, the diagnostic-discriminative value of the tick bites recalled as part of the clinical history, is much lower with a likelihood ratio of only 3.6 (Table 4). The likelihood ratio for the presence of positive antibodies to $B$. burgdorferi was 3.5 (Table 5). (We only calculated likelihood ratios for past erythema migrans, tick bites and positive antibodies to $B$. burgdorferi, since these features are the hallmarks of Lyme borreliosis, whereas none of the participants in our studies had had Bannwarth syndrome or atrio-ventricular block. Therefore, we were not able to calculate likelihood ratios for these less frequent Lyme disease manifestations).

These likelihood ratios were applied in a nomogram adapted from Fagan (figure 1-4) (13). In the normal Dutch population the pretest probability for Lyme borreliosis is low, being about $0.1 \%$. For someone who remembers a tick bite, the posttest probability of having Lyme borreliosis is $0.3 \%$ (figure 1 ). If a person recognizes erythema migrans from pictures, his posttest probability is $2 \%$. If somebody has antibodies to $B$. burgdorferi the posttest probability is $0.3 \%$. When two of these features occur together the maximum posttest probability is $5 \%$ (assuming independence). When three variables are combined the posttest probability may reach $15 \%$ (figure 2 ).

In a population with a higher pretest probability, such as that of the hunters in this study (nearly $2 \%$ ), the posttest probability was considerably higher: recognition of erythema migrans yields a posttest probability of as much as $30 \%$ (figure 3 ). When the three variables are combined (recognition of erythema 


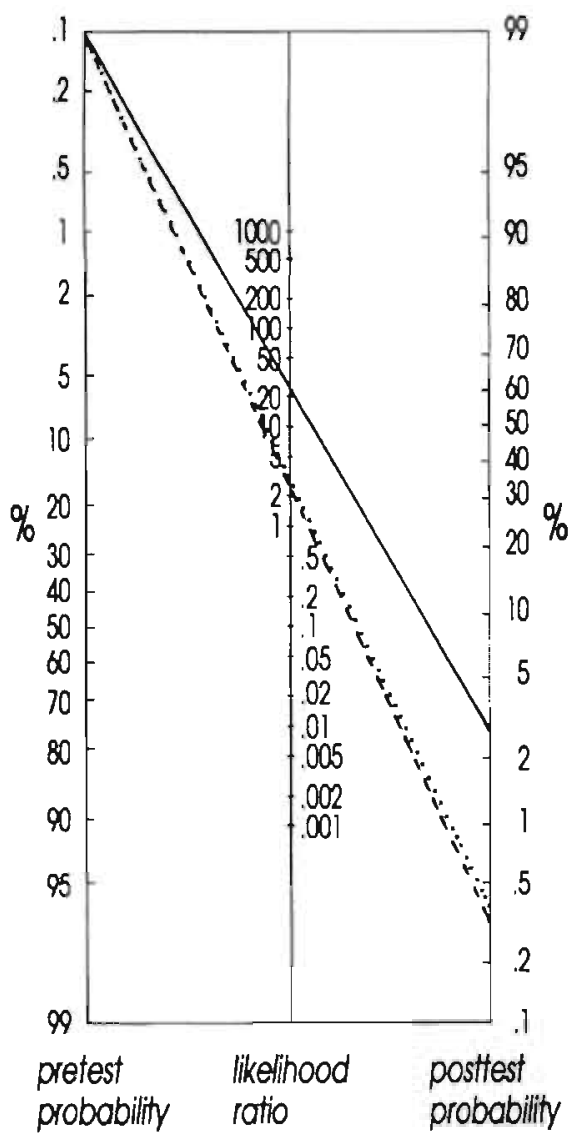

Figure 1. Posttest probability of Lyme borreliosis in the normal Dutch population after application of different likelihood ratios (pretest probability $0.1 \%$ ). (-) LR erythema migrans*, 21.3; (. . .) LR tick bite, 3.6; (- - -) LR positive Lyme serology, 3.5. *Confirmative answer when shown pictures of erythema migrans. (Nomogram reprinted by permission of the New England Journal of Medicine 1975;293:257.)

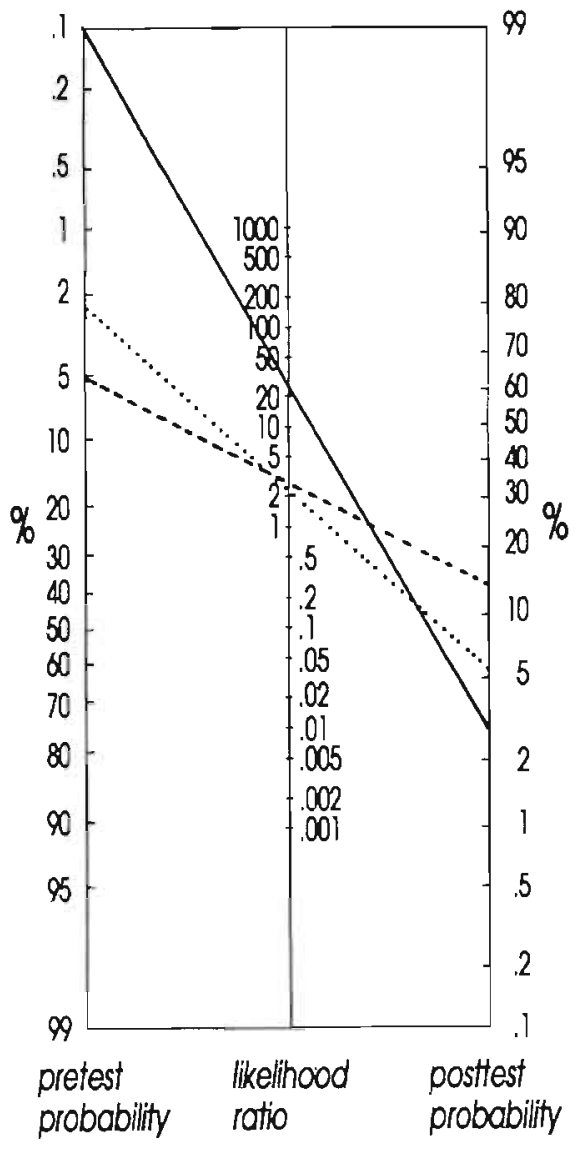

Figure 2. Posttest probability of Lyme borreliosis in the normal Dutch population when 3 diagnostic tools (erythema migrans, tick bite, positive Lyme serology) are used sequentially (assuming independence). LR erythema migrans*, 21.3; LR tick bite, 3.6; LR positive Lyme serology, 3.5. *Confirmative answer when shown pictures of erythema migrans. Presence of: (-) erythema migrans; (. . .) erythema migrans and tick bite; (- - ) erythema migrans, tick bite and positive Lyme serology. (Nomogram reprinted by permission of the New England Journal of Medicine 1975;293:257.) 


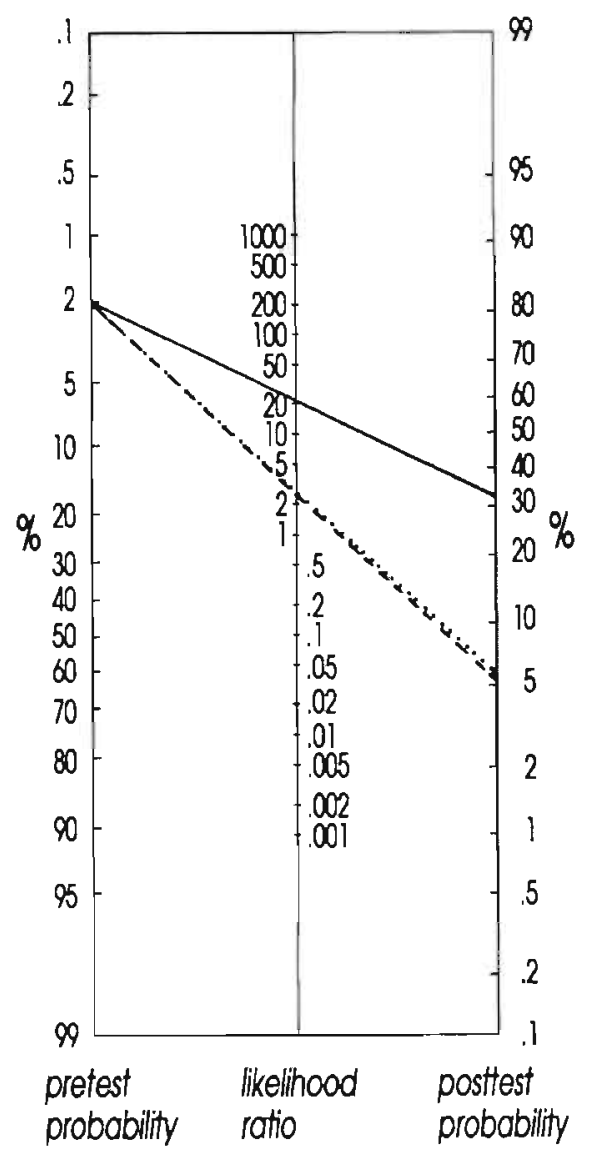

Figure 3. Posttest probability of Lyme borreliosis in a population with a pretest probability of nearly $2 \%$ (e.g. Dutch hunters) after application of different likelihood ratios. (- $\longrightarrow$ LR erythema migrans*, 21.3; (. .) LR tick bite, 3.6; (- - -) LR positive Lyme serology, 3.5. *Confirmative answer when shown pictures of erythema migrans. (Nomogram reprinted by permission of the New England Journal of Medicine 1975;293:257.)

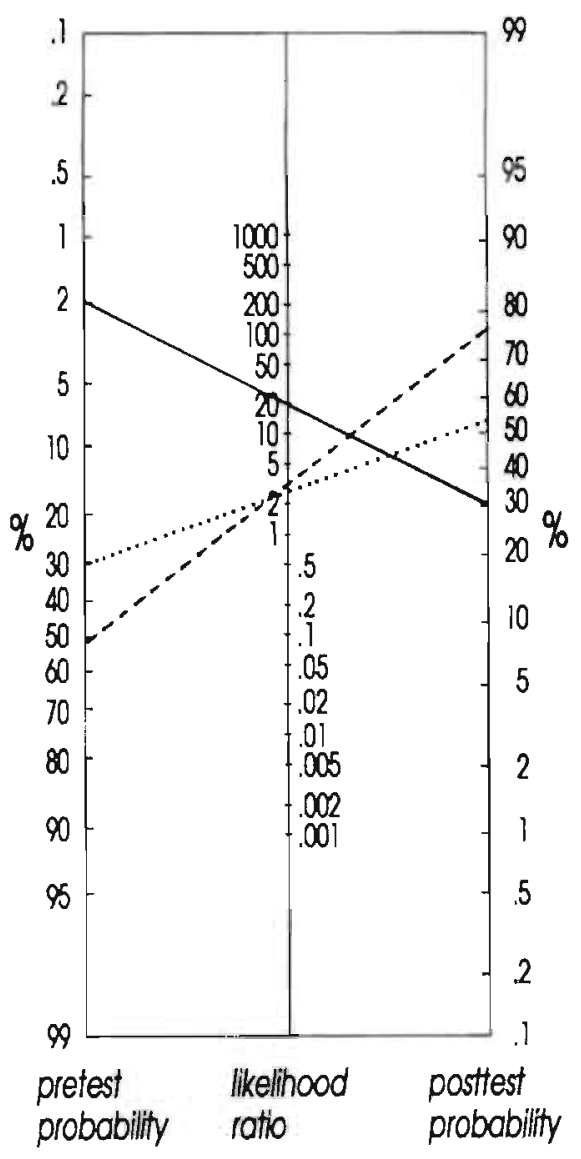

Figure 4. Posttest probability of Lyme borreliosis in a population with a pretest probability of nearly $2 \%$ (e.g. Dutch hunters) when diagnostic tools (erythema migrans, tick bite, positive Lyme serology) are used sequentially (assuming independence). LR erythema migrans*, 21.3; LR tick bite, 3.6; LR positive Lyme serology, 3.5. *Confirmative answer when shown pictures of erythema migrans. Presence of: (-) erythema migrans; (. . .) erythema migrans and tick bite; (- - ) erythema migrans, tick bite and positive Lyme serology. (Nomogram reprinted by permission of the New England Journal of Medicine 1975;293:257.) 
migrans, history of at tick bite and $\operatorname{IgG}$ antibodies to $B$. burgdorferi), the posttest probability is nearly $75 \%$ (assuming independence) (figure 4).

\section{DISCUSSION}

Our study confirms another study which concluded that hunting is associated with an increased risk of developing seropositivity for Lyme borreliosis (14). In control populations of healthy Dutch blood donors, we found only $9 \%$ seropositivity (9). We detected only 4 cases of definite and 4 cases of probable clinical Lyme borreliosis (total prevalence 1.9\%) among 431 Dutch hunters (14). Since seronegative hunters, who did not report complaints, were not retested after 6 months, we were not able to estimate the incidence of seropositivity and clinical Lyme borreliosis for Dutch people at risk (hunters). In a Swiss study the annual incidence for clinical Lyme borreliosis was estimated at $1.6 \%$ for a population at risk (orienteers) (5).

In the present study, $15.1 \%$ of the hunters showed positive antibodies to $B$. burgdorferi, but they did not report signs or symptoms attributable to Lyme borreliosis. Similar findings have been reported in a number of studies $(15,16,17)$. There is one study, however, which reports that 11 out of 12 farmers with antibodies had Lyme borreliosis (18). Generally, in the European countries, the risk of developing Lyme borreliosis given exposure would appear to be rather low.

It is not unusual that the clinical diagnosis of Lyme disease may be difficult to establish. Only approximately $50 \%$ of patients develop erythema migrans (1). Quite often Lyme borreliosis patients present fairly with late with manifestations in the nervous, cardiac, or musculoskeletal systems. For those patients who had erythema migrans in the past, it might be difficult to reliably elicit this sign from the patient's history. Based upon the results of the present study, we think it is worthwhile to show photographs of different stages of erythema migrans to patients, in whom a diagnosis of Lyme disease is considered. However, a few caveats regarding the use of pictures of erythema migrans as a diagnostic tool should be mentioned. Only pictures of erythema migrans were shown in our study. No other pictures of red annular skin lesions were included in the series. This may imply that erythema migrans may tend to be overdiagnosed, limiting the predictive value of this test. We used confirmation of erythema migrans by a physician (and not serologic results) as the "gold standard" for a definite diagnosis of Lyme borreliosis. A specific antibody response to B. burgdorferi may be suppressed early in Lyme disease and antibiotic treatment may abort specific antibody responses (19). Since the majority of the participants, who reported to have had erythema migrans in the past, did not have physician-confirmed erythema migrans, were not treated with antibiotics, and did not have 
antibodies to $B$. burgdorferi, recognition of erythema migrans from photographs almost certainly results in an overestimation of the true prevalence of this skin lesion. Nonetheless, we think that showing typical pictures of erythema migrans can be a useful tool in epidemiological studies. This applies to the clinical setting too, if one is aware of this bias, i.e. the tendency to overreport.

Another important issue is the setting in which a diagnostic test is performed: the strong influence of the prevalence (pretest probability) on the usefulness of a test. In a population, such as the Dutch population, with a low prevalence of Lyme borreliosis and a high prevalence of positive Lyme serology, diagnostic testing is of limited value as is easily shown when likelihood ratios are applied in the nomogram. These figures clearly show that the pretest probability has an overriding influence on the discriminative power of a test. The posttest probability for a person with a high degree of exposure (hunter) is much higher than for a person from the general population (figures 1-4). Only when the presence of three variables (erythema migrans, tick bite, positive Lyme serology) is applied sequentially, a considerable posttest probability can be reached. Theoretically, as several diagnostic tests are combined sequentially, there is a risk of creating a distorted posttest probability at the end of the sequence (10). The posttest probability will be overestimated, because the combined tests are not independent. This is, however, not often a major problem with relatively short series of 2 or 3 diagnostic tests (10).

The application of likelihood ratios clearly illustrates, that a clinical history of erythema migrans has more impact on the diagnosis of Lyme borreliosis than simply testing for antibodies to $B$. burgdorferi. This strengthens the view that the diagnosis of Lyme borreliosis should be based on clinical symptoms (20). The presence of antibodies to $B$. burgdorferi is enough to reinforce the clinical diagnosis. Lyme serology should not be used in any form of screening for Lyme disease.

In summary, only $1.9 \%$ of the studied population at risk had past symptoms of definite or probable Lyme borreliosis and $15.1 \%$ had antibodies to $B$. burgdorferi without any clinical symptoms. In Lyme borreliosis, as in many other diseases, the clinical history is a very powerful (and cost-effective) diagnostic tool. It is important to have a reliable estimate of the pretest probability of Lyme borreliosis, in the setting in which these diagnostic tests are done.

\section{Acknowledgements}

We thank all the participating members of the Koninklijke Nederlandse Jagers Vereniging for their enthusiastic cooperation. 


\section{REFERENCES}

1 Steere AC. Lyme disease. N Engl J Med 1989;321:586-596.

2 Hedberg CW, Osterholm MT. Serologic tests for antibady to B. burgdorferi. Another Pandora's box for medicine? Arch Intern Med 1990; 150:732-733. Editorial.

3 Schwartz BS, Goldstein MD, Ribeiro JM, Schulz TL, Shaheid SI. Antibody testing in Lyme disease. A comparison of results in four laboratories. JAMA 1989;262:34313434.

4 Luger SW, Krauss E. Serologic tests for Lyme disease. Interlaboratory variability. Arch Intern Med 1990;150:761-763.

5 Fahrer HF, van der Linden SM, Sauvain MJ, Gem L, Zhioua E, Aeschlimann A. The prevalence and incidence of clinical and asymptomatic Lyme borreliosis in a population at risk. J Infect Dis 1991;163:305-310.

6 Nohlmans L, de Boer R, van den Bogaard AEJM, Blaauw AAM, van Boven CPA. Prevalentie van B. burgdorferi in Ixodes Ricinus in Nederland. Ned Tijdschr Geneeskd 1990;34:1300-1303.

7 Craft JE, Grodzicki RL, Steere AC. Antibody response in Lyme disease: evaluation of diagnostic tests. J Infect Dis 1984; 149:789-795.

8 Barbour AG. Isolation and cultivation of Lyme disease spirochetes. Yale J Biol Med 1984;57:521-525.

9 Nohlmans MKE, Bogaard van den AEJM, Blaauw AAM, Boven van CPA. Prevalentie van Lyme borreliosis in Nederland. Ned Tijdschr Geneeskd 1991;135:2288-2292.

10 Sackett DL, Haynes RB, Tugwell P: The interpretation of diagnostic data. In: Sackett D, Haynes RB, Tugwell P. Clinical epidemiology, a basic science for clinical medicine. Little, Brown and Company 1985:59-138.

11 Blaauw AAM, Nohlmans MKE, Leffers P, Goei The HS, van der Linden Sj. Lyme borreliosis: a very infrequent cause of arthritis of undetermined etiology in the southern part of the Netherlands. Br J Rheum 1992;31:401-404.

12 Blaauw AAM, Nohlmans MKE, Peeters A, Dijkmans BAC, van der Linden Sj. Is there any evidence for an association between ankylosing spondylitis and $B$. burgdorferi infection? J Rheum 1992;19:579-581.

13 Fagan TJ. Nomogram for Bayes'theorem. N Engl J Med 1975;293:257.

14 Schwartz BS, Goldstein MD. Lyme disease in outdoor workers: risk factors, preventive measures, and tick removal methods. Am J Epidemiol 1990;131:877-885.

15 Kuiper H, de Jongh BM, Nauta AP, Houweling H, Wiessing LG, Moll van Charante AW, Spanjaard L. Lyme borreliosis in Dutch forestry workers. J Infect 1991;23:279286.

16 Guy EC, Bateman DE, Martyn CN, Heckels JE, Lawton NF. Lyme disease:prevalence and clinical importance of $B$. burgdorferi specific IgG in forestry workers. Lancet 1989;i:484-486.

17 Neubert U, Münchhof P, Völker B, Reimers CD, Pflüger KH. B. burgdorferi infection in Bavarian forest workers. Ann NY Acad Sci 1988;539:476-479.

18 Baird AG, Gillies JCM, Bone FJ, Dale BAS, Miscampbell NT. Prevalence of antibody indicating Lyme disease in farmers in Wigtownshire. Br Med J 1989;229:836-837. 
19 Stiemstedt G, Eriksson G, Enfors W, et al. Erythema Chronicum Migrans in Sweden: Clinical manifestations and antibodies to lxodes ricinus spirochete measured by indirect immunofluorescence and enzyme linked immunosorbent assay. Scand J Infect Dis 1986; 18:217-224.

20 Rahn DW, Malawista ED. Lyme disease: recommendations for diagnosis and treatment. Ann Intern Med 1991;114:472-481. 


\section{Rational diagnosis and treatment in unclassified arthritis: \\ how clinical data may guide requests for Lyme serology and antibiotic treatment.}

AAM Blaauw, BAC Dijkmans*, PAD Bouma**, $S$ van der Linden

Department of Internal Medicine, Division of Rheumatology, University Hospital Maastricht, Maastricht; Department of Rheumatology*, University Hospital Leiden, Leiden; Department of Neurology**, University Hospital Leiden, Leiden, The Netherlands.

Annals of the Rheumatic Diseases, in press 


\title{
Rational diagnosis and treatment in unclassified arthritis:
}

\section{how clinical data may guide requests for Lyme serology and antibiotic treatment.}

\begin{abstract}
In order to improve the appropriateness and efficiency of diagnostic serologic tests and subsequent antibiotic treatment, clinical data of 102 patients with unclassified arthritis were analysed, to investigate whether the presence of positive IgG antibodies to Borrelia burgdorferi could be predicted.

The clinical data were blindly ranked from 1 to 4 (1, Lyme arthritis unlikely; 4, Lyme arthritis very likely). Antibodies to $B$ burgdorferi were positive in 9 of 102 patients $(9 \%)$. Six of $15(40 \%)$ patients with rank numbers 3 and 4 were positive for antibodies to $B$ burgdorferi, in contrast with only three of $87(3 \%)$ patients with rank numbers 1 and 2 .

The likelihood ratio of positive Lyme serology for patients ranked 3 and 4 was 12.0, for patients ranked 2 to $4,4.5$, and for patients with arthritis of the knee, 3.0. These likelihood ratios were associated with a post-test probability of $55 \%$, $30 \%$, and $20 \%$ respectively.

The clinical history in patients with unclassified arthritis can largely predict the presence of antibodies to $B$ burgdorferi. The absolute value of a likelihood ratio can be a contributing factor in deciding to request antibodies to $B$ burgdorferi in patients with unclassified arthritis.
\end{abstract}

\section{INTRODUCTION}

In Lyme borreliosis, a disorder caused by the tick borne spirochete Borrelia burgdorferi, the musculoskeletal system is often affected (1). Common symptoms of this disease are migratory pain in joints, tendons and bursae, brief arthritis attacks, and in later stages prolonged arthritis attacks, chronic arthritis and peripheral enthesopathy (2). The musculoskeletal symptoms may occur without preceding erythema migrans, cardiac or neurologic symptoms (1). 
Lyme arthritis, though not a common cause of arthritis (at least not in the Netherlands), should be considered in the differential diagnosis because antibiotic therapy is usually effective (3-5). Owing to a large number of false positive results, and other reasons including economic aspects, however, it seems inappropriate to test for antibodies to $B$ burgdorfer $i$ in all patients with unclassified arthritis (6). It is important to know in which subset of patients with arthritis the test should preferably be ordered to obtain clinically meaningful results.

The presence of characteristic signs or symptoms of Lyme borreliosis in the clinical history and physical examination of patients with arthritis should guide rheumatologists in the decision to request antibodies to $B$ burgdorferi.

The purpose of the present study was to investigate how we could estimate the presence of antibodies to $B$ burgdorferi from clinical data in patients with arthritis, and how this influences the decision to prescribe antibiotic treatment.

\section{PATIENTS AND METHODS}

Antibodies to $B$ burgdorferi were determined in all patients with arthritis from the outpatient department of rheumatology of the University Hospital of Leiden - that is, those patients in whom a firm rheumatic diagnosis could not be made on their first visit or after several visits. Specifically, these patients did not fulfill criteria for rheumatoid arthritis, osteoarthritis, gout, systemic lupus erythematodes, chondrocalcinosis, reactive arthritis or seronegative spondylarthropathy. Based only on the clinical history and physical examination of the individual patient, all patients were given a rank number from 1 to 4 , where 1 is considered unlikely and 4 very likely to be Lyme arthritis. The criteria for these rank numbers were set for this particular study (table 1). These criteria were based on published work about the natural history and our own experience of patients with Lyme arthritis $(2,5,7,8)$. The surveillance case definition for Lyme disease as developed by the Centers for Disease Control in the United States, was also incorporated (9). Patients were given a rank number without knowledge of the serological results. We expected positive serologic results mainly in patients ranked 2 to 4 . Seronegativity was not expected among patients with arthritis due to Lyme borreliosis, which is a late stage of Lyme disease $(1,2,7)$.

\section{Serology}

IgG antibodies to $B$ burgdorferi were determined by an enzyme linked immunosorbent assay (ELISA) as described elsewhere by the National Institute of Public Health and Environmental Protection (Bilthoven, the Netherlands) $(10,11)$. The ELISA values are expressed as optical density ratios. An optical 
Table 1. Criteria for ranking patients with arthritis (arthritis with or without a history of an erythematous skin lesion, tick bite, neurological, or cardiac disorders) at their probability of Lyme borreliosis. Ranking based on the clinical history and physical examination of the individual patient

\begin{tabular}{|c|c|c|}
\hline Rank & Definition & Condition \\
\hline 4 & $\begin{array}{l}\text { Very likely to be } \\
\text { Lyme arthritis }\end{array}$ & $\begin{array}{l}\text { Erythematous skin lesion or ACA* and } \\
\text { tick bite; } \\
\text { erythematous skin lesion or ACA and neurological disorders } \\
\text { erythematous skin lesion or ACA and cardiac disorders } \\
\text { tick bite and neurological disorders; } \\
\text { tick bite and cardiac disorders; } \\
\text { neurological and cardiac disorders. }\end{array}$ \\
\hline 3 & $\begin{array}{l}\text { Likely to be } \\
\text { Lyme arthritis }\end{array}$ & $\begin{array}{l}\text { Erythematous skin lesion; } \\
\text { tick bite; } \\
\text { neurological disorders; } \\
\text { cardiac disorders; } \\
\text { ACA; } \\
\text { or recurrent arthritis of the knee. }\end{array}$ \\
\hline 2 & $\begin{array}{l}\text { May be } \\
\text { Lyme arthritis }\end{array}$ & Arthritis of the knee. \\
\hline 1 & $\begin{array}{l}\text { Unlikely to be } \\
\text { Lyme arthritis }\end{array}$ & $\begin{array}{l}\text { Mono or oligo arthritis of other joints; } \\
\text { polyarthritis }\end{array}$ \\
\hline
\end{tabular}

* ACA = Acrodermatitis Chronica Atrophicans; ++ For example, facial palsy, Bannwarth's syndrome; +++ For example, atrioventricular conduction defects.

density ratio of two is three standard deviations above the mean of 35 serum samples from blood donors. An optical density ratio equal to or greater than two is considered positive. If a positive test result was obtained the Treponema pallidum haemagglutination assay was performed to exclude false positivity due to antibodies to $T$ pallidum. Serum samples from this institute were also tested at the laboratory of the department of microbiology of the University of Limburg at Maastricht, the Netherlands (Dr MKE Nohlmans) in accordance with a Dutch Lyme study group. There was good agreement between laboratories ( $r=0.94$; $\mathrm{p}<0.001$ ) (unpublished results). In the absence of a reference or "gold" standard, an exchange of serum samples between the department of microbiology at Maastricht and the department of zoology, University of Neuchâtel, Switzerland (Dr L Gern), resulted in good agreement between the two laboratories $(r=0.68$; $\mathrm{p}=0.001)(12)$. 


\section{Diagnostic tools}

Sensitivity, specificity, positive predictive values and likelihood ratios (percentage true positive : percentage false positive) were calculated for patients in ranks 3 and 4, ranks 2 to 4 , and for all patients who presented with arthritis of the knee (13).

\section{Statistical analysis}

For categorical data the $\mathrm{X}^{2}$ test was used to test for significant differences between proportions. A value of $p \leq 0.05$ was considered statistically significant.

\section{RESULTS}

From January 1989 to April 1991 IgG antibodies to B burgdorferi were determined in 102 patients with unclassified arthritis. The mean age of these patients was 42.8 years (ranging from 14 to 75 years). The male to female ratio was 1.1: 1.0 .

Table 2 gives rank numbers and the proportion of patients positive for antibodies to $B$ burgdorferi. Nine patients were positive for antibodies to $B$ burgdorferi $(9 \%)$. Table 3 gives the clinical symptoms of the 15 patients with rank numbers 3 and 4 . Six of these 15 patients $(40 \%)$, were positive for antibodies to $B$ burgdorferi. Eight of these 15 patients had recurrent arthritis of the knee, whereas two were positive for antibodies to $B$ burgdorferi $(25 \%)$ (table 3 ). Of the 30 patients with non-recurrent arthritis of the knee and ranked 2, only

Table 2. Rank numbers of 102 patients and the proportion of patients positive for antibodies to Borrelia burgdorferi within each category

No (\%) of patients with positive IgG serology

$\begin{array}{lll}\text { Rank 4 } & (\mathrm{n}=2) & 2(100) \\ \text { Rank 3 } & (\mathrm{n}=13) & 4(31) \\ \text { Rank 2 } & (\mathrm{n}=30) & 1(3) \\ \text { Rank 1 } & (\mathrm{n}=57) & 2(4) \\ \text { Total } & 102 & 9(9)\end{array}$


Table 3. Clinical symptoms and antibodies to Borrelia burgdorferi of patients ranked 3 and 4.

\begin{tabular}{|c|c|c|c|}
\hline Patient & Clinical symptoms & Rank & Antibodies \\
\hline \multirow[t]{5}{*}{1} & 1986 tick bite & & \\
\hline & 1988 severe stiff neck & & \\
\hline & 1989 severe stiff neck & & \\
\hline & 1986-1990 arthralgia & & \\
\hline & 1990 frank arthritis of the knee and ankle & 4 & Positive \\
\hline \multirow[t]{2}{*}{2} & 1989 tick bite with erythematous skin lesion & & \\
\hline & 1990 anthritis of the knee & 4 & Positive \\
\hline 3 & 1990 facial palsy and polyarthritis & 3 & Negative \\
\hline 4 & 1989 bite, pericarditis and recurrent arthritis & 3 & Negative \\
\hline \multirow[t]{3}{*}{5} & 1985 erythema migrans (confirmed by doctor) & & \\
\hline & 1986 arthritis of the knee & & \\
\hline & 1990 arthritis of the knee & 3 & Negative \\
\hline \multirow[t]{2}{*}{6} & 1988 facial palsy and arthritis of the ankle & & \\
\hline & 1990 arthritis of the ankle & 3 & Negative \\
\hline 7 & 1991 polyarthritis and acrodermatitis chronica atrophicans & 3 & Positive \\
\hline 8 & 1990 tick bite and arthritis of the knee & 3 & Positive \\
\hline \multirow[t]{2}{*}{9} & 1987 tick bite & & \\
\hline & 1989 recurrent arthritis of the knee & 3 & Positive \\
\hline 10 & 1987-89 recurrent arthritis of the knee & 3 & Negative \\
\hline 11 & $1987-90$ recurrent arthritis of the knee & 3 & Negative \\
\hline 12 & $1988-89$ recurrent arthritis of the knee & 3 . & Positive \\
\hline 13 & $1987-90$ recurrent arthritis of the knee & 3 & Negative \\
\hline 14 & 1989 recurrent arthritis of the knee & 3 & Negative \\
\hline 15 & $1986-89$ recurrent arthritis of the knee & 3 & Negative \\
\hline
\end{tabular}

one (3\%) was positive for antibodies to $B$ burgdorferi. The two patients ranked $1(4 \%)$, who were positive for antibodies to $B$ burgdorferi had symmetrical polyarthritis and arthritis of the metatarsal joints of one foot.

Patients with rank numbers 3 and 4 were positive for antibodies to $B$ burgdorferi significantly more often than patients with rank numbers 1 and 2 $(p<0.001)$. Patients with recurrent arthritis of the knee were positive for antibodies to $B$ burgdorferi significantly more often than patients who had their first attack of arthritis of the knee $(\mathrm{p}<0.05)$.

The sensitivity was moderate for patients ranked 3 and $4(40 \%)$ (table 4$)$. The positive predictive value was $66 \%$. 
Table 4. Sensitivities, specificities, positive predictive values, and likelihood ratios of clinical evidence as a diagnostic test for Lyme arthritis at different levels of clinical suspicion of disease. Positive Lyme serology among 102 patients with unclassified arthritis is taken as the gold standard for the disease

$\begin{array}{lll}\text { Positive Sensitivity } & \text { Specificity } & \text { Positive Likelihood } \\ \text { serology }(\%) & (\%) & \text { Predictive ratio } \\ & & \text { Value }\end{array}$

$(\%)$

\begin{tabular}{lllllr} 
Ranks 3 and $4(n=15)$ & 6 & 40 & 96 & 66 & 12.0 \\
Rank 2,3, and $4(n=45)$ & 7 & 15 & 96 & 77 & 4.5 \\
Arthritis of the knee $(n=41)$ & 6 & 14 & 95 & 66 & 3.0 \\
\hline
\end{tabular}

The likelihood ratios calculated for each cutoff level were applied in a nomogram adapted from Fagan (14). The pretest probability for positive Lyme serology in this group (patients with unclassified arthritis) was 9\% (table 2). If Lyme serology was requested for patients with rank number 3 or 4 , the posttest probability to have Lyme borreliosis increased to nearly 55\%. If patients with arthritis of the knee (rank 2) are added to this group, the posttest probability decreased to $30 \%$ (figure 1 ).

Knees are the most affected joints in Lyme borreliosis $(2,5,7)$. Therefore we placed all the patients with a first attack of arthritis of the knee and with recurrent arthritis of the knee in one group (41 patients from rank 2 to 4). After this we calculated the sensitivity (14\%), the specificity $(95 \%)$, the positive predictive value $(66 \%)$ and the likelihood ratio (3.0) (table 4). This likelihood ratio was associated with a posttest probability of Lyme borreliosis of $20 \%$ (figure 1 ).

As only nine of the 102 patients with unclassified arthritis had positive Lyme serology, the serologic test can be regarded as unnecessary in 93 patients $(91 \%)$. If antibodies to $B$ burgdorfer $i$ had been determined in the 15 patients with rank numbers 3 and 4 only, the test would have been unnecessarily ordered in only nine patients. This implies that the number of requested tests for antibodies to $B$ burgdorferi would be decreased from 102 to 15 -that is, a decrease of $86 \%$. This would have been at the expense of the three patients with rank numbers 1 and 2 , who were also positive for antibodies to $B$ burgdorferi (table 2). These three patients are clinically believed to have a low probability of Lyme arthritis.

Antibodies to $B$ burgdorferi were determined in 41 patients with arthritis of the knee: six were positive for these antibodies. Therefore the test was unnecessarily ordered in 35 patients ( $85 \%$ ). Five of six patients with arthritis of the knee and positive antibodies to $B$ burgdorfer $i$ were placed in ranks 3 and 4 . If requests 


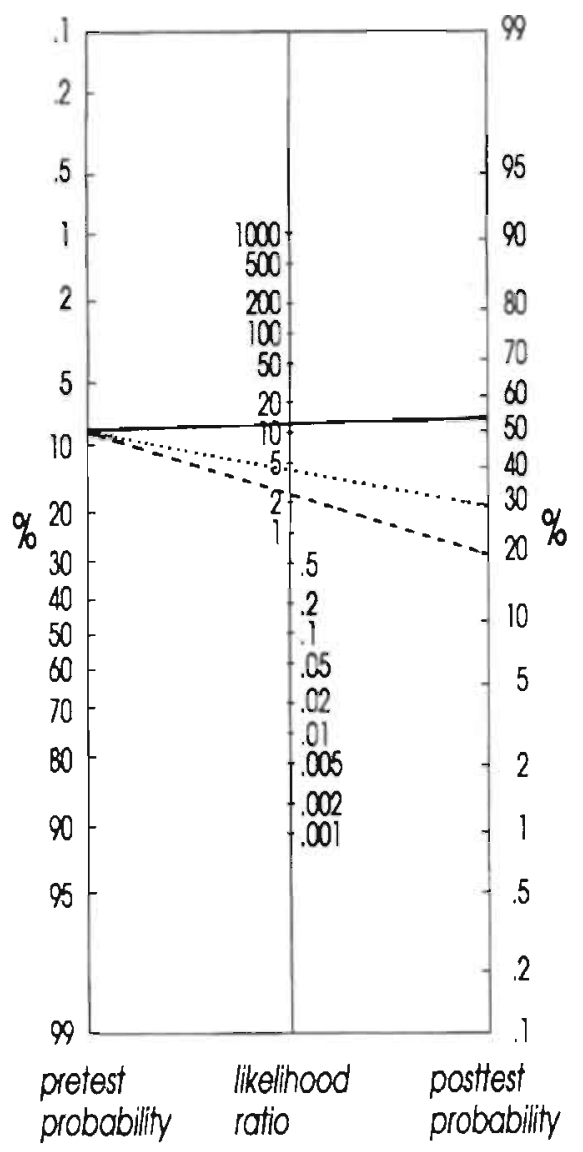

Figure 1: Posttest probability of Lyme arthritis at different cutoff levels in patients with unclassified arthritis after application of likelihood ratios (pretest probability 9\%). Likelihood ratio Ranks 3 and 4, 12.0 (—); Likelihood ratio Ranks 2-4, 4.5 (. . ); Likelihood ratio for arthritis of the knee, (3.0) (- - ). (Reprinted, by permission of the New England Journal of Medicine 1975;293:257.)

for antibodies to $B$ burgdorferi had been made for patients with arthritis of the knee with rank numbers 3 and 4 , requests could have been decreased from 41 to five tests $(88 \%)$ at the expense of one patient with rank number 2 . 


\section{DISCUSSION}

This study indicates that signs and symptoms of the clinical history of a patient with arthritis are important tools to predict the chances of a positive test for antibodies to $B$ burgdorferi. Patients who clinically were expected to have a high probability of positive antibodies to $B$ burgdorferi had a posttest probability of Lyme borreliosis of 55\% (based on serologic test results). It is often difficult to decide at what posttest probability the diagnostic process should be stopped and treatment should be started, and at which level a working diagnosis can be rejected (13). In the clinical situation there is currently, no other widely available test to increase the posttest probability of Lyme borreliosis. Culturing of the Lyme spirochetes, especially from synovial fluid, is difficult and time consuming $(1,15)$. The clinical value of Western blotting, cell mediated immunity testing, urine antigen testing, and the polymerase chain reaction still have to be determined. In the meantime, it is up to the clinician to decide whether a posttest probability of a disease of, say, $50 \%$, is sufficiently supportive to start treatment in a patient with arthritis. If the clinical history in a patient with arthritis is likely to be Lyme borreliosis (in our study patients with rank numbers 3 and 4), the chances of having Lyme borreliosis are about $55 \%$. This degree of suspicion is probably high enough to justify starting antibiotic treatment in a patient with arthritis, especially because first choice treatment with doxycycline by mouth is rather simple and usually has only minor side effects (4).

Determination of antibodies to $B$ burgdorferi, in patients with unclassified arthritis, can only be considered useful when it has direct therapeutic consequences-that is, subsequent antibiotic treatment. Four different strategies will now be discussed: (a) all patients with unclassified arthritis are to receive antibiotic treatment, serologic tests are not needed; (b) only patients with a high suspicion of Lyme borreliosis (rank numbers 3 and 4) are to receive antibiotic treatment, serologic tests are not needed; (c) antibodies to $B$ burgdorferi are requested for all patients with unclassified arthritis and, subsequently, the patients positive for antibodies to $B$ burgdorfer $i$ are treated with antibiotics; and (d) antibodies to $B$ burgdorferi are requested only for patients with rank numbers 3 and 4 and, subsequently, the patients positive for antibodies to $B$ burgdorfer $i$ are treated with antibiotics. These four strategies have immediate consequences for the appropriateness of treatment with antibiotics and for the request of tests for antibodies to $B$ burgdorferi, as is shown in table 5. Strategy (a) leads to the unnecessary antibiotic treatment of 93 patients (91\%). Strategy (b) decreases antibiotic treatment to 15 patients, but leads to unnecessary treatment in nine patients, and three patients from rank 1 and 2 are not diagnosed as having Lyme arthritis and do not receive treatment with antibiotics. In strategy (c), 93 tests for antibodies to $B$ burgdorferi are requested unnecessarily. None of the patients receive unnecessary antibiotic treatment. Strategy (d) leads to a decrease of 
Table 5. Sensitivities, specificities, predictive values, number of tests performed, and the appropriateness of antibiotic treatment for four strategies in 102 patients with unclassified arthritis. Positive Lyme serology among 102 patients with unclassified arthritis is taken as the gold standard for the disease

\begin{tabular}{|c|c|c|c|c|c|c|c|}
\hline & \multirow{2}{*}{$\begin{array}{l}\text { Sensitivity } \\
(\%)\end{array}$} & \multirow{2}{*}{$\begin{array}{l}\text { Specificity } \\
(\%)\end{array}$} & \multirow{2}{*}{$\begin{array}{l}\text { Positive } \\
\text { Predictive } \\
\text { Value (\%) }\end{array}$} & \multicolumn{2}{|c|}{ Tests performed } & \multicolumn{2}{|c|}{$\begin{array}{l}\text { Antibiotic } \\
\text { Treatment } \\
\text { justified }\end{array}$} \\
\hline & & & & Positive & $\overline{\text { Negative }}$ & Yes & No \\
\hline Strategy (a)* & 100 & 0 & 9 & - & - & 9 & 93 \\
\hline Strategy (b) & 67 & 90 & 40 & - & - & 6 & $9 * *$ \\
\hline Strategy (c) & 100 & 100 & 100 & 9 & 93 & 9 & 0 \\
\hline Strategy (d) & 67 & 90 & 40 & 6 & 9 & 6 & $0 * *$ \\
\hline
\end{tabular}

* See text for definition of each strategy; ${ }^{* *}$ At the expense of three patients in rank 1 and 2.

serologic tests from 93 to 15 . None of the patients will be treated wrongly; however, three patients will be missed and will not receive treatment with antibiotics. Comparing strategy (a) and (c), testing of 102 patients could have avoided unnecessary treatment for 93 patients. Reduction of the tests performed in strategy (d) avoids unnecessary treatment completely, but at the expense of the three patients with rank numbers 1 and 2 .

Several issues must be addressed with regard to our findings. There is no real "gold standard" for Lyme borreliosis. Lyme borreliosis is primarily defined by clinical evidence and serological results may only support this evidence $(6,9)$. It is necessary to evaluate the clinical signs and symptoms of patients who are suspected to have Lyme disease carefully. Clinical evidence should outweigh serological results. Therefore, it would be realized that the three patients positive for antibodies to $B$ burgdorferi who are clinically considered to have a low probability of Lyme arthritis (rank numbers 1 and 2), may in fact be asymptomatic. This would be the case if they have been infected by borrelia strains at some time in the past giving rise to the development of specific antibodies and if their arthritis was not due to Lyme borreliosis but to another (as yet unknown) cause. Asymptomatic infection with $B$ burgdorferi (positive antibodies but no clinical disease) has been found in $3 \%-20 \%$ of healthy subjects $(6,16)$. The prevalence of asymptomatic infection correlates roughly with the degree of exposure $(6,12)$. Secondly, if likelihood ratios are to be applied in clinical practice, the doctor must have a reasonable estimate of the probability for Lyme borreliosis in the patient. This implies that prevalence data should be available. Prevalence data of Lyme arthritis in patients with unclassified arthritis are 
available for two different parts of the Netherlands (3). These prevalence data can probably be extrapolated to other parts of the Netherlands. We feel that the calculated likelihood ratios can be transported to patients with unclassified arthritis in a setting comparable with ours. Thirdly, our intention was to point out that clinical findings should guide the decision to select a serologic test. If the doctor is convinced that a patient with arthritis has Lyme arthritis, the patient should be treated appropriately, independent of the serologic test result. Unfortunately, the clinical history and symptoms are not always clear and the doctor may feel that he or she needs more support for the diagnosis. We have tried to elucidate for which patients the serologic Lyme test should be selected to improve the appropriateness and efficiency.

In conclusion, in patients with unclassified arthritis clinical data are high associated with the likelihood of a positive test for antibodies to $B$ burgdorferi. Knowledge of the pretest probability of disease, extracting key elements from the patient's clinical history and the physical examination, and application of likelihood ratios, can guide the decision to request tests for antibodies to $B$ burgdorferi for these patients. Such data may promote a rational and appropriate diagnosis and treatment. 


\section{REFERENCES}

Steere AC. Lyme disease. N Engl J Med 1989;321:586-96.

2 Steere AC, Schoen RT, Taylor E. The clinical evolution of Lyme Arthritis. Ann Intern Med 1987; 107:725-31.

3 Blaauw AAM, Nohlmans MKE, Leffers P, Goei The H, van der Linden Sj. Lyme borreliosis: a very infrequent cause of arthritis of undetermined etiology in the southem part of the Netherlands. Br J Rheumatol 1992;31:401-04.

4 Liu NY, Dinerman H, Levin RE, et al. Randomized trial of doxycycline versus amoxicillin/probenecid for the treatment of Lyme arthritis: treatment of non-responders with iv penicillin or ceftriaxon. (Abstract). Arthritis Rheum 1989;32(Suppl):S32.

Blaauw AAM, Nohlmans MKE, van den Berg Loonen E, Rasker JJ, van der Linden Sj. Lyme arthritis in the Netherlands: a nationwide survey among rheumatologists. J Rheumatol 1991;18:1819-22.

6 Blaauw AAM, Nohlmans MKE, van den Bogaard AEJM, van der Linden Sj. Diagnostic tools in Lyme borreliosis: clinical history compared with serology. J Clin Epidemiol 1992; 11:1229-36.

7 Szer IS, Taylor E, Steere AC. The longtenn course of Lyme arthritis in children. N Engl J Med 1991;325:159-63.

8 Herzer P. Lyme-Borreliose. Epidemiologie, Ätiologie, Diagnostik, Klinik und Therapie. Steinkopff Verlag Darmstadt 1990:68-79.

9 Rahn DW, Malawista SE. Lyme disease: Recommendations for Diagnosis and Treatment. Ann Intern Med 1991;114:472-81.

10 Craft JE, Grodzicki RL, Stcere AC. The antibody response in Lyme disease Spirochetes. J Infect Dis 1984;149:789-95.

11 Barbour AG. Isolation and cultivation of Lyme disease spirochetes. Yale J Biol Med 1984;57:521-5.

12 Fahrer H, Linden van der SM, Sauvain MJ, Gem L, Zhioua E, Aeschlimann A. The prevalence and incidence of clinical and asymptomatic Lyme borreliosis in a population at risk. J Infect Dis 1991;163;305-310.

13 Sackett DL, Haynes RB, Tugwell P. The interpretation of diagnostic data. In: Sackett DL, Haynes RB, Tugwell P. Clinical epidemiology, a basic science for clinical medicine. Boston: Little, Brown and Company 1991:69-152.

14 Fagan TJ. Nomogram for Bayes'theorem. N Engl J Med 1975;293:257.

15 Snydman DR, Schenkein DP, Berardi VP, Lastavica CC, Pariser KM. B burgdorferi in joint fluid in chronic Lyme Arthritis. Ann Intern Med 1986;104:798-800.

16 Nohlmans MKE, Bogaard van den AEJM, Blaauw AAM, Boven van CPA. Prevalentie van Lyme borreliosis in Nederland. Ned Tijdschr Geneeskd 1991;135:2288-92. 


\title{
Lyme disease.
}

\author{
AAM Blaauw
}

In: RD Wigley, editor. The primary prevention of rheumatic diseases. Parthenon Publishing, United Kingdom, in press. 


\section{Lyme disease.}

Lyme borreliosis, which is caused by the tick-borne spirochete Borrelia burgdorferi (B. burgdorferi), often begins with a characteristic skin rash, erythema migrans, and may be followed by neurologic, cardiac, or joint abnormalities of variable duration (1).

Erythema migrans is reported in $50-60 \%$ of the patients. In $15-20 \%$ of patients in the United States, this is followed within several weeks to months by frank neurologic involvement, which may be accompanied by radicular pain, pleocytosis in the cerebrospinal fluid and meningitis with superimposed cranial nerve involvement or peripheral neuropathy (2). Cardiac involvement occurs in up to $8 \%$ of patients, most commonly in the form of fluctuating atrioventricular block. From 2 weeks to 2 years (usually six months) after the onset of the disease, often after intermittent episodes of arthralgia or migratory musculo-skeletal pain, nearly $80 \%$ of patients begin to have brief attacks of asymmetric, oligoarticular arthritis, primarily in the large joints, especially of the knee (3).

Chronic arthritis, defined as a year or more of continual joint inflammation, begins during the second or third year after the onset of the disease. In severe cases, chronic Lyme arthritis may lead to the erosion of cartilage and bone and, sometimes, though rarely, to permanent joint disability (3).

The pattern of joint involvement is similar in the United States and Europe, but has been described less commonly in the European literature, probably due to a lack of awareness in there $(4,6)$. Acrodermatitis chronica atrophicans is a late skin disorder of the disease which has been described primarily in Europe (5).

\section{PATHOGENESIS}

The Lyme disease spirochete is transmitted by Ixodes ticks that are part of the Ixodes ricinus complex. They include $I$. dammini in the northeastern and midwestern United States, I. pacificus in the western United States, I. ricinus in Europe and $I$. persulcatus in Asia. Ixodid ticks are also indigenous to Africa and South America, but it is not clear whether Lyme borreliosis occurs on those continents. 
Carrier rates in the ticks may vary. For I. dammini ticks in the United States infection rates vary from 10 to $35 \%$ and even to $50 \%$ on Shelter Island, New York (7). Only 1 to $3 \%$ of 1 . pacificus ticks are infected (8). The range of infection rates of $I$. ricinus in Europe varies from 2.2 to $40 \%(9,10)$. The infection rate of adult ticks exceeds that of nymphal and larval ticks. Infection rates of $I$. persulcatus are not exactly known, but $B$. burgdorferi has been isolated from these ticks in China and Russia $(11,12)$. Larvae and nymphs of $I$. dammini feed on at least 31 different species of mammals and 49 species of birds (13). White-footed mice, Peromyscus leucopus, are a particularly important host, but other animals such as short tailed shrews (Blarina brevicauda), raccoons (Procyon lotor), gray squirrels (Sciurus carolinensis), and white tailed deer (Odocoileus virginianus) may also be parasitized by many juvenile ticks. Birds are a natural vehicle for dispersing ticks into new areas (14). Adult ticks are more restricted, and are known to feed on 13 species of mammals; they do not feed on mice or birds. Deer are essential for the maintenance of dense tick populations. All postembryonic stages also feed on humans.

The infection is usually acquired when nymphal ticks feed between May and July, but only a minority of the patients remember the bite, probably because of the small size of the ticks. Adult ticks transmit the disease when they feed in the autumn. The disease affects people of all ages and both sexes.

In 1982, Burgdorfer and Barbour isolated a previously unrecognized spirochete, now called $B$. burgdorferi, from $I$. dammini ticks (15). The spirochete was subsequently recovered from patients with Lyme borreliosis $(5,7,16,17)$. The Borrelia species are fastidious, micro-aerophilic bacteria that grow best at $33^{\circ} \mathrm{C}$ in a complex, liquid medium called Barbour-Stoenner-Kelly medium (18). B. burgdorferi has a length of 20 to $30 \mu \mathrm{m}$ and a width of 0.2 to $0.3 \mu \mathrm{m}$, and it has 7 to 11 flagella. $B$. burgdorferi contains at least 30 different proteins, but the functions of only a few of them are currently known. These include the two major outer-surface proteins called oute- surface protein A (30 to $32 \mathrm{kd}$ ) and outer-surface protein B (34 to $36 \mathrm{kd})(19,20)$. The $41-\mathrm{kd}$ antigen is located on the flagellum (21). The 58- or 60-kd antigen appears to be a heat-shock protein that is cross-reactive with an equivalent antigen in a wide range of bacteria (22). Certain differences in morphology, outer surface proteins, plasmid and DNA homology have been noted between American and European isolates of $B$. burgdorferi (23).

\section{THE CLINICAL EVOLUTION OF LYME ARTHRITIS}

To determine the clinical evolution of Lyme arthritis, Steere conducted a longitudinal study of 55 patients, who had not received antibiotic therapy for erythema chronicum migrans, and followed them for a mean duration of 6 years 
(3). Of the 55 patients, $11(20 \%)$ had no subsequent manifestations of Lyme borreliosis. From 1 day to 8 weeks after disease onset, 10 of the patients (18\%) began to have brief episodes of joint, periarticular, or musculoskeletal pain lasting as long as 6 years, but none developed objective joint abnormalities. From 4 days to 2 years after disease onset, $28(51 \%)$ had one episode or began to have intermittent attacks of arthritis, primarily in large joints. The duration of these episodes ranged from three days to 11.5 months, with a mean of three months. Episodes of arthritis were often separated by months or even years of complete remission.

The total number of these patients who continued to have recurrences decreased by $10 \%$ to $20 \%$ each year. Six patients (11\%) developed chronic synovitis.

\section{PREVENTION}

Humans encounter ticks in forests, transitional vegetative zones, pastures, parks, lawns surrounding homes, brushwood and woodland areas bordering lawns, and even in houses after domestic animals have carried ticks inside. Reducing the incidence of tick bites is one of the first goals to attempt in preventing Lyme arthritis. Control methods can be divided into four categories: (1) Personal protection, (2) Biological control, (3) Environmental modification and physical control, and (4) Chemical control (24).

\section{PERSONAL PROTECTION}

Efforts made by the individual to prevent tick bites and to locate and promptly remove attached ticks may be the most effective measures that can be taken to reduce the risk of contracting Lyme disease.

\section{Repellents}

Repellents applied to outer clothing, including the insides of pant cuffs and socks, prevent tick bites. The acaricide permethin kills ticks (25). Standard repellents that do not kill but repel ticks when impregnated into clothing include deet, Indalone, dimethyl carbate, benzyl benzoate and M-1960. Treated clothing may be protected for several weeks and after several washings. Other personal measures to prevent tick bites are: taping the trouser cuffs, tucking the trousers into footwear, wearing one-piece zippered suits, wearing light colored clothing 
which makes it easier to observe ticks and wearing clothes made of a smooth weave rather than clothes of a coarse fabric.

\section{Tick removal}

Ticks attach to their hosts by cutting the skin with a pair of chelicerae and inserting the toothed hypostome.

Ticks may be removed by grasping the tick as close to the skin as possible with a pair of forceps or tweezers. An antiseptic should be applied to the skin where the tick was attached.

Humans should inspect their bodies after they have visited tick-infested areas and promptly remove ticks.

\section{Avoidance of tick-infested areas}

Avoiding visits to known tick-infested areas during the seasonal peak feeding of nymphs from May to mid-July can reduce the risk of acquiring Lyme borreliosis.

\section{BIOLOGICAL CONTROL}

Efforts should be made to introduce and to establish natural enemies of ticks. Until now, none of the known microbial pathogens and invertebrate or vertebrate predators have been used successfully to control ticks (24).

\section{ENVIRONMENTAL MODIFICATION AND PHYSICAL CONTROL}

\section{Altering vegetation}

Controlled burning may be useful by destroying the ticks active at the time of burning, reducing the abundance of suitable animals, and make the habitat inhospitable for ticks (26). Removal of trash piles and removal of bird feeders may help to reduce the number of ticks in the immediate vicinity of the home. 


\section{Denying ticks access to host animals}

Reductions in tick numbers may be achieved by eliminating the number of infected animals such as deer, but the killing of these animals will probably not be widely accepted by the public (27).

\section{CHEMICAL MODIFICATION}

Acaricides are used for treating tick-infested animals. Domestic animals may be dipped or fitted with a collar impregnated with acaricide. Nesting material treated with an acaricide has been used.

\section{Residual sprays}

Residual application of acaricides for control of ticks may be effective and practical when applied to relatively small areas frequented by humans, but will be too costly when applied to larger areas.

\section{Treatment of white footed mouse burrows}

Control of subadult $I$. dammini has been reported by the placement of the acaricide permethin directly on and in the burrows of white-footed mice. Studies have reported a marked reduction in numbers of larvae feeding on mice in treated versus untreated areas (28).

\section{PREVENTION OF LYME ARTHRITIS}

There are no data to support the common practice of treatment of tick bites with antibiotics, even in areas known to be endemic for Lyme borreliosis $(29,31)$. In a study comparing penicillin $\mathrm{V}$ and placebo, the risk of acquiring Lyme borreliosis was found to be lower than one would expect, given the infection rate in ticks, and it was similar to the risk of an adverse reaction to penicillin (30). Patients should be counseled about the early symptoms of Lyme borreliosis(29).

Recognition and adequate antibiotic treatment of the early stages of Lyme borreliosis is of paramount importance in preventing Lyme arthritis (31). Approximately $50 \%$ of the patients have the erythema migrans which is a characteristic of Lyme borreliosis. Individuals and doctors should be well aware of this skin lesion. Prompt antibiotic treatment should be started to prevent the later. 
complications of this disease (32). The optimal dose and duration of antibiotic treatment have not been established for any antibiotic agent (29). Despite adequate antibiotic treatment, chronic signs and symptoms of Lyme borreliosis may occur (3). Even in untreated patients, erythema migrans lesions fade within 3 to 4 weeks and other manifestations of the disease may occur only months later. A relationship with subsequent signs and symptoms may pass unnoticed. Adequate history taking and showing pictures of erythema migrans can be helpful in establishing the diagnosis (32). Since only 50 percent of the patients with Lyme borreliosis have erythema migrans preceding other signs and symptoms, a diagnosis of Lyme borreliosis can be difficult to make. Because the culture or direct visualization of $B$. burgdorferi from patient specimens is difficult, serology is currently the only practical laboratory aid for diagnosis. Antibody titers to $B$. burgdorferi are present after 4-6 weeks in almost all patients with Lyme borreliosis. Serologic results, however, should be interpreted with caution. False positive results and inter and intra laboratory variation have been reported (33-35). In addition to this problem, there are a large number of patients with asymptomatic $B$. burgdorferi infections (36). At present, it is impossible to differentiate between asymptomatic infections and false positive serology.

The discriminative value of reporting tick bites as part of the clinical history is low $(32,36)$. Even the presence of antibodies to B. burgdorferi in the absence of typical features of Lyme borreliosis such as erythema migrans has a very low impact on a definite diagnosis of Lyme borreliosis in the normal population (32).

Lyme arthritis has been treated successfully with both oral and parenteral antibiotics $(37,38)$. The optimal therapy remains to be established. The response rate to oral doxycycline has been reported to be $72 \%$ (38). In cases of persisting Lyme arthritis other factors such as immunogenetic factors and autoimmunity may play a role $(39,40)$. The response to antibiotics may occur three months or longer after completion of the therapy. In all cases of arthritis of unknown origin the diagnosis of Lyme borreliosis should be considered (41). Progression of joint damage or other manifestations which occur in the later stages of the disease may be prevented if appropriate treatment is provided immediately after the diagnosis of Lyme borreliosis has been established.

\section{SUMMARY}

Lyme arthritis may be avoided by preventing tick bites, by recognizing the early signs and symptoms of Lyme borreliosis, such as erythema migrans, and by timely antibiotic therapy. Antibiotic treatment of Lyme arthritis may prevent chronic arthritis. 


\section{REFERENCES}

1. Steere AC. Lyme disease. N Engl J Med 1989;321:586-595.

2. Logigian EL, Kaplan RF, Steere AC. Chronic neurologic manifestations of Lyme disease. N Engl J Med 1990; 323:1438-1444.

3. Steere AC, Schoen RT, Taylor E. The clinical evolution of Lyme arthritis. Ann Intem Med 1987; 107:725-731.

4. Blaauw AAM, Nohlmans MKE, van den Berg-Loonen E, Rasker JJ, van der Linden Sj. L.yme arthritis in the Netherlands: a nationwide survey among rheumatologists. $J$ Rheum 1991;18:1819-22.

5. Herzer P. Lyme arthritis in Europe: comparisons with reports from North America. Ann Rheum Dis 1988;47:789-791.

6. Äsbrink E, Hovmark A, Hederstedt B. Acta Derm Venereol 1984;64:506-512.

7. Steere AC, Grodzicki RL, Kornblatt AN, et al. N Engl J Med 1983;308:733-739.

8. Lane RS, Lavoie PE. Lyme borreliosis in Califomia. Ann NY Acad Sci 1988;539:192.

9. Nohlmans MKE, de Boer R, van den Bogaard AEJM, Blaauw AAM, van Boven CPA. Voorkomen van I. ricinus in Nederland. Ned Tijdschr Geneeskd 1990;134:1300-1303.

10. Aeschlimann A, Chamot E, Gigon H, Jeanneret JP, Kesseler D, Walther C. B. burgdorferi in Switzerland. Zentralbl Mikrobiol Hyg (A) 1987;263:450-458.

11. Kriuchechnikov VN, Korenberg EI, Shcherbakov SV, Kovalevski IV, Levin ML. [Identification of Borrelia isolated in the USSR from I.persulcatus ticks]. Zh Mikrobio] Epidemiol Immunobiol. 1988;12:41-44.

12. Ai $C X$, Wen $Y X$, Zhang YG, et al. Clinical manifestations and epidemiological characteristics of Lyme disease in Hailin county. Ann NY Acad Sci 1988;539:302-313.

13. Anderson JF. Mammalian and avian reservoirs for B. burgdorferi. Ann NY Acad Sci 1988;539:180-191.

14. Anderson JF, Magnarelli LA. Avian and mammalian hosts for spirochete-infected ticks and insects in a Lyme disease focus in Connecticut. Yale J Biol Med 1984;57:617.

15. Burgdorfer W, Barbour AG, Hayes SF, Benach Л, Grunwaldt E, Davis JP. Lyme discase- a tickborne spirochetosis? Science 1982;216:1317-1319.

16. Snydman DR, Schenkein DP, Berardi VP, et al. B. burgdorferi in joint fluid in chronic Lyme arthritis. Ann Intem Med 1986; 104:798-800.

17. Benach J, Bosler EM, Hanrahan JP, et al. Spirochetes isolated from the blood of two patients with Lyme disease. N Engl J Med 1983;308:740-742.

18. Barbour AG. Isolation and cultivation of Lyme disease spirochetes. Yale J Biol Med 1984;57:521-525.

19. Barbour AG, Tessier SL, Todd WJ. Lyme disease spirochetes and ixodid tick spirochetes share a common surface antigenic determinant defined by a monoclonal antibody. Infect Immun 1983;41:795-804.

20. Benach JL, Coleman $\mathrm{L}$, Golightly MG. A murine IgM monoclonal antibody binds an antigenic determinant in outer surface protein $A$, an immunodominant basic protein of the Lyme disease spirochete. J Immunol 1988;140:265-272.

21. Barbour AG, Hayes SF, Heiland RA, Schrumpf ME, Tessier SL. A Borrelia specific monoclonal antibody binds to a flagellar epitope. Infect Immun 1986;52:549-554. 
22. Hansen K, Bangsborg JM, Fjordvang H, Pedersen, NS, Hindersson P. Immunochemical characterization of and isolation of the gene for a Borrelia burgdorferi immunodominant 60-kilodalton antigen common to a wide range of bacteria. Infect Immun 1988;56:20472053.

23. Barbour AG, Heiland RA, Howe TR. Heterogeneity of major proteins in Lyme disease borreliae: a molecular analysis of North American and European isolates. J Infect Dis $1985 ; 152: 478-484$.

24. Anderson JF. Preventing Lyme disease. Rheum Dis Clin 1989; 15:757-766.

25. Schreck CE, Snoddy EL, Spielman A. Pressurized sprays of permethrin or Deet on military clothing for personal protection against $I$. dammini. J Med Entomol 1986;23:396.

26. Wilson ML. Reduced abundance of adult $I$. dammini following destruction of vegetation. J Econ Entomol 1986;79:693.

27. Wilson ML, Telford SR III, Piesman J, et al. Reduced abundance of immature $I$. dammini following elimination of deer. J Med Entomol 1988;25:224.

28. Mather TN, Ribeiro JMC, Moore S. Reducing transmissions of Lyme disease spirochetes in a suburban setting. Ann NY Acad Sci 1988;539:402.

29. Rahn DW, Malawista SE. Lyme disease: recommendations for diagnosis and treatment. Ann Intern Med 1991;1 14:472-481.

30. Costello CM, Steere AC, Pinkerton RE, Feder HM. A prospective study of tick bites in an endemic area for Lyme disease. J infect Dis 1989;25:136-139.

31. Steere AC, Bartenhagen NH, Craft JE, et al. The early clinical manifestations of Lyme disease. Ann Intern Med 1987; 197:725-731.

32. Blaauw AAM, Nohlmans MKE, van den Bogaard A, van der Linden Sj. Diagnostic Tools in Lyme borreliosis: clinical history compared with serology. J Clin Epidemiol 1992;1 1:1229-1236.

33. Hedberg CW, Osterholm MT. Serologic tests for antibody to B. burgdorferi. Another Pandora's box for medicine? Arch Intem Med 1990; 150:732-733. Editorial.

34. Luger SW, Krauss E. Serologic tests for Lyme disease. Interlaboratory variability. Arch Intern Med 1990;150:761-763.

35. Schwartz BS, Goldstein MD, Ribeiro JM, Schulze TL, Shaheid SI. Antibody testing in Lyme disease. A comparison of results in four laboratories. JAMA 1989;262:3431 3434.

36. Fahrer H, van der Linden SjM, Sauvain MJ, Gern L, Zhioua E, Aeschlimann A. The prevalence and incidence of clinical and asymptomatic Lyme borreliosis in a population at risk. J Infect Dis 1991;163:305-310.

37. Steere AC, Green J, Schoen RT, et al. Successful parenteral penicillin therapy of established Lyme arthritis. N Engl J Med 1985;312:869-874.

38. Liu NY, Dinerman H, Levin, et al. Randomized trial of doxycycline versus amoxicillin/probenecid for the treatment of Lyme arthritis: treatment of the non-responders with iv penicillin or ceftriaxone. Arthritis Rheum 1989;32:S32.

39. Sigal LH. Lyme disease, 1988: Immunologic manifestations and pussible immunopathogenetic mechanisms. Sem Arthritis Rheum 1989:18:151-167.

40. Steere AC, Dwyer E, Wichester R. Association of chronic Lyme arthritis with HLADR4 and HLA-DR2 alleles. N Engl J Med 1990;323:219-223.

41. Kryger P, Hansen K, Vinterberg H, Pedersen FK. Lyme borreliosis among Danish patients with arthritis. Scand J Rheum 1990;19:77-81. 


\section{.}




\title{
How well do general practitioners, rheumatologists and dermatologists recognize Lyme borreliosis?
}

\author{
AAM Blaauw, LWT Schuwirth*, CPM van der Vleuten*, \\ MJM de Rooij**, $S$ van der Linden
}

Department of Internal Medicine, Division of Rheumatology, University Hospital Maastricht; Department of Educational Development and Research*, University of Limburg, Maastricht; Department of Dermatology**, University Hospital Maastricht, the Netherlands.

Submitted for publication 


\section{How well do general practitioners, rheumatologists and dermatologists recognize Lyme borreliosis?}

\section{ABSTRACT}

Objective: To assess how well early stages of Lyme borreliosis (erythema migrans and arthritis) are recognized by general practitioners, rheumatologists, and dermatologists.

Design: Cross-sectional study.

Setting: A sample of 51 general practitioners, 23 rheumatologists and 13 dermatologists.

Measurements: General practitioners and rheumatologists were tested on 2 cases of Lyme arthritis. General practitioners and dermatologists were tested on 2 cases of erythema migrans shown as photographs. All cases were presented, among 10 other rheumatological or dermatological cases, using 2 different formats: open ended questions, prompting for the most likely diagnosis, and multiple probability estimate questions.

Results: In the open ended questions, the first case of Lyme arthritis was correctly diagnosed by $55 \%$ of the general practitioners and $96 \%$ of the rheumatologists. In the multiple probability estimates, $61 \%$ of the general practitioners and $87 \%$ of the rheumatologists rated this case of Lyme borreliosis as highly probable. The second case of Lyme arthritis was never recognized in the open ended questions, whereas only 2 general practitioners rated Lyme borreliosis as highly probable in the multiple probability estimates. The 2 photographs of erythema migrans were recognized by $16 \%$ and $45 \%$ of the general practitioners, and by $92 \%$ and $54 \%$ of the dermatologists, in the open ended questions. In the multiple probability estimates, $14 \%$ and $14 \%$ of the general practitioners and $77 \%$ and $46 \%$ of the dermatologists rated these 2 cases of erythema migrans as highly probable.

Conclusions: General practitioners, rheumatologists and dermatologists had difficulty recognizing early stages of Lyme borreliosis as erythema migrans or arthritis. Better instruction and education in recognizing the early manifestations of Lyme borreliosis seems indicated. 


\section{INTRODUCTION}

Lyme borreliosis, a tick-borne spirochetal infection, frequently begins with a characteristic skin lesion, erythema migrans, and is often followed by systemic manifestations involving the heart, nervous system, or the joints (1). Erythema migrans is reported in $50-60 \%$ of patients. In $15-20 \%$ of patients in the United States, this is followed within several weeks to months by neurological involvement, which may be accompanied by radicular pain, pleocytosis in cerebrospinal fluid and meningitis, cranial nerve involvement or peripheral neuropathy (2). Cardiac involvement occurs in $4-8 \%$ of patients. most commonly as an atrioventricular block (3). From two weeks to two years (usually six months) after the onset of the disease, often after intermittent episodes of arthralgia or migratory musculoskeletal pain, nearly $60-80 \%$ of patients begin to have brief attacks of asymmetric, oligoarticular arthritis, primarily in the large joints, and especially in the knee (4). Chronic arthritis, defined as a year or more of continual joint inflammation, begins during the second or third year after the onset of the disease. In severe cases, chronic Lyme arthritis may lead to the erosion of cartilage and bone and, sometimes, though rarely, to permanent joint disability (4). Progressive encephalomyelitis has also been described as a severe late stage of this disease (5). Acrodermatitis chronica atrophicans is a late skin disorder of the disease, which has been described primarily in Europe (6). In long-standing cases, chronic joint and bone involvement, including periostitis and subluxations of the small joints, may be seen underlying the cutaneous lesions.

Recognition and adequate antibiotic treatment of the early stages of Lyme borreliosis is of paramount importance in preventing the late stages of the disease (7). One should be aware of the fact that erythema migrans lesions may fade within 3 to 4 weeks, even in untreated patients, and other manifestations of the disease, like arthritis may occur only months later. One may be unaware of the relationship between subsequent signs and symptoms. Lyme borreliosis may also present itself without proceeding skin lesions, for instance as arthritis of the knee. Recognition and knowledge of the early dermatologic, especially erythema migrans, cardiac, neurologic, and rheumatic manifestations of the disease, is important to prevent later stages such as chronic arthritis.

The exact incidence and prevalence of Lyme borreliosis in the Netherlands are as yet unknown. The estimated incidence is 559 cases of Lyme borreliosis a year in a population of $15,000,000$ (8). Therefore, general practitioners will not frequently encounter patients with Lyme borreliosis. However, knowledge of the disease, clinical suspicion and recognition of manifestations, and appropriate and timely antibiotic treatment, will decrease the burden of illness. At early stages of the disease (for example erythema migrans) clinical history and physical examination are the most important tools to detect Lyme borreliosis for 
general practitioners, since antibodies to Borrelia burgdorferi only become positive after 6 to 8 weeks (9).

Data of the whole spectrum of Lyme borreliosis have only become available since the first publication by Steere in 1977 (10). The first publications of the early manifestations of the disease in Dutch literature date from 1987 and 1988 (11-15). The general practitioner may have gained his or her knowledge of Lyme borreliosis from medical journals rather than from medical textbooks. The chance that general practitioners have gained experience with Lyme borreliosis from patients, is estimated as being low, due to the low incidence of the disease.

The present study was performed to answer the following questions: (1) how well do general practitioners and rheumatologists recognize a typical case description of Lyme borreliosis, (2) how well do they recognize a later stage of Lyme borreliosis as arthritis, and (3) how well do general practitioners and dermatologists recognize erythema migrans.

\section{METHODS}

The study was undertaken to assess knowledge of general practitioners about rheumatic diseases, and was carried out before discussions on a rheumatic post-graduate training program were started. The ultimate purpose is to install post- graduate training, which fits the specific needs of the participants. Participating in the study was supported by the board of the Post-Graduate Education Committee of the local organization of general practitioners.

\section{General practitioners}

In november 1991, a random sample of $58(73 \%)$ of all 79 general practitioners from Maastricht and the immediate surroundings, was invited to participate in an evaluation program of knowledge about rheumatic disease. A total of 51 general practitioners agreed to cooperate (a response rate of $88 \%$ ). Seven refused to cooperate, mostly due to lack of time. All participating practitioners were visited in their office by one investigator $(A B)$. The entire evaluation program lasted 45 minutes for each participant.

\section{Rheumatologists and dermatologists}

Twenty-three rheumatologists attending a scientific meeting at the University Hospital Maastricht in November 1991, agreed to participate. Fourteen rheumatologists worked in private practice and 9 in an academic setting. 
Thirteen dermatologists, 3 from private practice and 10 from an academic setting cooperated in the study, while attending a meeting of the Dutch Society of Dermatology in September 1991.

\section{Cases and photographs of skin lesions}

Written case descriptions presented to general practitioners and rheumatologists were: one case each of rheumatoid arthritis, psoriatic arthritis, gout, polymyalgia rheumatica, pseudogout, systemic lupus erythematodes, ankylosing spondylitis, reactive arthritis, and two cases of Lyme borreliosis. The furst case of Lyme borreliosis was a classical case with a bite, skin lesion, atrio-ventricular block, and arthritis. The second case was a patient with recurrent arthritis of the knee without any other symptoms of Lyme borreliosis (see appendix 1 for detailed case descriptions).

All ten rheumatologic cases were derived from real patients and compiled by one of the investigators $(\mathrm{AB})$. Only signs and symptoms of the patients were given. Results from laboratory tests were not included. A differential diagnosis for each rheumatic case was composed by one of the investigators $(\mathrm{AB})$ and three rheumatologists from the Department of Rheumatology of the University Hospital Maastricht. Each of these four rheumatologists composed a differential diagnosis for each case description. The eight diagnoses mentioned the most were used for the definite differential diagnosis used in the study.

Ten colored photographs, (13 x 18-centimeter) of skin lesions, which may occur in connection with rheumatic diseases, were placed in plastic binders and presented to the general practitioners and the dermatologists. Skin lesions presented were: one photograph each of cutaneous lupus erythematodes, erythema nodosum, erythema annulare multiforme, urticaria, vasculitis, drug eruption, and two photographs of psoriasis and erythema migrans. A differential diagnosis for each case was composed by 2 dermatologists from the Department of Dermatology of the University Hospital Maastricht in the same way as was described for the rheumatologists. Regarding the two photographs of erythema migrans, the clinical diagnosis was confirmed by 2 dermatologists (chapter 1 , figure 1 and 2). Both patients developed erythema migrans within 2 weeks of a tick bite.

\section{Questions}

All rheumatic cases and skin lesions were presented in two formats. The first was an open-ended question, prompting for the most likely diagnosis. The second was a so-called multiple probability estimate consisting of several (eight) 
possible diagnoses, for each of which the participant had to rate the probability on a seven points scale (16). The questions were presented in these two different formats to assess a possible discrepancy in the answers. The results of the answers to these two different formats will be touched upon briefly. A thorough discussion of this subject will be presented elsewhere.

\section{Presentation}

The rheumatic cases were presented to the participating general practitioners and rheumatologists using a computer-interface specially developed for testing (17). Firstly, all cases were presented linked to the open-ended question. Secondly, the same cases were presented but were then linked to the multiple probability estimate. It was not possible to return to a previous screen or correct answers already given to the open-ended questions, after a participant had seen the differential diagnosis given in the multiple probability estimate questions. The answers to all questions were immediately filed in the computer.

The photographs were presented to the general practitioners and dermatologists by two of the investigators ( $\mathrm{AB}$ and $\mathrm{MRR}$ ) without any specific comment. The diagnoses for each photograph were written on separate sheets. The differential diagnoses for the multiple probability estimate questions were presented on separate sheets. The participants were not allowed to read back.

\section{Scoring}

Since all cases and photographs were derived from real patients, each case served as its own "gold" standard. Answers to the open-ended questions to both rheumatic cases and skin lesions were evaluated in two ways: a correct answer mentioned as a first diagnosis, and listing of the correct answer within the first three diagnosis. In the multiple probability ratings, rate 6 and 7 were considered highly probable, rate 3,4 , and 5 probable, and rate 1 and 2 , highly improbable.

\section{Medical journals}

At the end of the test, a list of 17 Dutch and 10 English medical journals of supposedly easy access to general practitioners was presented. The instruction for this list was to rate how frequently these journals were read by the general practitioners on a scale from 1 (never) to 5 (every issue).

The number of published articles about Lyme borreliosis (period 1983-1991) was known for each journal. 


\section{Computer program}

The program used for presentation, data filing, and scoring was written by Donkers, et al (17). It consists of an instruction set which allows easy presentation of a case text, and linking of the text to several (preprogrammed) types of questions.

\section{Statistics}

Counts of correct answers were calculated for each group, variance and means were compared to each other. Cross-tabulations were made to compare answers to open-ended questions and probabilities given on the multiple probability estimates. For categorical data, a $\mathrm{X}^{2}$ test was used to test for significant differences between groups. A probability value $\mathrm{p}<0.05$ was considered statistically significant.

\section{RESULTS}

\section{Case 1. (a typical case of Lyme borreliosis with erythema migrans, bite, atrioventricular block, and arthritis)}

Lyme borreliosis as the first diagnosis in the open-ended questions was given by 21 , out of the 51 general practitioners (41.2\%), compared to 22 out of 23 rheumatologists $(95.7 \%)(\mathrm{p}<0.001)$. Lyme borreliosis listed in the differential diagnosis (first three diagnoses) occurred in 28 of the general practitioners $(54.9 \%)$, compared to 22 of 23 rheumatologists $(95.7 \%)(\mathrm{p}<0.001)$ (Table 1). The diagnoses mentioned for this case by the general practitioners in the open ended-questions were rheumatic fever $(8 \mathrm{x})$, reactive arthritis $(6 \mathrm{x})$, septic arthritis $(3 x)$, endocarditis $(3 x)$, gout $(3 x)$, postinfectious arthritis $(3 x)$, viral infection $(1 \mathrm{x})$, erysipelas $(1 \mathrm{x})$, and arthritis of unknown etiology $(2 \mathrm{x})$.

In the multiple probability estimate questions, Lyme borreliosis was rated as highly probable (rate 6 and 7) by 31 of the general practitioners $(60.7 \%)$, as probable (rate 3,4 , and 5 ) by $7(13.7 \%$ ), and as highly improbable (rate 1 and 2 ) by $13(25.5 \%)$ (Table 2$)$.

When the answers to the open-ended questions and the multiple probability estimates were compared, 54.9\% gave the correct answer and 60.8\% rated Lyme borreliosis as highly probable.

Of the 21 general practitioners who diagnosed Lyme borreliosis correctly as the first diagnosis in the open-ended questions, eighteen rated Lyme borreliosis 
Table 1. Presence of correct answers within the first three diagnoses given to two cases of Lyme borreliosis and two photographs of erythema migrans (open-ended questions) by rheumatologists, general practitioners, and dermatologists.

\begin{tabular}{|c|c|c|c|c|c|c|}
\hline & \multicolumn{2}{|c|}{$\begin{array}{l}\text { Rheumatologists } \\
\mathrm{N}=23\end{array}$} & \multicolumn{2}{|c|}{$\begin{array}{l}\text { General Practitioners } \\
N=51\end{array}$} & \multicolumn{2}{|c|}{$\begin{array}{l}\text { Dermatologists } \\
\mathrm{N}=13\end{array}$} \\
\hline & $N$ & $\%$ & $N$ & $\%$ & $\mathbf{N}$ & $\%$ \\
\hline Case 1 & 22 & 95.7 & 28 & 54.9 & & \\
\hline Case 2 & 1 & 4.3 & 0 & 0 & & \\
\hline Photo 1 & & & 8 & 15.6 & 12 & 92.3 \\
\hline Photo 2 & & & 23 & 45.0 & 7 & 53.8 \\
\hline
\end{tabular}

Table 2. Probability ratings in the multiple probability estimate questions to two cases of Lyme borreliosis presented to general practitioners and rheumatologists.

\begin{tabular}{|c|c|c|c|c|c|c|c|c|c|c|c|c|}
\hline & \multicolumn{6}{|c|}{ General practitioners $(n=51)$} & \multicolumn{6}{|c|}{ Rheumatologists ( $n=23$ ) } \\
\hline & \multicolumn{2}{|c|}{$\begin{array}{l}\text { Highly } \\
\text { Probable }\end{array}$} & \multicolumn{2}{|c|}{ Probable } & \multicolumn{2}{|c|}{$\begin{array}{l}\text { Highly } \\
\text { Improbable }\end{array}$} & \multicolumn{2}{|c|}{$\begin{array}{l}\text { Highly } \\
\text { Probable }\end{array}$} & \multicolumn{2}{|c|}{ Probable } & \multicolumn{2}{|c|}{$\begin{array}{l}\text { Highly } \\
\text { Improbable }\end{array}$} \\
\hline & $\mathrm{N}$ & $\%$ & $\mathrm{~N}$ & $\%$ & $\mathrm{~N}$ & $\%$ & $\mathrm{~N}$ & $\%$ & $\mathrm{~N}$ & $\%$ & $\mathrm{~N}$ & $\%$ \\
\hline Case 1 & 31 & 60.7 & 7 & 13.7 & 13 & 25.5 & 20 & 86.9 & 0 & $0^{\circ}$ & 3 & 13 \\
\hline Case 2 & 2 & 3.9 & 4 & 7.8 & 45 & 88.2 & 0 & 0 & 4 & 17.4 & 19 & 82.6 \\
\hline
\end{tabular}

in the multiple probability estimate questions as highly probable (rate 6 and 7), one as probable (rate 5), and two as improbable (rate 1 and 2) (Table 3).

In the multiple probability estimate questions, Lyme borreliosis was rated highly probable (rate 6 and 7 ) by 20 rheumatologists ( $86.9 \%$ ), and improbable (rate 1 and 2) by 3 of the rheumatologists (13\%) (Table 2). Of the 22 rheumatologists who gave the correct answer in the open-ended questions, nineteen rated Lyme borreliosis as highly probable (rate 6 and 7), two as probable (rate 5), and one as improbable (rate 2) (Table 3). 
Table 3. Distribution of probability scores on multiple probability estimate questions among those participants who correctly diagnosed Lyme borreliosis or erythema migrans as a first diagnosis in the open-ended questions.

\begin{tabular}{llrlll}
\hline & & N & $\begin{array}{l}\text { Highly } \\
\text { probable }\end{array}$ & Probable & $\begin{array}{l}\text { Highly } \\
\text { improbable }\end{array}$ \\
\hline Rheumatologists & Case 1 & 22 & 19 & 2 & 1 \\
General practitioners & Case 1 & 21 & 18 & 1 & 2 \\
Rheumatologists & Case 2 & 0 & 0 & 0 & 0 \\
General practitioners & Case 2 & 0 & 0 & 0 & 0 \\
Dermatologists & Photo 1 & 9 & 9 & 0 & 0 \\
General practitioners & Photo 1 & 6 & 2 & 2 & 2 \\
Dermatologists & Photo 2 & 3 & 3 & 0 & 0 \\
General practitioners & Photo 2 & 16 & 6 & 1 & 9 \\
\hline
\end{tabular}

\section{Case 2 (recurrent arthritis of the knee)}

None of the general practitioners and rheumatologists mentioned Lyme borreliosis in their diagnosis to the open ended-questions. Only one rheumatologist mentioned Lyme borreliosis in his differential diagnosis (Table 1). This rheumatologist rated Lyme borreliosis as improbable (rate 2) in the multiple probability estimate questions.

In the multiple probability estimate questions, Lyme borreliosis was rated as highly probable (rate 6 ) by only 2 of the general practitioners (3.9\%), as probable (rate 3,4 , and 5 ) by $4(7.8 \%$ ) and as improbable (rate 1 and 2 ) by 45 of the general practitioners $(88.2 \%$ ) (Table 2 ). Lyme borreliosis was rated as highly probable by none of the rheumatologists, as probable by $4(17 \%)$, and as improbable by 19 of the rheumatologists (82.6\%) (Table 2). The first diagnosis given by both the general practitioners and rheumatologists to this case, in the open-ended questions, are shown in Table 4.

\section{Erythema migrans (photograph 1)}

Six, out of the 51 general practitioners $(11.8 \%)$ mentioned erythema migrans as the first diagnosis in the open-ended question to the first photograph compared to 9 , out of 13 dermatologists $(69.2 \%)$ ( $p<0.001)$. Erythema migrans occurred in the differential diagnosis (first three diagnoses) of the first photograph in 8 of 
Table 4. First diagnosis mentioned by general practitioners and rheumatologists to the case: with recurrent arthritis of the knee in the open-ended questions

\begin{tabular}{|c|c|c|c|c|}
\hline & \multicolumn{2}{|c|}{$\begin{array}{l}\text { General practitioners } \\
n=51\end{array}$} & \multicolumn{2}{|c|}{$\begin{array}{l}\text { Rheumatologists } \\
n=23\end{array}$} \\
\hline & $\mathrm{n}$ & $\%$ & $n$ & $\%$ \\
\hline Gout & 24 & 47.1 & 10 & 43.5 \\
\hline Arthritis of unknown etiology & 14 & 27.5 & 2 & 8.7 \\
\hline Reactive arthritis & 2 & 4 & 6 & 26.1 \\
\hline Rheumatoid arthritis & 4 & 7.8 & 0 & 0 \\
\hline Ankylosing spondylitis & 0 & 0 & 4 & 17.4 \\
\hline Gonococcal arthritis & 3 & 5.9 & 0 & 0 \\
\hline Viral arthritis & 1 & 2 & 0 & 0 \\
\hline Trauma & 0 & 0 & 1 & 4.3 \\
\hline Osteoarthritis & 2 & 3.9 & 0 & 0 \\
\hline Locking phenomenon & 1 & 2 & 0 & 0 \\
\hline
\end{tabular}

Table 5. Probability ratings in the multiple probability estimate questions to two photographs of erythema migrans presented to general practitioners and dermatologists.

\begin{tabular}{|c|c|c|c|c|c|c|c|c|c|c|c|c|}
\hline & \multicolumn{6}{|c|}{ General practitioners $(n=51)$} & \multicolumn{6}{|c|}{ Dermatologists $(n=13)$} \\
\hline & \multicolumn{2}{|c|}{$\begin{array}{l}\text { Highly } \\
\text { Probable }\end{array}$} & \multicolumn{2}{|c|}{ Probable } & \multicolumn{2}{|c|}{$\begin{array}{l}\text { Highly } \\
\text { Improbable }\end{array}$} & \multicolumn{2}{|c|}{$\begin{array}{l}\text { Highly } \\
\text { Probable }\end{array}$} & \multicolumn{2}{|c|}{ Probable } & \multicolumn{2}{|c|}{$\begin{array}{l}\text { Highly } \\
\text { Improbable }\end{array}$} \\
\hline & $\mathrm{N}$ & $\%$ & $\mathrm{~N}$ & $\%$ & $\mathrm{~N}$ & $\%$ & $\mathrm{~N}$ & $\%$ & $\mathrm{~N}$ & $\%$ & $\mathrm{~N}$ & $\%$ \\
\hline Photo 1 & 7 & 13.7 & 10 & 19.6 & 34 & 66.7 & 10 & 76.9 & 3 & 23.1 & 0 & 0 \\
\hline Photo 2 & 7 & 13.7 & 9 & 17.6 & 35 & 68.6 & 6 & 46.2 & 6 & 46.2 & 1 & 7.6 \\
\hline
\end{tabular}

the general practitioners (15.6\%), compared to 12 of the dermatologists $(92.3 \%)$ $(p<0.001)$ (Table 1).

When the multiple probability estimate questions for the first photograph were assessed, 7 of the general practitioners $(13.7 \%)$ rated erythema migrans as highly probable (rate 6 and 7), $10(19.6 \%$ ) as probable (rate 3,4 , and 5), and 34 $(66.7 \%)$ as improbable (rate 1 and 2) (Table 5). 
Of the six general practitioners who listed the first photograph as erythema migrans in the open-ended question, two rated erythema migrans as highly probable, two as probable, and two as highly improbable in the multiple probability estimate questions (Table 3 ).

Ten of the 13 dermatologists $(76.9 \%)$ rated the first photograph as highly probable for erythema migrans, $3(23.1 \%)$ as probable and none as improbable, in the multiple probability estimate questions (Table 5).

All nine dermatologists who listed erythema migrans in the open-ended questions of the first photograph, rated erythema migrans as highly probable in the multiple probability estimate questions (Table 3 ).

\section{Erythema migrans (photograph 2)}

Sixteen general practitioners $(31.4 \%)$ correctly diagnosed the second photograph as erythema migrans, compared to 3 of the dermatologists (23.1\%) (NS). Twenty-three general practitioners (45\%) listed Lyme borreliosis in the differential diagnosis to the second photograph, and 7 of the dermatologists $(53.8 \%)$ (NS) (Table 1).

The second photograph of erythema migrans was rated as highly probable by 7 of the general practitioners $(13.7 \%)$, as probable by $9(17.6 \%)$, and as improbable by $35(68.6 \%)$ (Table 5$)$.

Of the sixteen general practitioners who listed erythema migrans in the open-ended questions of the second photograph, six rated erythema migrans as highly probable, one as probable, and 9 as highly improbable (Table 3 ).

The second photograph of erythema migrans was rated as highly probable for erythema migrans by 6 dermatologists $(46.2 \%)$, as probable by $6(46.2 \%)$, and as improbable by one (7.6\%) (Table 5).

All three dermatologists who listed erythema migrans in the open-ended questions of the second photograph, also rated erythema migrans as highly probable in the multiple probability estimate questions (Table 3).

Four $(7.8 \%)$ general practitioners suggested erythema migrans as a diagnosis to the open-ended question, when a photograph of erythema nodosum was shown, and six (11.7\%) when a photograph of erythema annulare multiforme was shown. Ten dermatologists $(76.9 \%)$ listed erythema migrans in the openended question, when a picture of erythema annulare was shown.

A variety of diagnoses was suggested as a first diagnosis by general practitioners and dermatologists in the open-ended questions to both photographs of erythema migrans. Diagnoses mentioned most were: contact allergy $(6 \mathrm{x})$, mycosis $(4 \mathrm{x})$, discoid lupus erythematodes $(4 \mathrm{x})$, erythema annulare centrifugum $(2 \mathrm{x})$, epizoonosis $(27 \mathrm{x})$. All other diagnoses were mentioned only once. 


\section{Cases of Lyme borreliosis and erythema migrans}

Twenty-eight general practitioners (54.9\%) suggested Lyme borreliosis in their differential diagnosis (first three diagnoses) to case 1. Only three of these twenty-eight, correctly diagnosed both photographs of erythema migrans. Six diagnosed photograph 1 , and thirteen photograph 2.

Two general practitioners correctly diagnosed both photographs of erythema migrans, however they did not recognize case 1 . Two general practitioners recognized photograph 1 , but did not recognize case 1 . Seven general practitioners recognized photograph 2, but did not recognize case 1 as Lyme borreliosis. As stated before, none of the general practitioners recognized case 2 as Lyme borreliosis.

\section{Medical journals}

Eight Dutch medical journals were read regularly by more than $50 \%$ of the general practitioners. Articles about Lyme borreliosis appeared in five of these eight journals in 1987 to 1991 (11-15,18-32). One journal published an article about Lyme borreliosis, which included photograph 1 of erythema migrans just one month before the study was started (8). The other journals were read by less than $12 \%$ of the general practitioners.

\section{DISCUSSION}

By assessing knowledge of rheumatic diseases of general practitioners, we evaluated the recognition and knowledge of Lyme borreliosis among general practitioners, rheumatologists and dermatologists.

A typical case of Lyme borreliosis with almost all clinical features of the disease, was easily recognized by most rheumatologists. However, a case of Lyme borreliosis with recurrent arthritis of the knee, without other preceding signs and symptoms, was not diagnosed either by rheumatologists or by general practitioners. Recurrent arthritis attacks, especially of the knee, are a common feature of Lyme borreliosis and should be recognized by rheumatologist at all events $(4,33)$.

Most of the general practitioners did not recognize the photographs of erythema migrans. On the other hand, the second photograph of erythema migrans was only recognized by $54 \%$ of the dermatologists. When patients with erythema migrans are not recognized as having Lyme borreliosis, they will probably not be treated with appropriate antibiotics. This will then increase the risk of the development of later stages of Lyme borreliosis. Despite the fact several 
papers about Lyme borreliosis have been published in the Dutch literature and also in journals commonly read by general practitioners, it is clear more information about the manifestations of erythema migrans should be given to both general practitioners and dermatologists. Most of these articles focus on the entire spectrum of the disease.

The presentation of the questions (open-ended or with a differential diagnosis) had a varying influence on the answers of the general practitioners, rheumatologists and dermatologists to the two cases of Lyme borreliosis and the two photographs of erythema migrans. Some diversity was noticed in the answers accompanying the two different assessment methods.

We presented the cases of Lyme borreliosis as written cases, primarily for practical reasons. A possible criticism of this method is, that hypothetical case scenarios may include selected aspects of clinical reality while neglecting others, and that physicians may not respond in the same way to hypothetical scenarios as they do to real ones. We tried to avoid this criticism by deriving our cases from real patients. A study by Rethans and van Boven suggested no significant difference in overall score for written case simulations and the use of standardized real patients (34). Moreover, correlations between written and performance-based tests appear to be sizable (35). Nevertheless, whenever possible, it would be interesting to use standardized (simulated) patients with different stages of Lyme borreliosis to evaluate the real performance of general practitioners, rheumatologists and dermatologists.

Regarding the photographs of erythema migrans, observing a patient's cutaneous problem directly and providing a possibility to ask for accompanying symptoms and to palpate the skin lesion, is of course a better assessment procedure. We presented the photographs of erythema migrans without any comment, because about half the patients with erythema migrans do not remember a tick bite and sometimes only notice their skin lesion by accident. Frequently, there are no additional supportive data from the clinical history.

For the purpose of gathering knowledge for later use, physicians consistently report that reading, primarily of medical journals, is their predominant source of information (36). Since articles about Lyme borreliosis were published in the majority of journals commonly read by general practitioners, lack of direct knowledge and low suspicion is probably due to the low chance of encountering a patient with this disease. We did not inquire about journals read by rheumatologists and dermatologists.

In summary, better education aimed at recognition of the (early) manifestations of Lyme borreliosis is necessary for general practitioners, rheumatologists, and dermatologists to limit morbidity due to late stages of Lyme borreliosis. 


\section{Acknowledgements}

The enthusiastic cooperation of the general practitioners, rheumatologists, and dermatologists to participate in the "evaluation rheumatic knowledge study" is greatly appreciated. 


\section{REFERENCES}

1 Steere AC. Lyme disease. N Engl J Med 1989;321:586-595.

2 Pachner AR, Steere AC. The triad of neurologic manifestations of Lyme disease: meningitis, cranial neuritis, and radiculoneuritis. Neurology 1985;35:47-53.

3 Steere AC, Batsford WP, Weinberg M, et al. Lyme carditis: cardiac abnormalities of Lyme disease. Ann Intern Med 1980;93:8-16.

4 Steere AC, Schoen RT, Taylor E. The clinical evolution of Lyme arthritis. Ann Intern Med 1987;107:725-731.

5 Ackermann R, Rehse-Kupper B, Gollmer E, Schmidt R. Chronic neurologic manifestations of erythema migrans borreliosis. Ann NY Acad Sci 1988;539:16-23.

6 Äsbrink E, Hovmark A, Hederstedt B. The spirochetal etiology of acrodermatitis atrophicans Herxheimer. Acta Derm Venereol. 1984;64:506-512.

7 Rahn DW, Malawista SE. Lyme disease: recommendations for diagnosis and treatment. Ann Intern Med 1991;114:472-481.

8 Blaauw AAM, van der Linden S. Epidemiologische aspecten van Lyme borreliosis in Nederland. Modern Medicine 1991;11:1067-1971.

9 Steere AC, Bartenhagen NH, Craft JE, et al. The early clinical manifestations of Lyme disease. Ann Intern Med 1983;197:725-731.

10 Steere AC, Malawista SE, Snydham DR, et al. Lyme arthritis: an epidemic of oligoarticular arthritis in children and adults in three Connecticut communities. Arthritis Rheum 1977;20:7-17.

11 van Duin BJ. Erythema migrans als eerste teken van Lyme ziekte. Ned Tijdschr Geneeskd 1987;131:679-80.

12 van Furth R. Lyme disease: een nieuwe infectieziekte met localisatie in verschillende organen. Ned Tijdschr Geneeskd 1987;131:657-8.

13 van den Hoogen FHJ, Boerbooms AMTH, Rasker JJ, van de Putte LBA. Gewrichtsklachten na tekebeet; Lyme artritis in Nederland. Ned Tijdschr Geneeskd 1988;132: 1300-03.

14 Blaauw AAM, Braat S, van Santen-Hoefft MS, van der Linden S. Cardiologische afwijkingen bij patiènten met Lyme borreliosis. Ned Tijdschr Geneeskd 1988;131: 2111-14.

15 Kuiper H, de Jongh BM, Senden PJ. Pacemaker implantatie wegens atrioventriclair blok bij Lyme borreliose. Ned Tijdschr Geneeskd 1988;132:2111-4.

16 van Rossum HJM, Bender W, Meinders AE. De invloed van biografische details in casuistische mededelingen op het diagnostisch oordeel. Ned Tijdschr Geneeskd 1991; 135:802-05.

17 Donkers HHLM, van der Vleuten CPM, Schuwirth LWT. Computer gestuurd casus gericht toetsen. In: CPM van der Vleuten, AJJA Scherpbier, MC Pollemans; eds. Proceedings Gezond Onderwijs Congres Veldhoven, the Netherlands 1991; 138-143. Available from Nederlandse Vereniging voor Medisch Onderwijs.

18 Kuiper H, van Doornum GJ. Lyme disease: een infectie met localisatie in verschillende organen [Letter]. Ned Tijdschr Geneeskd 1987;131:1361.

19 Wokke JH. Lyme disease [Letter]. Ned Tijdschr Geneeskd 1987;131:1141.

20 Muhlemann MF. De ziekte van Lyme, een nieuwe bedreiging voor de volksgezondheid? Patient Care (Dutch Edition) 1987;14:23-30. 
21 Korff KJ, de Kreek EJ. Gewrichtsklachten na tekebeet [Letter]. Ned Tijdschr Geneeskd 1988;132:1596-6.

22 Blaauw AAM, van de Linden S. Cardiologische afwijkingen bij patiënten met Lyme borreliosis [Letter]. Ned Tijdschr Geneeskd 1989:416.

23 Blaauw AAM, van der Linden S. Lyme borreliose, de "Hocus Pas" onder de infectieziekten [Letter]. Ned Tijdschr Geneeskd 1989;51:2578-79.

24 van der Meer JW. Lyme-borreliose, de "Hocus Pas" onder de infectieziekten. Ned Tijdschr Geneeskd 1989;133:2214-6.

25 Plotz F, Houwerzijl J. Cardiologische afwijkingen bij patiënten met tekebeet [Letter]. Ned Tijdschr Geneeskd 1989;133:416.

26 Blaauw AAM, van der Linden S. Lyme borreliosis. Practitioner (Dutch Edition) 1990; 13:1009-13.

27 Nohlmans L, de Boer R, van den Bogaard AEJM, Blaauw AAM, van Boven CPA. Prevalentie van Borrelia burgdorferi in Ixodes ricinus in Nederland. Ned Tijdschr Geneeskd 1990;34:1300-03.

28 Lyme ziekte, een borreliose. In: GHI Bulletin 1990, available from the Chief Inspectorate of Public Health of the Ministry of Welfare, Health and Cultural Affairs, Rijswijk, the Netherlands.

29 Hoogkamp-Korstanje JAA. Telefonische consultatie over de Lyme-ziekte [Letter]. Ned Tijdschr Geneeskd 1990; 134:306.

30 van Furth R. Telefonische consultatie over de Lyme-ziekte. Ned Tijdschr Geneeskd 1990;134:3-4.

31 Bosch MMC, Boon ME. Lyme borreliosis of "Lyme disease" met de nadruk op de vroege verschijnselen. Patient Care (Dutch Edition) 1990;17:9-25.

32 Nohlmans MKE, van den Bogaard AEJM, Blaauw AAM, van Boven CPA. Prevalentie van Lyme borreliosis in Nederland. Ned Tijdschr Geneeskd 199 1;135:2288-2292.

33 Blaauw AAM, Dijkmans BAC, Bouma PAD, van der Linden S. Rational diagnosis and treatment in unclassified arthritis: how clinical data may guide requests for Lyme serology and antibiotic treatment. Ann Rheum Dis 1993. In press.

34 Rethans JJ, van Boven CPA. Simulated patients in general practice: a different look at the consultation. Br Med J 1987;294:809-812.

35 van der Vleuten CPM, van Luyk SJ, Beckers HJM. A written test as an alternative to performance testing. Medical Education 1989;23:97-107.

36 Haynes RB, McKibbon A, Fitzgerald D, et al. How to keep up with the medical literature: 1. Why try to keep up and how to get started. Ann Intem Med 1986;105:149153. 


\section{APPENDIX 1}

\section{Case 1}

A 35 year old, male nurse from a wooded area, visits your practice complaining about a warm, swollen right knee he has had for a couple of days. In fact he already complained about his knee during a short stay in the coronary care unit. He was admitted because of acute dizziness. The diagnosis was second degree atrio-ventricular block, which came in to remission spontaneously. You prescribed him some acetaminophen some weeks before this admission, because of flu-like complaints with slight fever, chills and lymphadenopathy. He remembered some sort of bite with redness on his right leg, which had been visible during a couple of weeks after this bite.

At physical examination, there is a warm, heavily swollen knee with severe limitation of movements.

Open-ended question: what is (are) your most likely diagnoses?

Multiple probability estimate question: rate the probability of each of the following diagnoses on a scale from 1 (highly improbable to 7 (highly probable):

- Viral arthritis

- Rheumatic fever

- Reactive arthritis

- Gout

- Lyme borreliosis

- Septic arthritis

- Systemic Lupus Erythematodes

- Rheumatoid arthritis

\section{Case 2}

A 47 year old pilot, visits your practice complaining about a warm, swollen left knee, which has lasted several weeks already. He does not complain about any pain. Flexion is severely limited. He has used some NSAID's without any result.

Last year he had the same problem. The arthritis lasted for 8 weeks. Due to his job, he travels around the whole world. After long-distance flights, he has some lower back pain. He takes a drink now and then to fall asleep.

Open-ended question: What is (are) your most likely diagnoses? 
Multiple probability estimate question: rate the probability of each of the following diagnoses on a scale from 1 (highly improbable) to 7 (highly probable):

- Rheumatoid arthritis

- Reiter's syndrome

- Gout

- Spondylitis ankylopoetica

- Lyme borreliosis

- Osteoarthritis

- Meniscal tear

- Gonococcal arthritis 


\section{General discussion.}

\section{Lyme borreliosis}

Differences in the prevalence of rheumatic manifestations of Lyme borreliosis have been reported between various countries, especially between the United States and Europe. Arthritis is said to be a common manifestation of the disease in the United States, Germany, Switzerland and Belgium (1-4). Other studies also from Europe, have reported considerably lower prevalence of rheumatic manifestations of Lyme borreliosis (5-10).

Several reasons have been proposed for these differences. (1) A diversity between American and European isolates of Borrelia burgdorferi (B. burgdorferl) has been pointed out (11). (2) The definition of Lyme disease in the United States results from the identification of patients with arthritis or erythema migrans only, leading to probable overreporting of rheumatic manifestations. (3) Early (versus late or no) treatment of erythema migrans which is supposed to be common in Europe, could have prevented the development of arthritis (12). (4) A lack of diagnostic awareness of Lyme borreliosis or its rheumatic manifestations, and the impression that Lyme disease is a rare disease in Europe could also be responsible for the reported differences $(13,14)$. (5) Patients with Lyme borreliosis are seen by different medical specialists like general practitioners, dermatologists, neurologists, and rheumatologists. Each of these specialists will focus on their own specialty, and there is a possibility that other Lyme symptoms will be overlooked.

The clinical features of the reported Dutch patients with Lyme borreliosis, closely resemble the description of the disease reported from the United States. However, the majority of the Dutch patients presented with arthritis to rheumatologists. The possibility of bias in the direction of arthritis can not be precluded. At this time, it is impossible to say whether there are real differences between the United States and Europe in the incidence of rheumatic manifestations of Lyme borreliosis. We have the feeling that a lack of awareness is responsible for most of the reported differences in the rheumatic manifestations of the disease. 
The exact incidence and prevalence of Lyme borreliosis in the Netherlands is unknown. The estimated incidence is 560 cases a year. Lyme arthritis usually responds to antibiotic treatment. Although not a frequent cause of arthritis, early diagnosis may significantly reduce the burden of illness due to this disease and may prevent long-lasting disability. Lyme borreliosis should be considered in the differential diagnosis of patients with arthritis.

\section{Pitfalls of antibody testing}

Serologic testing for diagnostic confirmation is used when a pathogen cannot be easily cultivated or observed. This is a less desirable method, but it is essentially the only choice now available for laboratory support of Lyme borreliosis. The predictive accuracy of a positive or negative serologic result depends on the pre-test likelihood of Lyme disease being present. The serologic test should not be requested indiscriminately; it should be ordered solely to confirm a diagnosis based on epidemiological and clinical evidence (15-17).

There is a risk that the test will be falsely negative if serum is obtained too early in the infection, since antibodies only become positive after 3 to 6 weeks. Erythema migrans needs no serologic confirmation before antibiotic treatment is started.

There is also a risk of false positivity. The illnesses known to be associated with false positive serology results include infectious mononucleosis, rheumatoid arthritis, systemic lupus erythematodes, and other spirochetal diseases such as periodontal disease (18). It remains to be determined whether Western blot analysis can discriminate between false positivity and true positivity.

In addition, a large number of people have asymptomatic $B$. burgdorferi infections. For instance, positive Lyme serology is common in Swiss orienteers, but the disease itself occurs infrequently (15). The same results have been found in our study described in chapter 5 of this thesis. It is therefore necessary, to carefully evaluate the clinical signs and symptoms of patients who are suspected to have Lyme disease. Complaints present should be attributable to Lyme disease (19). In countries with a low prevalence of Lyme disease, such as Switzerland and the Netherlands, and a high prevalence of asymptomatic positive serology, diagnostic testing is of limited value as was easily shown by application of likelihood ratios for antibodies to B. burgdorferi in chapter 5 .

Another major point of concern is the quality of serologic testing (20-24). The lack of a national reference collection or other common source of serum specimens, antigens, and other reagents forces laboratories to establish their own standards. All tests should meet acceptable performance standards, and there should be intra-laboratory standardization and reproduction of results. The clinician should demand information from the laboratory about their inter and 
intra-test accuracy, sensitivity, and specificity. In the absence of a reference standard, we compared our results of testing with sera from the laboratory of the Department of Zoology, University of Neuchâtel, Switzerland (Head Prof. A Aeschlimann). There was good agreement between laboratories $(r=0.68 ; p$ 0.001 ). With our methods, the sensitivity of the serologic tests varied from $40 \%$ to $96 \%$ depending on the clinical manifestations in cases of definite Lyme disease: early Lyme borreliosis, $40 \%(n=25)$; and late Lyme borreliosis, $96 \%$ $(n=27)$ (unpublished results). Evaluation of commercial kits and controlled proficiency testing of diagnostic laboratories are badly needed.

\section{Likelihood ratios}

Application of likelihood ratios in the clinical situation can be an easy way to decide whether a diagnostic test may be of any help in supporting a diagnosis. Likelihood ratios need not change with changes in the prevalence (or pretest probability) of the target disorder (25). The pretest or prevalence of disease, however, has a strong influence on the usefulness of a test as was demonstrated in our studies described in chapter 5 and 6 . Prevalence of disease should be known before likelihood ratios can be applied. The prevalence of disease in the individual patient can usually be estimated based on experience or literature.

Diagnostic tests discriminate best when the pretest probability is about 40$60 \%$. When the pretest probability of Lyme borreliosis is as low as $0.1 \%$ (normal Dutch population), one should try to increase the pretest probability by subsequent application of likelihood ratios for known symptoms and signs, and possible laboratory tests. We believe that the likelihood ratios provided in this thesis for recognition of photographs of erythema migrans, tick bites, antibodies to $B$. burgdorferi, and different levels of the clinical history of patients with arthritis of undetermined etiology, can be helpful in making a diagnosis of Lyme borreliosis, if a certain degree of dependency is taken into account (25).

\section{Education}

In chapter 8 , we conclude that better education is needed about the early manifestations of Lyme borreliosis for general practitioners, as well as for dermatologists and rheumatologists. If one is unaware of the diagnosis Lyme disease, one will probably not treat patients with appropriate antibiotics, and subsequent later stages of the disease are likely to occur. For instance, arthritis will probably be treated with non-steroidal anti-inflammatory drugs. The general practitioner plays the most crucial role in diagnosing patients with Lyme borreliosis. Publications about the disease have been published in journals 
reported to be read by general practitioners. Lack of knowledge is probably due to the low chance of encountering a patient with this disease. Registration of all patients diagnosed as having Lyme disease, could give information about the true incidence and prevalence of Lyme disease in the Netherlands. This is probably the only way to embrace the entire problem of Lyme borreliosis in our country. Based on this information, strategies for better instruction and education can be developed.

\section{Diagnosis}

Lyme disease is typically defined by clinical evidence and serologic results should only be used to support a clinical diagnosis. Seropositivity for antibodies to $B$. burgdorferi does not ensure the current clinical problem is due to Lyme borreliosis. Complaints, symptoms and signs should be related to manifestations described in patients with Lyme borreliosis, especially in reports about the natural history of untreated Lyme patients $(1,26)$. Since there is no real "gold" standard, clinical evidence should outweigh serologic results. Patients with Lyme arthritis usually remain seropositive for antibodies to $B$. burgdorferi after appropriate antibiotic treatment. Vague or mild to moderate symptoms and fatigue may incorrectly suggest persistence of infection, leading to further antibiotic therapy (27). Unnecessarily prolonged antibiotic therapy of previously treated Lyme disease for these kinds of symptoms should be avoided. On the other hand, recurrent courses with antibiotics for Lyme arthritis may be necessary.

In chapter 6, we have tried to indicate in which patients with arthritis a diagnosis of Lyme borreliosis can be expected and for which patients with arthritis, requests for serology can be of any help. Exclusion of other causes for arthritis is essential. However, it is still possible that patients with arthritis without any other features of Lyme borreliosis, and positive antibodies to $B$. burgdorferi, in fact may be asymptomatic, and that their arthritis is due to another cause. A follow-up study of these patients would be necessary. If the clinical presentation of the arthritis suggests Lyme arthritis, like for instance recurrent arthritis of the knee, the diagnosis of Lyme arthritis should be considered. However, if the arthritis is located in joints not easily affected by $B$. burgdorferi, other causes for the arthritis should be considered. Currently, however, in case of doubt, these patients will probably be treated with antibiotic therapy. As long as we have no definite "gold" standard, physicians may be advised to prescribe antibiotic treatment for patients with arthritis and positive serology for $B$. burgdorferi to prevent development of later stages of Lyme borreliosis. 


\section{In summary}

Lyme borreliosis is a clinical diagnosis, and serologic tests should only be used to support a high clinical suspicion.

The clinical features of the Dutch patients with Lyme arthritis closely resemble the descriptions of the disease reported from the Unites States. Reported differences are probably due to a lack of awareness.

Although not a frequent diagnosis, Lyme arthritis should be considered in the diagnosis of patients with arthritis, since antibiotic treatment is usually effective and may reduce the burden of illness and development of later stages of this disease.

There is no evidence that $B$. burgdorferi is associated with ankylosing spondylitis.

Asymptomatic seropositivity for antibodies to $B$. burgdorferi does frequently occur. These patients do not require antibiotic treatment. The clinical history is a more powerful diagnostic tool than Lyme serology. Recognition of erythema migrans has more impact on the diagnosis of Lyme borreliosis than simply testing for antibodies to $B$. burgdorferi.

Likelihood ratios can be a contributing factor in deciding to request antibodies to B.burgdorferi in patients with arthritis of undetermined etiology.

Lyme arthritis may be avoided by preventing tick bites, by recognition of the early symptoms and signs of Lyme borreliosis, such as erythema migrans, and by timely antibiotic treatment.

Better instruction and education about the early manifestations of Lyme borreliosis is necessary for general practitioners, dermatologists, and rheumatologists to prevent later stages of Lyme borreliosis. 


\section{REFERENCES}

1 Steere AC, Schoen RT, Taylor E. The clinical evolution of Lyme arthritis. Ann Intem Med 1987; 107:725-31.

2 Herzer P. Lyme-Borreliose. Steinkopff Verlag Darmstadt, 1990.

3 Aeschlimann A, Chamot E, Gigon F, Jeanneret JP, Kesseler D, Walther C. B. burgdorferi in Switzerland. Zbl Bakt Hyg A 1986;263:450-58.

4 Bigaignon J, Tomasi J-P, Goubau P, et al. A clinical and sero-epidemiological study of 190 Belgian patients suffering from Lyme borreliosis. Acta Clin Belgica 1989;44:17481 .

5 Huaux JP, Bigaignon G, Stadtsbaeder S, Zangerlé PF, Nagant de Deuxchaisnes C. Pattern of Lyme arthritis in Europe: report of 14 cases. Ann Rheum Dis 1988;47:164. 65.

6 Muhlemann MF, Wright DJM. Emerging pattern of Lyme disease in the United Kingdom and Irish Republic. Lancet 1987; i:260-62.

7 Hovmark A, Äsbrink E, Olsson I. Joint and bone involvement in Swedish patients with Ixodes ricinus-bome Borrelia infection. Zbl Bakt Hyg A 1986;263:275-84.

8 Dekonenko EJ, Steere AC, Berardi VP, Kravchuk LN. Lyme borreliosis in the Soviet Union: a cooperative US-USSR Report. J Infect Dis 1988; 158:748-53.

9 Giraudet JS, Awada H, Amor B, Menkes CJ. Manifestations rhumatologiques de la maladie de Lyme. Ann Med Inteme 1988;139:460-63.

10 Bianchi G, Rovetta G, Monteforte P, et al. Articular involvement in European patients with Lyme disease. A report of 32 Italian patients. Br J Rheum 1990;29:178-80.

11 Stanek J, Wewalka G, Groh V, Neumann R, Kristoferitsch W. Differences between Lyme disease and European arthropod-bome borrelia infections. Lancet 1985;i:401.

12 Holström E. Successful treatment of erythema chronicum migrans Afzelii. Acta Derm Venereol (Stockh) 1951;31:235-43.

13 Herzer P. Lyme arthritis in Europe: comparisons with reports from North America. Ann Rheum Dis 1988;47:789-91.

14 Blaauw AAM, Schuwirth LWT, van der Vleuten CPM, de Rooy MJM, van der Linden $S$. How well do General Practitioners, Rheumatologists and Dermatologists recognize Lyme borreliosis? Submitted for publication.

15 Fahrer $\mathrm{H}$, van der Linden S, Sauvain MJ, Gern L, Zhioua E, Aeschlimann A. The prevalence and incidence of clinical and asymptomatic Lyme borreliosis in a population at risk. J Infect Dis 1991;163:305-310.

16 Blaauw AAM, Nohlmans L, van den Bogaard AEJM, van der Linden S. Diagnostic tools in Lyme borreliosis: clinical history compared with serology. J Clin Epidemiol 1992; 19: 579-581.

17 Blaauw AAM, Dijkmans BAC, Bouma PAD, van der Linden S. Rational Diagnosis and Treatment in Unclassified Arthritis: How clinical data may guide requests for Lyme serology and antibiotic treatment. Ann Rheum Dis, in press.

18 Magnarelli LA, Miller JN, Anderson JF, Rivere GR. Cross-reactivity of nonspecific treponemal antibody in serologic tests for Lyme disease. J Clin Microbiol. 1990;28: 1276-9.

19 Rahn DW, Malawista SE. Lyme disease: recommendations for diagnosis and treatment. Ann Intern Med 1991;114:472-481. 
20 Craft JE, Grodzicki RL, Steere AC. Antibody response in Lyme disease: evaluation of diagnostic tests. J Infect Dis 1984;149:789-95.

21 Magnarelli LA. Quality of Lyme disease tests. JAMA;1989:262:3464-5.

22 Scwartz BS, Goldstein MD, Ribeiro JMC, Schulze TL, Shahied SI. Antibody testing in Lyme disease. A comparison of results in four laboratories. JAMA 1989;262:3431-34.

23 Luger SW, Krauss E. Serologic tests for Lyme disease. Interlaboratory variability. Arch Intern Med 1990;150:761-63.

24 Barbour AG. The diagnosis of Lyme disease: rewards and perils. Ann Intern Med 1989;110:501-2.

25 Sackett DL, Haynes RB, Tugwell P. The interpretation of diagnostic data. In: Clinical epidemiology. A basic science for clinical medicine. Little, Brown and Company 1991:69-152.

26 Szer IS, Taylor BA, Steere Ac. The long-term course of Lyme arthritis in children. N Engl J Med 1991;325;159-63.

27 Sigal LH. Summary of the first 100 patients seen at a Lyme disease referral center. Am J Med 1990;88:577-81. 


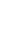




\section{Summary}

This thesis deals with several steps of the Technology Assessment Iterative Loop as applied to Lyme borreliosis.

Chapter 1 gives an overview of the entire spectrum of Lyme borreliosis. The causative agent, the spirochete Borrelia burgdorferi (B. burgdorferi), and vector, Ixodes ricinus ticks, are briefly discussed. Clinical manifestations are described, but, the chapter focuses on Lyme arthritis in particular. A summary is given of the diagnostic tests currently used, and of the antibiotic treatment recommended up to the present.

In chapter 2, the results of a survey among all 118 Dutch rheumatologists are described (response rate $85 \%$ ). The survey was conducted to investigate how frequently cases of Lyme borreliosis were diagnosed among Dutch rheumatologists, to determine whether there are striking differences in the clinical pattern of Lyme arthritis between the United States and Europe, and to assess the prevalence of HLA-DR antigens among Dutch patients with Lyme arthritis. The survey yielded 42 patients with Lyme arthritis. The arthritis was non-persisting in all these patients. A tick bite was reported by 23 of the patients (55\%). Erythema migrans was recalled by 19 patients (45\%). Cardiac manifestations occurred in 4 patients (9\%), and neurologic symptoms in 14 patients (33\%). Using ELISA or IFA technique 37 patients (88\%) were found to have positive antibodies to $B$. burgdorferi. The distribution of HLA-DR alleles of 28 of these patients was not different from the normal population. It was concluded that the clinical features of the Dutch patients with Lyme arthritis closely resemble the description of the disease reported from the United States.

In chapter 3, 73 patients with arthritis of undetermined etiology from the outpatient departments of rheumatology situated in the most southern part of the Netherlands, were studied by questionnaire and interviewed for clinical manifestations suggestive of Lyme borreliosis, together with patients who had otherwise classified arthritis and healthy controls. The prevalence of antibodies to $B$. burgdorferi was determined in these three groups. A definite diagnosis of Lyme borreliosis could be made in only one patient, who belonged to the arthritis of undetermined etiology group. This patient had erythema migrans, arthritis of the 
knee, and positive antibodies to $B$. burgdorferi. Nine patients ( 3 from the arthritis of undetermined etiology group, 2 from the classified arthritis group, and 4 from the healthy controls) had positive antibodies to $B$. burgdorferi without any other clinical symptoms of Lyme disease. They were not considered to have Lyme disease.

The presence of clinical manifestations of Lyme borreliosis and the prevalence of IgG antibodies to B. burgdorferi, were assessed among 125 patients with ankylosing spondylitis from the outpatient departments of rheumatology of the University Hospital of Leiden, the Medisch Spectrum Alkmaar, and the Gemini-Hospital of Den Helder (chapter 4) to study the relationship between $B$. burgdorferi and spondylarthropathy. Several pictures of erythema migrans were shown to all participants. A standardized questionnaire assessing tick bites, cardiac, neurological, and musculoskeletal manifestations was completed. None of the ankylosing spondylitis patients had clinical features of Lyme borreliosis. IgG antibodies to $B$. burgdorferi were present in 11 of 125 patients $(8.8 \%)$. There was no difference regarding positive antibodies to $B$. burgdorfer $i$ between HLA-B27 positive and HLA-B27 negative patients. The results were compared to age-matched controls. The percentage of positive antibodies $(20 \%)$ in the control group was even higher than in the ankylosing spondylitis patients. However, this percentage of seropositivity is quite comparable to the findings in a group of blood donors from the same geographic area (17\%). This study does not provide evidence that $B$. burgdorferi is associated with ankylosing spondylitis as has been suggested before for reactive arthritis.

In chapter 5, the history of clinical Lyme borreliosis and the prevalence of positive antibodies to $B$. burgdorferi were studied in 431 Dutch hunters. Four pictures of erythema migrans in different stages were shown to all participating hunters. They were also asked to complete a questionnaire, which dealt with exposure to ticks and possible manifestations of Lyme borreliosis. The presence of antibodies to $B$. burgdorferi was determined in all participants. After six months, a follow-up study was performed among the hunters with a probable or definite diagnosis of Lyme borreliosis, with positive serology and hunters with ambiguous symptoms. The purpose of this follow-up study was to detect a delayed increase of the optical density value of serum in hunters with ambiguous symptoms, and to evaluate development of possible clinical Lyme manifestations in hunters with positive serology, who did not have any symptoms in the first study. The majority of the hunters (336 or $78 \%$ ) did not report any complaints, had not suffered from erythema migrans as shown on the pictures provided them, and had no positive antibodies to $B$. burgdorferi. Four hunters had definite Lyme borreliosis; three hunters had erythema migrans without antibodies to $B$. burgdorferi and one had arthritis with positive antibodies. Sixty-five of the 431 hunters did not have any complaints, but had positive antibodies to $B$. burgdorferi. This means that $15.1 \%$ of the hunters were asymp- 
tomatic seropositive. The 6 month follow-up study among 95 eligible hunters had a response of $69.5 \%$. It did not reveal any new cases of Lyme borreliosis.

Data from this study and the studies described in chapter 3 and 4 , were pooled to calculate likelihood ratios for the recognition of erythema migrans, the recognition of tick bites, and the presence of antibodies to $B$. burgdorferi. The likelihood ratio for recognition of erythema migrans is 21.3 ; for tick bites, 3.6, and for the presence of antibodies to B. burgdorferi, 3.5. These likelihood ratios were applied in a nomogram adapted from Fagan for the normal population and a population at risk to strengthen the influence of the pretest probability on the usefulness of a test. In a normal population, which has a low pretest probability of about $0.1 \%$, a considerable posttest probability of Lyme borreliosis can only be reached when the presence of the three variables is applied sequentially. In a population with a higher pretest probability such as Dutch hunters (2\%), the posttest probability was considerably higher; recognition of erythema migrans yields a posttest probability of as high as $30 \%$. When the three variables are combined, the posttest probability is nearly $75 \%$. It was concluded that the clinical history of a patient is a more powerful diagnostic tool than Lyme serology. Lyme serology should not be used in any form of screening for Lyme disease.

Chapter 6 describes a study in which clinical data of 102 patients with arthritis of undetermined etiology were analyzed to investigate whether the presence of positive antibodies to $B$. burgdorferi could be predicted, in order to improve the appropriateness and efficiency of diagnostic serologic tests and subsequent antibiotic treatment. The clinical data were blindly ranked from 1 to 4 (1: Lyme arthritis unlikely, and 4: Lyme arthritis very likely). Antibodies to $B$. burgdorferi were positive in 9 out of 102 patients (9\%). Six, out of fifteen patients with rank 3 and 4 , had positive antibodies $(40 \%)$, in contrast to only 3 , out of 87 patients, with rank number 1 and $2(4 \%)$. The likelihood ratio of positive Lyme serology for patients ranked 3 and 4 was 12.0 , for patients ranked 2 to $4,4.5$, and for patients with arthritis of the knee, 3.0. These likelihood ratios were associated with a posttest probability of $55 \%, 30 \%$, and $20 \%$ respectively. The conclusions from this study are that the clinical history in patients with arthritis of undetermined etiology can largely predict the presence of antibodies to $B$. burgdorferi, and that the likelihood ratio can be a contributing factor in deciding to request antibodies to $B$. burgdorferi in this group of patients.

Chapter 7 gives a brief overview of how to prevent Lyme borreliosis and especially Lyme arthritis. Reducing the incidence of tick bites is one of the first goals to attempt in preventing Lyme arthritis. Control methods are briefly discussed. Recognition and adequate antibiotic treatment of the early stages of Lyme borreliosis is of paramount importance in preventing Lyme arthritis. General practitioners, rheumatologists, and dermatologists play a crucial role in 
preventing Lyme disease, since they are probably among the physicians who first encounter patients with tick bites, erythema migrans, and arthritis.

The results of a study, in which the recognition and knowledge of Lyme borreliosis among general practitioners, rheumatologists, and dermatologists are evaluated, are described in chapter 8. Two cases of Lyme borreliosis, and two colored pictures of erythema migrans were presented to 51 general practitioners, 23 rheumatologists, and 13 dermatologists. Although several papers have been published in the Dutch literature about Lyme borreliosis, only 16\% of the general practitioners recognized the first photograph of erythema migrans compared to $92 \%$ of the dermatologists. The second photograph of erythema migrans was recognized by $45 \%$ of the general practitioners, and only by $54 \%$ of the dermatologists. One case of Lyme borreliosis was diagnosed by 55\% of the general practitioners and $96 \%$ of the rheumatologists. The other case of Lyme arthritis was not recognized at all, neither by general practitioners nor by rheumatologists. It was concluded that better instruction and education about the early manifestations of Lyme borreliosis is necessary for general practitioners, rheumatologists, and dermatologists to prevent morbidity due to later stages of Lyme borreliosis. 


\section{Samenvatting}

In dit proefschrift worden verschillende stappen van de Technology Assessment Iterative Loop besproken, toegepast op Lyme borreliosis.

Lyme borreliosis is een systeem ziekte met voornamelijk afwijkingen in de huid, het centraal en perifeer zenuwstelsel, het hart, de spieren en gewrichten. De ziekte wordt veroorzaakt door de spirocheet Borrelia burgdorferi (B. burgdorferi) die wordt overgebracht door de beet van een teek, in Nederland Ixodes ricinus.

In Hoofdstuk 1 wordt een overzicht gegeven van de ontdekking van de ziekte, de vector, de spirocheet, de klinische symptomen, de methoden om de ziekte te diagnostiseren en de tot nu toe gebruikte therapie.

Hoofdstuk 2, laat de resultaten zien van een enquête gehouden onder alle Nederlands reumatologen. Deze enquête werd gehouden om te onderzoeken hoe vaak de diagnose Lyme borreliosis werd gesteld, of er verschillen zijn tussen de klinische verschijnselen van Nederlandse patiënten en de voornamelijk in de Amerikaanse literatuur beschreven patiënten en om de HLA typering van de Nederlandse patiënten te bepalen. De enquête bracht 42 patiënten aan het licht met gewrichtsontstekingen ten gevolge van Lyme borreliosis. Erythema migrans ging bij 19 (45\%) patiënten vooraf aan de artritis. Drie en twintig patiënten (55\%) konden zich een teek beet herinneren. Cardiale verschijnselen kwamen voor bij 4 patiënten (9\%) en neurologische klachten bij 14 patiënten (33\%). Zeven en dertig patiënten (88\%) hadden positieve antistoffen tegen $B$. burgdorferi. De HLA typering van 28 Lyme artritis patiënten was niet verschillend van de Nederlandse bevolking. De klinische symptomen van de Nederlandse Lyme patiënten lijken overeen te komen met de in de literatuur beschreven patiënten.

Hoofdstuk 3 beschrijft het resultaat van een studie onder 73 patiënten met artritis van onbekende oorsprong afkomstig van de 3 zuid Limburgse reumatologie poliklinieken. Deze patiënten werden geïnterviewd over mogelijke symptomen passend bij Lyme borreliosis. Twee controle groepen bestaande uit patiënten met een geclassificeerde artritis en een groep gezonde personen werden eveneens geïnterviewd. Bij al deze personen werden antistoffen tegen 
B. burgdorferi bepaald. Slechts één patiënt bleek te lijden aan Lyme borreliosis. Hij had een erythema migrans voorafgaand aan een artritis van zijn knie. Zijn antistoffen waren positief. Negen patiënten (3 uit de groep van artritis met onbekende origine, 2 uit de groep met geclassificeerde artritis en 4 uit de gezonde personen groep) hadden positieve antistoffen tegen $B$. burgdorferi zonder klinische verschijnselen van Lyme borreliosis. Zij worden beschouwd als asymptomatisch seropositief.

De mogelijke klinische manifestaties van Lyme borreliosis en de aanwezigheid van antistoffen tegen $B$. burgdorferi werden onderzocht bij 125 patiënten met spondylitis ankylopoetica uit Leiden, Alkmaar en den Helder (Hoofdstuk 4). Bij geen van deze patiënten kon de diagnose Lyme borreliosis worden gesteld. Wel hadden 11 van deze 125 patiënten positieve antistoffen tegen $B$. burgdorferi. Er was geen verschil tussen HLA B27 positieve en HLA B27 negatieve patiënten. In vergelijking met een naar leeftijd vergelijkbare groep controle personen was het aantal patiënten met antistoffen tegen $B$. burgdorfer $i$ zelfs lager. $B$. burgdorferi lijkt derhalve niet te kunnen worden toegevoegd aan de lijst met mogelijke verwekkers voor spondylitis ankylopoetica.

Het voorkomen van Lyme borreliosis werd ook onderzocht in een groep personen die een hoger risico op deze ziekte hebben dan de algemene bevolking (Hoofdstuk 5). Nederlandse jagers werden geïnterviewd aan de hand van een gestandaardiseerde lijst met vragen zoals ook gebruikt voor de patiënten met artritis van onbekende oorsprong en de spondylitis ankylopoetica patiënten. Bij alle deelnemers werden antistoffen tegen $B$. burgdorfer $i$ bepaald. Na 6 maanden werden 95 jagers met mogelijke Lyme borreliosis, dubieuze symptomen en positieve serologie, uitgenodigd voor een vervolg studie. De meerderheid van de jagers $(336,78 \%$ ) bleek geen enkele klacht passend bij Lyme borreliosis te hebben en had ook geen positieve antistoffen. Vier jagers $(0.9 \%)$ bleken Lyme borreliosis te hebben, 3 met erythema migrans zonder positieve antistoffen en cén met een artritis en positieve antistoffen. Opvallend was dat 65 jagers $(15.1 \%)$ antistoffen tegen $B$. burgdorferi hadden zonder enig klinisch symptoom van deze ziekte. De vervolg studie liet geen nieuwe gevallen zien van Lyme borreliosis.

De gegevens van de studies beschreven in hoofdstuk 3, 4 en 5, werden samengevoegd om likelihood ratio's te berekenen voor het herkennen van foto's met erythema migrans, teek beten en de aanwezigheid van antistoffen tegen $B$. burgdorferi. De likelihood ratio voor het herkennen van foto's van erythema migrans is 21.3; voor teek beten, 3.6, en voor de aanwezigheid van antistoffen tegen $B$. burgdorferi, 3.5. Deze likelihood ratio's werden toegepast in een nomogram volgens Fagan zowel voor de normale Nederlandse bevolking als voor een risico groep. Voor de Nederlandse bevolking wordt pas een aanzienlijke post-test waarschijnlijkheid behaald als deze 3 likelihood ratio's achter elkaar toegepast worden. In een bevolkingsgroep met een hogere pre-test waar- 
schijnlijkheid zoals jagers, is de post-test waarschijnlijkheid hoger; herkenning van foto's met erythema migrans geeft een post-test waarschijnlijkheid van $30 \%$. Als de drie mogelijkheden worden gecombineerd is de post-test waarschijnlijkheid bijna $75 \%$. De anamnese van een patiënt is derhalve belangrijker dan het testen op de aanwezigheid van antistoffen tegen $B$. burgdorferi.

Om te onderzoeken of de aanwezigheid van antistoffen tegen $B$. burgdorferi bij patiënten met artritis van onbekende oorsprong voorspeld kon worden op grond van de anamnese en het lichamelijk onderzoek, werden de klinische gegevens van 102 Leidse patiënten onderzocht (Hoofdstuk 6). Alle patiënten kregen een rangnummer van 1 tot 4, op basis van de klinische gegevens: rangnummer 1 betekende geen aanwijzingen voor Lyme borreliosis en rangnummer 4, duidelijk aanwijzingen voor Lyme borreliosis. Negen van de 102 patiënten $(9 \%)$ bleken antistoffen te hebben. Van de patiënten met rangnummer 3 en 4 hadden 6 patiënten ( $40 \%$ ) positieve antistoffen in tegenstelling tot 3 van de 87 patiënten (4\%) met rangnummer 1 en 2 . De likelihood ratio voor rangnummer 3 en 4 is 12.0; voor patiënten met rangnummer 1 en 2, 4.5. Voor patiënten met een artritis van de knie is de likelihood ratio 3.0. De hiermee corresponderende post-test waarschijnlijkheden zijn 55\%, 30\% en 20\%. Ook uit deze studie blijkt dat de anamnese en het lichamelijk onderzoek de belangrijkste factoren zijn voor het stellen van de diagnose Lyme borreliosis.

Hoofdstuk 7 geeft een kort overzicht van de manieren om Lyme borreliosis en vooral artritis ten gevolge van deze ziekte te voorkomen. Het herkennen van de vroege verschijnselen van Lyme borreliosis zoals erythema migrans en de artritis aanvallen en het op tijd behandelen van deze verschijnselen is zeer belangrijk om latere stadia van de ziekte te voorkomen. Hierbij is de rol van huisartsen, dermatologen en reumatologen zeer belangrijk omdat zij de patiënten in een vroeg stadium van de ziekte zullen zien.

De kennis van huisartsen, dermatologen en reumatologen op het gebied van Lyme borreliosis kon worden getest aan de hand van 2 foto's van erythema migrans en 2 gevallen van patiënten met Lyme borreliosis (Hoofdstuk 8). Slechts $16 \%$ van de onderzochte huisartsen herkende de eerste foto van erythema migrans en $45 \%$ de tweede foto. De dermatologen echter herkenden de eerste foto in $92 \%$ en de tweede foto slechts in $54 \%$. Het eerste geval met Lyme borreliosis werd herkend door 55\% van de huisartsen en door $96 \%$ van de reumatologen. Het tweede geval van Lyme borreliosis, een patiënt met recidiverende artritis van de knie, werd door huisartsen, noch door reumatologen herkend. Betere instructie en voorlichting over de verschijnselen van Lyme borreliosis lijkt derhalve aangewezen om de latere gevolgen van de ziekte te voorkomen. 



\section{Acknowledgements}

Zonder de medewerking van de Nederlandse reumatologen en in het bijzonder de Twentse (Prof dr JJ Rasker, dr JJM Festen en dr MWM Kruijsen), de Limburgse (Dr HS Goei Thè, dr HHML Houben en $\mathrm{H}$ van der Tempel) en Leidse reumatologen (Dr BAC Dijkmans en dr AJ Peeters) had dit onderzoek nooit kunnen starten.

Overweldigend waren de enthousiaste medewerking, interesse en stimulerende opmerkingen van de "Lyme" patiënten, de zuid Limburgse patiënten met artritis van onbekende origine, hun familie leden en controle patiënten, de jagers en hun jachthonden en de spondylitis patiënten.

Het achtste hoofdstuk kwam tot stand dankzij de zeer gewaardeerde medewerking van de huisartsen uit Maastricht en omgeving en Lambert Schuwirth, Cees van der Vleuten, Michette de Rooij en Frank Smits.

De (oud) medewerkers van onze werkgroep reumatologie, Ellen DrenthTheunissen, Linda Jorisssen-Schreurs, Peggy Lamkin, Lilian Stassen, Alita Hidding, Paulien Bolwijn, Zuzana de Jong-Straková, Marijke van SantenHoefft en Maarten Boers zorgden voor ontroerende en niet aflatende ondersteuning.

Carla Bakker en Irene Speyer waren mijn maatjes, in voor en tegenspoed, tijdens het onderzoek en in de kliniek.

Liesel Nohlmans was op vakkundige wijze verantwoordelijk voor het moeilijke en tijdrovende onderwerp Lyme serologie.

Prof Dr Sj van der Linden, beste Sjef: jij verstaat de kunst mensen aan het werk te zetten en ze toch vrij te laten. Jouw komst naar Maastricht is voor mij heel bijzonder geworden. Je energieke betrokkenheid met de klinische epidemiologie en de Nederlandse reumatologie is zeer stimulerend. Ik hoop in de toekomst nog veel met je samen te kunnen werken.

Mijn ouders hebben de gave hun kinderen zelf keuzes te laten maken. Zij zijn altijd op de achtergrond aanwezig, behalve bij de omslag van dit proefschrift.

Dirk was er altijd. 


\section{Curriculum vitae}

Ineke Blaauw werd geboren op 21 april 1953 te Breda. Na het behalen van het gymnasium $\beta$ diploma aan het van Maerlantlyceum in Eindhoven, ging zij in 1971 geneeskunde studeren aan de Katholieke Universiteit te Nijmegen. Na haar afstuderen was zij als vakantie assistent Inwendige Geneeskunde werkzaam in het Mariaziekenhuis te Tilburg. In 1980 werd gestart met de opleiding Inwendige Geneeskunde in het ziekenhuis Sint Annadal, later het Academisch Ziekenhuis Maastricht (opleiders drs J Coenegracht en Prof dr JA Flendrig). Tijdens de opleiding werd een jaar doorgebracht in het MD Anderson Hospital and Tumor Institute in Houston, Texas, Verenigde Staten (Dr K Dicke en Dr G Spitzer). Registratie als internist volgde in 1985. Sindsdien is zij werkzaam als internist bij de vakgroep Interne Geneeskunde van het Academisch Ziekenhuis Maastricht, binnen de werkgroep reumatologie. Zij is gehuwd met Dirk Gouma. 
Datawyse I Universitaire Pers Maastricht ISBN $905278065 \mathrm{X}$

NUGi $742 / 741$ 